\title{
Three Essays on Product Collusion
}

\author{
by
}

Christopher John Sullivan
A dissertation submitted in partial fulfillment of the requirements for the degree of Doctor of Philosophy (Economics)
in the University of Michigan
2017

Doctoral Committee:

Professor Daniel A. Ackerberg, Chair Assistant Professor Ying Fan Assistant Professor David A. Miller Assistant Professor A. Yesim Orhun 
Christopher J. Sullivan

sullivcj@umich.edu

ORCID iD: 0000-0001-6107-0182

(C) Christopher J. Sullivan 2017 


\section{Dedication}

To my parents, who taught me the value of education and tirelessly sacrificed so I could achieve any goal. They have made this possible. (Though, given that this dissertation will likely be read by at most six people, I am not sure they got a great return on their investment). And to Sarah, for her indefatigable love and support. 


\section{ACKNOWLEDGeMents}

I would first like to thank my advisor, Daniel Ackerberg for the incredible amount of time, energy, and support he has given to me. The other members of my committee: Ying Fan, David Miller, and Yesim Orhun provided tremendous advice and encouragement for which I can't thank them enough. This dissertation was vastly improved through conversations with Jim Adams, Sarah Johnston, Paul Brehm, Adam Dearing, Alan Griffith, Julian Hsu, Andrew Litten, Andrew Usher, and by comments from seminar participants at the University of Michigan. I would also like to thank my grandmother who always kept a pint of Chunky Monkey in her freezer for me. All remaining errors are my own. 


\section{TABle of Contents}

Dedication. ...................................... ii

Acknowledgements ................................... iii

List of Figures $\ldots \ldots \ldots \ldots \ldots \ldots \ldots \ldots$. . . . . . . . . . . . . . . . . . . .

List of Tables . . . . . . . . . . . . . . . . . . . . . . . . . . . vii

List of Appendices . . . . . . . . . . . . . . . . . . . . . viii

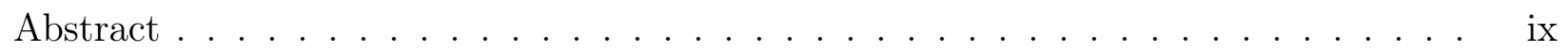

Chapter

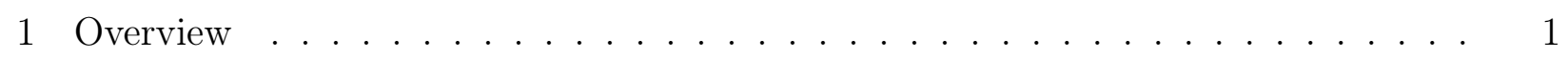

2 The Theory Behind Reduced-Form Profit Weights . . . . . . . . . . . . . . . . . . 4

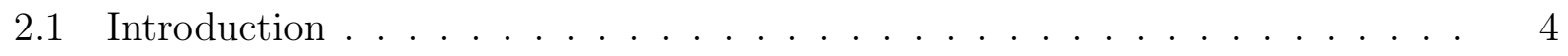

2.2 The Reduced-Form Game $\ldots \ldots \ldots \ldots \ldots$

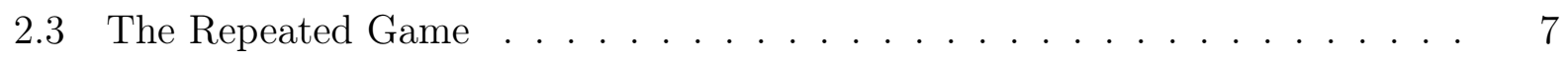

$2.3 .1 \quad$ Firm Strategies $\ldots \ldots \ldots \ldots$

2.3 .2 Pareto Refinement . . . . . . . . . . . . . . . . . . . . . . 12

2.4 Deriving The Equivalence $\ldots \ldots \ldots \ldots \ldots$

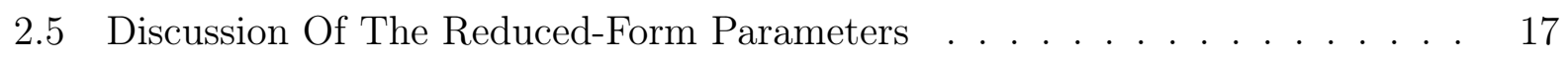

2.6 Extension To Multiple Markets $\ldots \ldots \ldots \ldots \ldots$

3 Will You Just Hold Still?: Using Cross- Sectional Variation to Circumvent the

Corts Critique . . . . . . . . . . . . . . . . . . . . . . . . 21 
3.1 Introduction . . . . . . . . . . . . . . . . . . . . . . . . . 21

3.2 Approach to Identifying Market Power in Bresnahan [1982] $\ldots . . . . .23$

3.3 Reinterpreting the Corts Critique . . . . . . . . . . . . . . . 25

3.4 The Infinitely Repeated Game in Corts (1999) . . . . . . . . . . . . . . . 27

$3.5 \quad$ Deriving the Reduced Form Conduct Parameter . . . . . . . . . . . . . . . 30

3.6 Circumventing the Corts Critique with Cross Sectional Data from Multiple

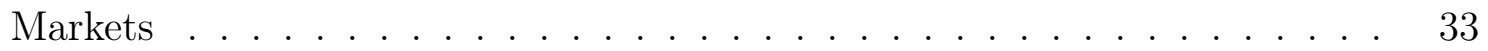

4 The Ice Cream Split: Empirically Distinguishing Price and Product Space Collusion 36

4.1 Introduction . . . . . . . . . . . . . . . . . . . . . . . 36

4.2 The Market For Super-Premium Ice Cream $\ldots \ldots \ldots$

4.2 .1 Market Definitions . . . . . . . . . . . . . . . . . . . . . . . . 38

4.2 .2 Who Chooses Prices and Flavors? . . . . . . . . . . . . . . . . . . . 39

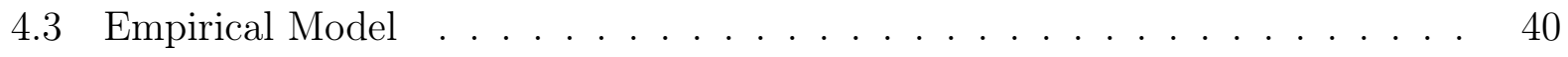

4.3 .1 Consumer Demand . . . . . . . . . . . . . . . . . . . . . . . . 40

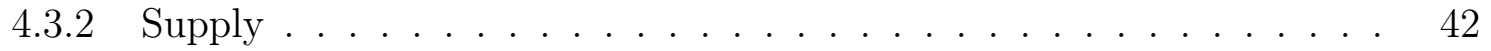

$4.3 .2 .1 \quad$ Second Stage Pricing Decision . . . . . . . . . . . . . 43

$4.3 .2 .2 \quad$ First Stage Product Decision . . . . . . . . . . . . . 45

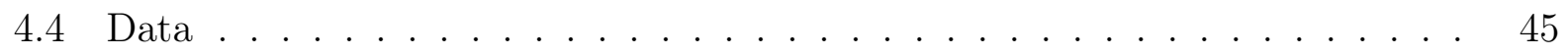

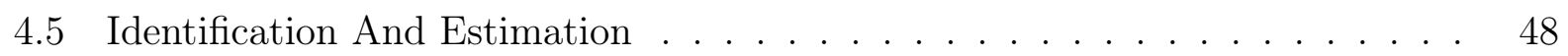

4.5 .1 Demand Parameters . . . . . . . . . . . . . . . . . . . . . . 48

$4.5 .2 \quad$ Pricing Stage Parameters $\ldots \ldots \ldots$

4.5 .3 Product Stage Parameters $\ldots \ldots \ldots \ldots$

4.6 Results . . . . . . . . . . . . . . . . . . . . . . . . . . . . . . . . 58

4.6 .1 Demand Parameter Estimates . . . . . . . . . . . . . . . . . 58

4.6 .2 Pricing Stage Parameters . . . . . . . . . . . . . . . . . . . . . 60

4.6 .3 Product Stage Parameters $\ldots \ldots \ldots$

4.7 Counterfactuals . . . . . . . . . . . . . . . . . . . . . 65

$4.7 .1 \quad$ Effect Of Eliminating Price Collusion . . . . . . . . . . . . . . 65

4.7 .2 Effect Of Eliminating Product \& Price Collusion. . . . . . . . . . 67

4.8 Conclusion $\ldots \ldots \ldots \ldots$

Appendices . . . . . . . . . . . . . . . . . . . . . . . . . . . . . 72

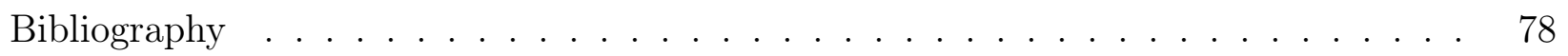




\section{List of Figures}

Figure 2.1 $\quad$ Diagram Of Equilibrium Strategies For Firm b . . . . . . . . . . . 9

\begin{tabular}{lll}
\hline Figure 2.2 & Sustainable Payoffs In The Pricing Stage As A Function Of $\delta$
\end{tabular} . 11

Figure 2.3 $\quad$ Planner's Pricing Decision Problem . . . . . . . . . . . . . . . . . 13

Figure 2.4 Equivalence Of Equilibria Depending On Firm Choosing Actions. 15

Figure $3.1 \quad$ Shifting Demand to Identify Market Power . . . . . . . . . . . . . 24

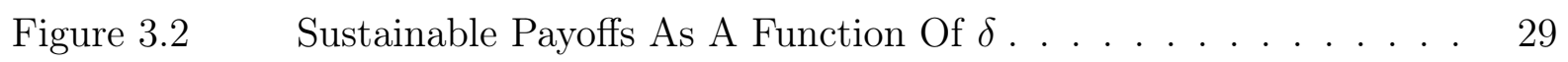

Figure 3.3 Collusive Equilibrium As Solution To Coordinator's Problem . . . 31

Figure 4.1 Average Change In Profits For Each Brand By Replacing Ten . . 55

Worst Selling Ben \& Jerry's Flavors With Chocolate

Figure 4.2 Average Change In Profits For Each Brand By Replacing Ten . . 56

Worst Selling Ben \& Jerry's Flavors With Black \& Tan

Figure $4.3 \quad$ Estimated Seasonality Of Ice Cream Demand . . . . . . . . . . . 59

Figure $4.4 \quad$ Estimated Cross Brand Substitution . . . . . . . . . . . . . . . . 60

Figure 4.5 $\quad$ Estimated Distribution Of Marginal Costs (in \$) . . . . . . . . . . 62

\begin{tabular}{lll}
\hline Figure $4.6 \quad$ Estimated Distribution Of Price Cost Markup $\left(p_{b t}-c_{b t}\right)$ \\
\hline
\end{tabular}

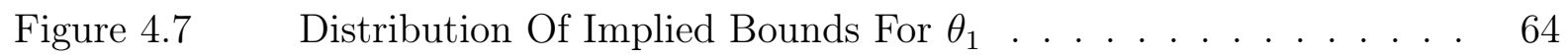

Figure 4.8 Price Increase Above Nash Pricing At Observed Product Choice . 66 


\section{List of TABles}

Table 4.1 Possible Bounds on Product Parameters . . . . . . . . . . . . . . . 54

Table 4.2 Estimates Of Demand Parameters . . . . . . . . . . . . . . . . . . 58

Table $4.3 \quad$ Estimates Of Pricing Stage Parameters . . . . . . . . . . . . . . . 61

Table $4.4 \quad$ Estimates Of Product Stage Parameters . . . . . . . . . . . . . . . 63

Table $4.5 \quad$ Total Firm Profits And Costs In Sample (in millions) . . . . . . . 63

Table 4.6 Total Changes In Producer Surplus From Collusion (in millions) . 66

Table $4.7 \quad$ Welfare Effects Of Price Collusion . . . . . . . . . . . . . . . . . . 67

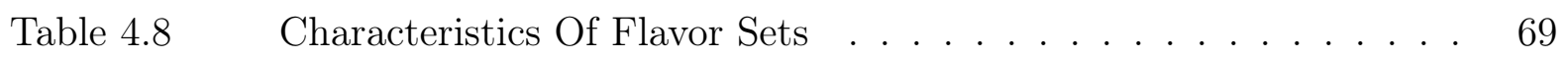

Table $4.9 \quad$ Effect Of Collusion In Median Market . . . . . . . . . . . . . . . . 69 


\section{List of Appendices}

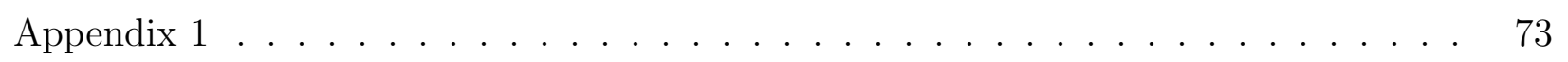

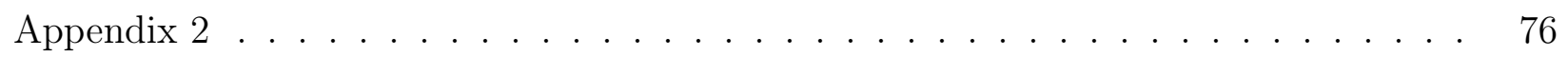




\begin{abstract}
In a market for differentiated products, firms have the ability to collude on the choice of products offered in addition to or in lieu of colluding on the prices charged for those products. However, the empirical literature has only considered price collusion. This dissertation proposes a methodology to measure product space and price collusion. To do so, I model firms as competing in an infinitely repeated extensive form game. I show that a subset of equilibria to the dynamic game can be represented as subgame perfect Nash equilibria to a static game. The static equilibria index the degree to which firms collude through reducedform parameters. I show that these parameters are robust to the Corts Critique and can be estimated using standard techniques when researchers have access to market level data. I then use this methodology to study competition in the market for super-premium ice cream during 2013. I find evidence that Ben \& Jerry's and Häagen-Dazs not only colluded in the prices they charged, but substantially colluded in the choice of flavors that were offered. Then, I construct counterfactuals to measure the impact of collusion on the set of products offered, the prices charged, and welfare. I find that conventional policy analysis that considers only price collusion understates the welfare effects.
\end{abstract}




\section{Chapter 1 Overview}

At the heart of oligopoly lies the tension between adhering to or defecting from a collusive agreement, be it tacit or explicit. Because collusion is illegal and actively prosecuted, there is an exhaustive empirical literature trying to detect collusion and measure its impact on welfare. However, these papers only consider collusion on price. In a market for differentiated products, might not firms collude on the types of products offered in addition to or in lieu of colluding on the prices charged for those products? As was noted in Fershtman and Pakes (2000) "... the ability to collude will have an impact on the variety, cost, and quality of the products marketed by the industry, and this can have as much or more of an effect on welfare as do the price effects of collusion" (pg. 208).

Understanding product space collusion is important for many reasons, two of which I highlight here. First, economists and antitrust authorities may be ignoring many instances of anticompetitive behavior by restricting their attention to price. Consider a market with two fixed products. In one state of the world, each firm offers both products and they agree to collude on price. In another state of the world, the firms compete on price but do so after agreeing to produce different products. With our current techniques, collusion would only be detected in the first scenario, yet both are anticompetitive, leading to higher prices for consumers and lower social welfare.

Second, if we relax the assumption that the set of products remain fixed, then collusion may affect the positioning of a firm's offerings in the product space. When one allows for this possibility, the effect of increased market power on consumer surplus becomes ambiguous, as has been discussed in the literature studying endogenous product selection and mergers $!^{1}$ In particular, if product and price collusion result in firms offering a more diverse set of products, this increased variety may lead to higher consumer welfare and offset the loss in consumer surplus from higher prices.

In this dissertation, I propose an estimation strategy that allows researchers to separately test for both product and price collusion. Unlike previous empirical studies of collusion, I

\footnotetext{
${ }^{1}$ These include Draganska, Mazzeo and Seim (2009) and Fan (2013).
} 
explicitly derive the reduced-form parameters measuring collusion from the structural parameters of a repeated game in Chapter 2. In Chapter 3, I show that these reduced-form parameters are robust to the Corts Critique when researchers observe firms competing in multiple markets. This ensures that the estimated parameters correctly measure the degree to which firms collude. Then, in Chapter 4, I show how these parameters can be estimated in the setting familiar to IO economists and apply this methodology to study competition in the market for super-premium ice cream in 2013. In doing so, I find evidence that Ben \& Jerry's and Häagen-Dazs colluded both in the set of flavors they offered and the prices they charged for those flavors. Then, I construct counterfactuals to measure the impact of collusion on the set of products offered, the prices charged, and welfare. With these counterfactuals, I am able to measure the degree to which ignoring collusion on the product space misstates the impact of collusion on outcomes and welfare. I find that ignoring product collusion understates the negative effect on welfare.

If the antitrust authorities do not fully account for collusion by ignoring the product space, current antitrust policies could have unintended effects. Consider a scenario in which firms are colluding on both the choice of products and price. If the antitrust authorities detect price collusion in a market and take steps to prevent it, firms also colluding in the product space might respond by adjusting their product offerings. This repositioning in the product space can lead to unintended welfare consequences; in particular, the policy intervention may result in lower consumer surplus. To investigate this possibility, I simulate a counterfactual in which Ben \& Jerry's and Häagen-Dazs continue to collude on product choice but are prevented from colluding on price. Though the counterfactual is not robust to the Lucas Critique and is therefore speculative, it is offered as an illustration of the potential ramifications that might result from implementing policies without considering the full scope of firm collusion. In doing so, I find that policy interventions prohibiting only price collusion have the potential to reduce consumer surplus relative to policy inaction. This occurs because the firms choose to greatly curtail their product offerings when they are limited to only colluding in the product space.

My research is most closely related to Bresnahan (1987), Nevo (1998), and Miller and Weinberg (2015), which estimate similar reduced-form parameters to measure price collusion, and Black, Crawford, Lu, and White (2004) which investigates the theoretical justification of these reduced-form price collusion parameters. It also related to Hackner (1995) and Xu and Coatney (2015), which to my knowledge are the only two theoretical papers that explicitly model collusion on the product space. Furthermore, because, the counterfactuals allow me to measure the effects of collusion on the set of products offered, this dissertation relates to the literature on endogenous product choice. In addition to Draganska, Mazzeo and Seim 
(2009) (hereafter DMS), which considers the market for premium ice cream, and Fan (2013), these include Mazzeo (2002), Crawford and Shum (2007), Sweeting (2013), Crawford and Yurukoglu (2012), Orhun (2013), Orhun, Venkataraman and Chintagunta (2015), Fan and Yang (2016), and Wollmann (2016). 


\section{Chapter 2 The Theory Behind Reduced-Form Profit Weights}

\subsection{INTRODUCTION}

The empirical literature largely models collusion via reduced-form parameters in a static game in lieu of specifying a structural model of collusion. Using simpler static models to proxy for the dynamic structural game allows researchers to avoid the computational issues associated with estimating multi-agent dynamic games with multiple equilibria. One strand of the empirical literature measures price collusion by estimating reduced-form profit weights (also called cooperation or ownership matrices). These papers, which include Bresnahan (1987), Nevo (1998), and Miller and Weinberg (2015), model firms as maximizing a weighted sum of their own profit and the profit of each of their rivals. The weight a firm places on each of its rivals captures the degree to which it internalizes the impact of its actions on that rival and therefore serves as a useful measure of collusion. I begin in Section 2.2 by extending the reduced-form framework used in these papers to a two-stage static game in which firms sequentially choose products and prices. In this game, which will form the basis of the empirical model, each firm has two parameters that measure its conduct, one indexing the degree to which that firm colludes in the choice of products and one indexing the degree to which it colludes in price.

A criticism of the literature estimating profit weights is that the reduced-form parameters are not derived from a structural model, making interpretation of the collusion parameters difficult. Furthermore, it is unclear how the reduced-form parameters might change in alternative market or policy settings without mapping the structural parameters to the reduced-form parameters. In an unpublished paper, Black, Crawford, Lu, and White (2004) (hereafter BCLW) show how the structural parameters in a repeated Bertrand game can be mapped to the reduced-form profit weights measuring the degree to which firms collude on price. In Section 2.4, I extend their methodology to a model in which firms compete in two stages, a product setting stage and a price stage. This permits me to show that the subgame perfect Nash equilibrium in the reduced-form game is equivalent to a stationary equilibrium of an infinitely repeated game, which is introduced in Section 2.3. Because the equilibria are 
equivalent, I can derive a mapping from the structural parameters of the repeated game to the reduced-form parameters. Section 2.5 provides an extended discussion of this mapping. For simplicity of exposition, Sections 2.2-2.5 only consider firms competing in one geographic market. In Section 2.6, I extend the results to a setting in which firms compete in multiple markets. As will be seen in Chapter 3, competition in multiple markets allows me to consider reduced-form collusion parameters that are robust to the Corts Critique.

\subsection{The Reduced-Form Game}

I consider a reduced-form game that is related to the strain of the IO literature, e.g. Bresnahan (1987), Nevo (1998), and Miller and Weinberg (2015), that models price collusion using the following approach. Two firms $!^{1} b=\{1,2\}$ compete in a static Bertrand game, each choosing price $p_{b}$ to maximize a weighted sum of their own profits and the profit of their rival:

$$
\max _{p_{b}} \pi_{b}+\theta_{b} \pi_{-b}
$$

The Nash equilibrium is a set of prices satisfying the first order condition for each firm.

$$
\frac{\partial \pi_{b}}{\partial p_{b}}+\theta_{b} \frac{\partial \pi_{-b}}{\partial p_{b}}=0
$$

The reduced-form parameters $\theta=\left(\theta_{b}, \theta_{-b}\right)$ are then estimated via the first order condition. There are several advantages to this approach. Foremost, the first order conditions index a large set of equilibria, from Nash-Bertrand when $\theta=0$ to perfect collusion when $\theta=$ 1. Furthermore, the $\theta$ 's have a compelling interpretation: they summarize the degree to which each firm internalizes the externality its pricing decision imposes on its rival, which is consistent with their role in measuring collusive behavior. In addition, the $\theta$ 's are estimated via standard techniques.

Given the appeal of this framework, I use it as a basis for modelling product and price collusion. Specifically, I extend this framework to a two-stage game in which firms first choose products, then choose prices. Formally, each product represents a unique combination of $K$ continuous product characteristics such that the product space is given by $\mathbb{R}^{K}$. I let $d_{b} \subset \mathbb{R}^{K}$ be the set of products offered by firm $b$ where $d_{b j}=\left(d_{b j 1}, \ldots, d_{b j K}\right)$ represents the $K$-dimensional vector of characteristics defining the $j^{\text {th }}$ product in $d_{b}$. In the second stage, after observing the product offerings of their rival, firms simultaneously set the prices

\footnotetext{
${ }^{1}$ These papers consider $N$ firms. In my empirical example, there are only two firms, Ben \& Jerry's and Häagen-Dazs. Therefore without loss of generality, I consider two firms.
} 
for these products. The price charged by firm $b$ for product $j$ is $p_{b j}\left(d_{b}, d_{-b}\right)$ which depends on the entire set of products offered by both firms. At the end of the two stages, the firm receives profits according to

$$
\pi_{b}=\tilde{\pi}_{b}\left(d_{b}, d_{-b}, p_{b}, p_{-b}\right)-\eta_{b} N_{b}
$$

where $\tilde{\pi}_{b}$ are the variable profits earned by the firm, $\eta_{b}$ is a per product fixed cost, and $N_{b}$ is the number of products offered by the firm.2 I assume that the variable profits for each firm are concave in the prices and characteristics chosen by that firm.

The subgame perfect Nash equilibrium (SPNE) to this game can be found by backwards induction. In the second stage, firm $b$ chooses its price given the set of products being offered to solve:

$$
\max _{p_{b}} \pi_{b}\left(d_{b}, d_{-b}, p_{b}, p_{-b}\right)+\theta_{2, b} \pi_{-b}\left(d_{b}, d_{-b}, p_{b}, p_{-b}\right)
$$

Thus, for a given choice of products, the equilibrium set of prices satisfies the first order condition for each firm.

$$
\frac{\partial \pi_{b}}{\partial p_{b}}+\theta_{2, b} \frac{\partial \pi_{-b}}{\partial p_{b}}=0 \quad \forall b
$$

In the first stage, firm $b$ chooses a subset of products to offer taking into account the second stage pricing decision.

$$
\max _{d_{b}} \pi_{b}\left(d_{b}, d_{-b}, p_{b}\left(d_{b}, d_{-b}\right), p_{-b}\left(d_{b}, d_{-b}\right)\right)+\theta_{1, b} \pi_{-b}\left(d_{b}, d_{-b}, p_{b}\left(d_{b}, d_{-b}\right), p_{-b}\left(d_{b}, d_{-b}\right)\right)
$$

Since the characteristics defining each product are continuous, a subset of the necessary conditions for the equilibrium set of products can generally be written as:

$$
\frac{\mathbf{d} \pi_{b}}{\mathbf{d} d_{b}}+\theta_{1, b} \frac{\mathbf{d} \pi_{-b}}{\mathbf{d} d_{b}}=0 \quad \forall b
$$

\footnotetext{
${ }^{2}$ The restricted specification where fixed costs do not depend on product characteristics is motivated by my empirical context, super-premium ice cream. This is discussed further in Section 4.3.

${ }^{3}$ These conditions would not necessarily hold if a firm was indifferent between the number of products to offer. However, because the characteristics are continuous, indifference is unlikely. Therefore, these conditions generically hold at the equilibrium product choice. In addition, I omit the first order condition associated with the optimal number of products because that is a discrete choice. These caveats hold throughout this section.
} 
where the total derivatives in the first order condition are defined as:

$$
\frac{\mathbf{d} \pi_{b}}{\mathbf{d} d_{b}}=\frac{\partial \pi_{b}}{\partial d_{b}}+\frac{\partial \pi_{b}}{\partial p_{b}} \frac{\partial p_{b}}{\partial d_{b}}+\frac{\partial \pi_{b}}{\partial p_{-b}} \frac{\partial p_{-b}}{\partial d_{b}}
$$

and

$$
\frac{\mathbf{d} \pi_{-b}}{\mathbf{d} d_{b}}=\frac{\partial \pi_{-b}}{\partial d_{b}}+\frac{\partial \pi_{-b}}{\partial p_{b}} \frac{\partial p_{b}}{\partial d_{b}}+\frac{\partial \pi_{-b}}{\partial p_{-b}} \frac{\partial p_{-b}}{\partial d_{b}}
$$

In this reduced-form game there is a distinct price collusion parameter and product collusion parameter for each firm. At first it may seem odd to the reader that a firm has a different collusion parameter in each stage of the game, changing the objective function in each stage. I offer two related justifications. Intuitively, it seems likely that a firm would differentially internalize the effect of its product and pricing decisions on its rival. In the next section, I also provide a theoretical justification by deriving a mapping from the structural parameters in the underlying repeated game to the reduced-form parameters. In order to derive the mapping, I extend the work of BCLW (2004). In BCLW (2004), the authors show how to derive the mapping for a repeated Bertrand game in which firms collude in price. I adapt their framework to accommodate a two-stage game in which firms can compete in prices and products.

\subsection{The Repeated Game}

In this section, I present a structural model of collusion in a market for differentiated products. Two firms with complete information and a common discount factor play an infinitely repeated extensive-form game. Every period has two stages. During the first stage, each firm simultaneously chooses a set of products to produce. In the second stage, after observing the product choices of their rival, firms simultaneously set prices. Firms receive one payoff at the end of the period.

The strategy space and profits in each period are identical to those defined in the reducedform game. In period $t$, firm $b$ chooses a set of products $d_{b t} \in \mathbb{R}^{K}$ to offer and sets a price $p_{b t}\left(d_{b t}, d_{-b t}\right)$. The profits earned at the end of the period are given as:

$$
\pi_{b t}\left(d_{b t}, d_{-b t}, p_{b t}, p_{-b t}\right)=\tilde{\pi}_{b t}\left(d_{b t}, d_{-b t}, p_{b t}, p_{-b t}\right)-\eta_{b} N_{b t}
$$

where I assume that the variable profits for each firm are concave in the prices and characteristics chosen by that firm. Each firm $b$ maximizes the present discount value of its future stream of profits $\sum_{t=0}^{\infty} \delta^{t} \pi_{b t}$ where $\delta$ is a discount factor common to both firms. 
The Folk Theorem makes it clear that this game has a large set of equilibria. I focus attention on on finding and describing one particular stationary equilibrium which is equivalent to the subgame perfect Nash equilibrium of the reduced-form game presented in the previous section. I impose two refinements in order to select the desired equilibrium. First I define a set of stationary strategies which ensure that the selected equilibrium will be a subgame perfect Nash equilibrium for the firms in the repeated game. These strategies combine both stick and carrot and grim trigger punishments to keep the firms on the equilibrium path. However, these strategies still permit a large set of equilibria. Thus, I make an additional refinement: firm actions must be Pareto optimal in that no one firm can be made better off without hurting its rival. Taken together, these refinements select the appropriate equilibrium.

\subsubsection{Firm Strategies}

Before play begins, the firms agree to a set of collusive products $\left(d_{1}^{C}, d_{2}^{C}\right)$ and a menu of collusive prices $\left(p_{1}^{C}\left(d_{1}, d_{2}\right), p_{2}^{C}\left(d_{1}, d_{2}\right)\right)$. Then play proceeds according to the strategies depicted in Figure 2.1.4 Firm $b$ begins the game offering $d_{b}^{C}$ in the product stage. If firm $b$ observes its rival produced $d_{-b}^{C}$, it charges $p^{C}\left(d_{b}^{C}, d_{-b}^{C}\right)$ in the pricing stage. If its rival does not defect in the pricing stage, firm $b$ begins the next period by again offering the collusive products. The two firms continue cooperating until defection is observed.

There are three ways in which a firm can defect in a given period: in the product stage only, in the pricing stage only, or in both the product stage and pricing stage. If any of these cases occur, the punishment phase begins at the start of the next period. During the punishment phase, firms revert to playing the actions associated with the one-shot subgame perfect Nash equilibrium $d_{b}^{N E}$ and $p_{b}^{N E}\left(d_{b}^{N E}, d_{-b}^{N E}\right)$. These actions can be found by backwards induction. In the second stage of a period in the punishment phase, the prices for a given set of products satisfy:

$$
\frac{\partial \pi_{b}}{\partial p_{b}}=0 \quad \forall b
$$

Likewise a necessary condition for firm b's choice of products in the punishment phase is

\footnotetext{
${ }^{4}$ These strategies are non-standard; admittedly both simpler and harsher punishments exist. However, if firms are patient enough, these strategies are sufficient to maintain any level of collusion. Also, it would be difficult to derive the optimal penal code for this extensive form game. See Mailath, Nocke and White (forthcoming) which explains the difficulties in doing so.
} 
FIGURE 2.1

Diagram Of Equilibrium Strategies For Firm $b$

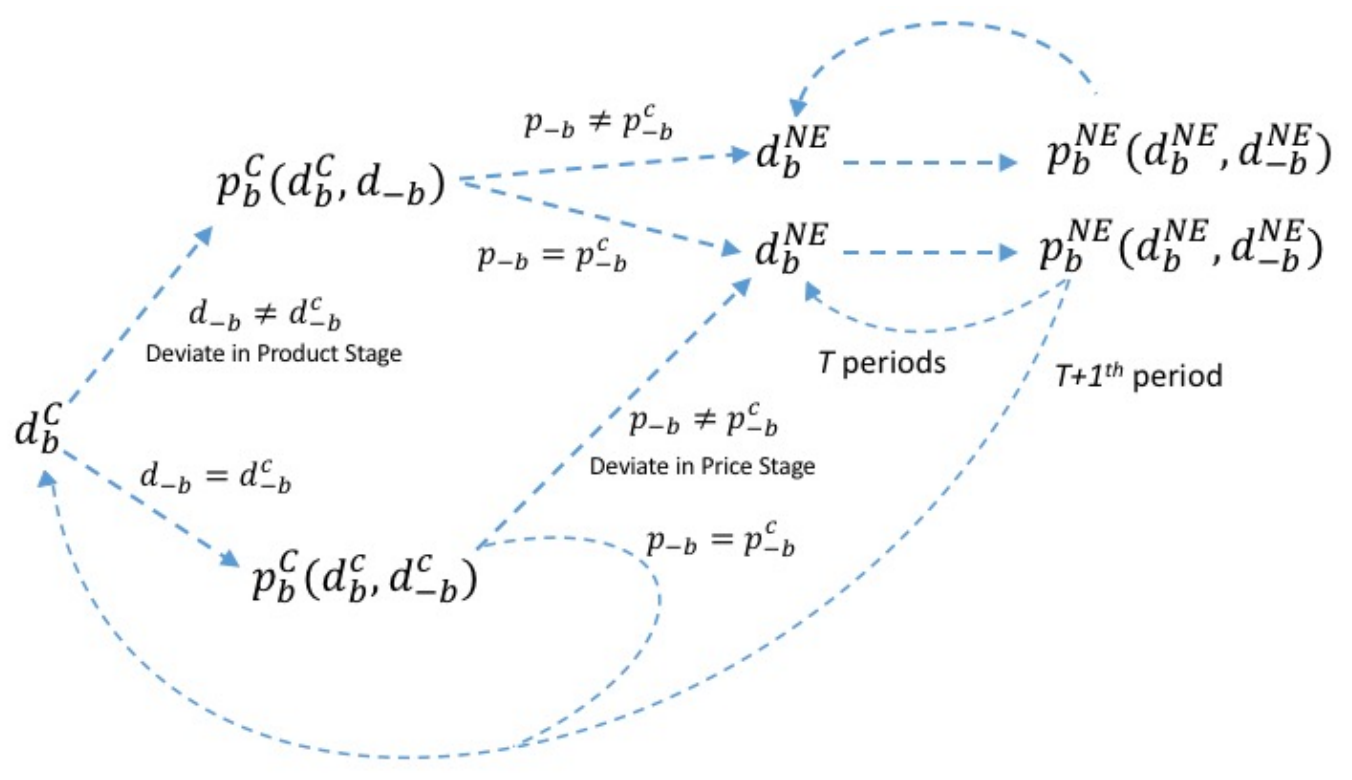

given as:

$$
\frac{\partial \pi_{b}}{\partial p_{b}^{N E}} \frac{\partial p_{b}^{N E}}{\partial d_{b}}+\frac{\partial \pi_{b}}{\partial p_{-b}^{N E}} \frac{\partial p_{-b}^{N E}}{\partial d_{b}}=0 \quad \forall b
$$

The length of the punishment phase depends on whether firm $-b$ deviates in only one of the stages or if it deviates in both the product and price stage. If deviation occurs in only one of the two stages, the punishment lasts for $T$ periods after which the firms resume cooperation. However, if a firm deviates in both the product stage and price stage, the punishment phase lasts forever. Because punishment does not begin until the start of the period after which it occurs, there remains the question of what prices firms charge if deviation occurs on the product space. If firm $-b$ deviates in products, firm $b$ offers the collusive prices given the set of products that were offered in the previous stage, represented as $p_{b}^{C}\left(d_{b}^{C}, d_{-b}\right)$. If its rival also plays the collusive prices conditional on the set of products, the punishment lasts for $T$ periods. If firm $-b$ deviates again in the pricing stage, the punishment lasts forever.

In order for a set of collusive actions to constitute a subgame perfect Nash equilibrium given these strategies, the present discounted value of colluding in both stages by playing these actions must exceed the present discounted value of any one-period deviation. Since there are three ways in which a firm can deviate, these strategies place three restrictions on the set of SPNE.

First, the profits from colluding in both stages must exceed the profits from deviating 
only in the pricing stage. This implies:

$$
\sum_{\tau=0}^{\infty} \delta^{\tau} \pi_{b}^{C, C} \geq \pi_{b}^{C, D}+\sum_{\tau=1}^{T} \delta^{\tau} \pi_{b}^{N E}+\sum_{\tau=T+1}^{\infty} \delta^{\tau} \pi_{b}^{C, C}
$$

where $\pi_{b}^{C, C}$ represents the per period payoff earned by firm $b$ from colluding in both stages, $\pi_{b}^{C, D}$ represents the maximal profits that can be earned by firm $b$ from colluding on the choice of products but defecting in the pricing stage, and $\pi_{b}^{N E}$ represents the one-shot subgame perfect Nash equilibrium profits earned by firm $b$ during each period of the punishment phase. This condition can be rewritten as follows:

$$
\pi_{b}^{C, C} \geq \frac{1-\delta}{1-\delta^{T+1}} \pi_{b}^{C, D}+\frac{\delta-\delta^{T+1}}{1-\delta^{T+1}} \pi_{b}^{N E}
$$

Likewise, the profits from colluding in both stages must exceed the profits from deviating in the product stage but colluding on price.

$$
\sum_{\tau=0}^{\infty} \delta^{\tau} \pi_{b}^{C, C} \geq \pi_{b}^{D, C}+\sum_{\tau=1}^{T} \delta^{\tau} \pi_{b}^{N E}+\sum_{\tau=T+1}^{\infty} \delta^{\tau} \pi_{b}^{C, C}
$$

where $\pi_{b}^{D, C}$ represents the maximal profits firm $b$ can earn by deviating in the product stage but colluding on price. This can be written as:

$$
\pi_{b}^{C, C} \geq \frac{1-\delta}{1-\delta^{T+1}} \pi_{b}^{D, C}+\frac{\delta-\delta^{T+1}}{1-\delta^{T+1}} \pi_{b}^{N E}
$$

Finally, the firms must find it unprofitable to deviate in both stages. This requires:

$$
\pi_{b}^{D, C}+\sum_{\tau=1}^{T} \delta^{\tau} \pi_{b}^{N E}+\sum_{\tau=T+1}^{\infty} \delta^{\tau} \pi_{b}^{C, C} \geq \pi_{b}^{D, D}+\sum_{\tau=1}^{\infty} \delta^{\tau} \pi_{b}^{N E}
$$

where $\pi_{b}^{D, D}$ represents the maximal profits firm $b$ can earn by deviating in both stages. This can be written as:

$$
\pi_{b}^{D, C}+\frac{\delta^{T+1}}{1-\delta} \pi_{b}^{C, C} \geq \pi_{b}^{D, D}+\frac{\delta^{T+1}}{1-\delta} \pi_{b}^{N E}
$$

I assume that firms are sufficiently patient such that deviating in both stages is never profitable. Therefore, given the incentive constraints defined by 2.14 and 2.16 I can recursively find the set of actions in each stage that constitute subgame perfect Nash equilibria. For any given set of products produced in the first stage, we can find the set of prices such that 
neither firm wants to deviate in the second stage.

$$
\mathcal{P}\left(\delta, d_{1}, d_{2}\right)=\left\{\left(p_{1}, p_{2}\right) \mid \pi_{b}^{C, C} \geq \frac{1-\delta}{1-\delta^{T+1}} \pi_{b}^{C, D}+\frac{\delta-\delta^{T+1}}{1-\delta^{T+1}} \pi_{b}^{N E} \forall b=1,2\right\}
$$

Then we can find the set of products in the first stage from which firms will not want to deviate given that firms charge prices according to $\mathcal{P}$ in the second stage:

$$
\mathcal{D}(\delta)=\left\{\left(d_{1}, d_{2}\right) \mid \pi_{b}^{C, C} \geq \frac{1-\delta}{1-\delta^{T+1}} \pi_{b}^{D, C}+\frac{\delta-\delta^{T+1}}{1-\delta^{T+1}} \pi_{b}^{N E} \forall b=1,2\right\}
$$

Thus a subgame perfect Nash equilibrium consists of a set of products $\left(d_{b}, d_{-b}\right) \in \mathcal{D}(\delta)$ and a set of prices $p_{b}, p_{-b} \in \mathcal{P}\left(\delta, d_{b}^{c}, d_{-b}^{c}\right)$.

Notice that for a given $\delta$, the set of collusive payoffs is not unique. In Figure 2.2, I fix a choice of products $\left(d_{b}, d_{-b}\right)$ and find the set of payoffs for both firms that are attainable given $\mathcal{P}$. When $\delta=0$, the only feasible payoffs are those in which the firms charge the Nash prices $p_{b}^{N E}\left(d_{b}, d_{-b}\right)$. As $\delta$ increases above zero, so too does the set of feasible prices and payoffs. For high enough values of $\delta$, the firms are able to achieve some payoffs on the profit possibility frontier 5 Because the set of equilibria is not unique for a given choice of $\delta$, additional structure is needed.

FIGURE 2.2

Sustainable Payoffs In The Pricing Stage As A Function Of $\delta$

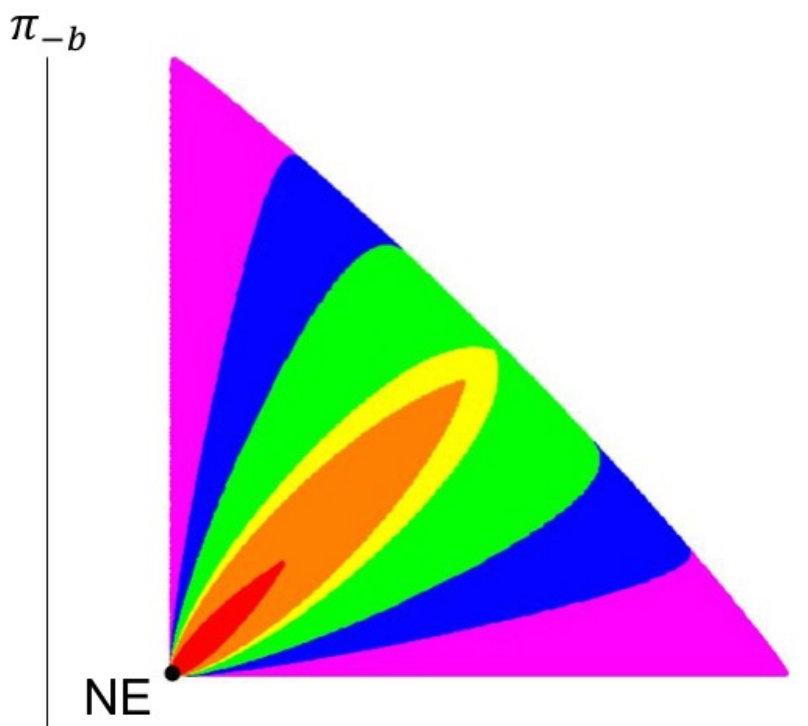

\section{$\pi_{b}$}

\footnotetext{
${ }^{5}$ This helps justify the strategies I impose. Because the entire set of payoffs implied by the Folk Theorem is attainable if firms are patient enough, the strategies are not excessively restrictive.
} 


\subsubsection{Pareto Refinement}

Given that there still exists a set of feasible subgame perfect Nash equilibria, I have to define which collusive equilibrium the firms choose. I assume that when firms collude, they choose actions for which it is impossible to make one firm better off without hurting its rival. Thus, the collusive equilibrium is Pareto optimal from the perspective of the firms. A standard result in welfare economics is that Pareto optimal equilibria can be expressed as solutions to welfare maximization problems.

"FFor economies with convex [profit] possibility sets, there is a close relation between Pareto optima and linear social welfare optima: Every linear social welfare optima with [weight $\omega>0$ ] is Pareto optimal, and every Pareto optimal allocation...is a social welfare optimum for some welfare [weight]." (Mas-Colell, Whinston and Green (1995); pg. 560).

Here I invoke the metaphor of a third party "coordinator" appointed by the firms to maintain their collusive arrangement ${ }^{6}$ The coordinator selects collusive actions $\left(d_{1}^{C}, d_{2}^{C}, p_{1}^{C}, p_{2}^{C}\right)$ from the set of feasible subgame perfect Nash equilibria (that can be expressed through constraints) in order to maximize its own welfare function. I assume that the coordinator has a linear welfare function: $W(\tilde{\omega})=\pi_{1}^{C C}+\tilde{\omega} \pi_{2}^{C C}$ where $\tilde{\omega}$ is the weight placed by the coordinator on firm 2's payoffs relative to firm 1.

The coordinator's problem can be represented as a two-stage problem in which it selects an equilibrium by backwards induction. In the price setting stage, the coordinator chooses prices to maximize $W(\tilde{\omega})$.

$$
\begin{aligned}
& \left(p_{1}^{C}\left(d_{1}, d_{2}\right), p_{2}^{C}\left(d_{1}, d_{2}\right)\right)=\arg \max _{p_{1}, p_{2}} \pi_{1}\left(d_{1}, d_{2}, p_{1}, p_{2}\right)+\tilde{\omega} \pi_{2}\left(d_{1}, d_{2}, p_{1}, p_{2}\right) \\
& \text { st } \quad \pi_{1}\left(d_{1}, d_{2}, p_{1}, p_{2}\right) \geq \frac{1-\delta}{1-\delta^{T+1}} \pi_{1}^{C D}+\frac{\delta-\delta^{T+1}}{1-\delta^{T+1}} \pi_{1}^{N E} \\
& \pi_{2}\left(d_{1}, d_{2}, p_{1}, p_{2}\right) \geq \frac{1-\delta}{1-\delta^{T+1}} \pi_{2}^{C D}+\frac{\delta-\delta^{T+1}}{1-\delta^{T+1}} \pi_{2}^{N E}
\end{aligned}
$$

Then given these collusive prices, the coordinator maximizes $W(\tilde{\omega})$ in the product setting

\footnotetext{
${ }^{6}$ The coordinator is analogous to a social planner except that the coordinator's welfare is only a function of firm profit.
} 
stage in order to satisfy:

$$
\begin{aligned}
&\left(d_{1}^{C}, d_{2}^{C}\right)=\arg \max _{d_{1}, d_{2}} \pi_{1}\left(d_{1}, d_{2}, p_{1}^{C}, p_{2}^{C}\right)+\tilde{\omega} \pi_{2}\left(d_{1}, d_{2}, p_{1}^{C}, p_{2}^{C}\right) \\
& \text { st } \quad \pi_{1}\left(d_{1}, d_{2}, p_{1}^{C}, p_{2}^{C}\right) \geq \frac{1-\delta}{1-\delta^{T+1}} \pi_{1}^{D C}+\frac{\delta-\delta^{T+1}}{1-\delta^{T+1}} \pi_{1}^{N E} \\
& \pi_{2}\left(d_{1}, d_{2}, p_{1}^{C}, p_{2}^{C}\right) \geq \frac{1-\delta}{1-\delta^{T+1}} \pi_{2}^{D C}+\frac{\delta-\delta^{T+1}}{1-\delta^{T+1}} \pi_{2}^{N E}
\end{aligned}
$$

Thus, the refined equilibrium in this game is given by $\left(d_{1}^{C}, d_{2}^{C}, p_{1}^{C}, p_{2}^{C}\right)$ as defined in 2.21) and 2.22 and each firm $b$ earns collusive profits $\pi_{b}^{C C}=\pi_{b}\left(d_{b}^{C}, d_{-b}^{C}, p_{b}^{C}, p_{-b}^{C}\right)$ each period.

The coordinator's decision problem can be illustrated graphically. In Figure 2.3, I consider the pricing decision in (2.21). The two constraints and the profit possibility frontier define the lens of feasible payoffs available to the two firms for a given first stage product choice. The coordinator has social indifference curves with slope $-\tilde{\omega}$ and finds the point on the constrained set that lies on its highest indifference curve. Thus, the Pareto refinement ensures that the collusive equilibrium will lie on the frontier of the feasible payoff sets in each stage. 7

\section{Figure 2.3}

Planner's Pricing Decision Problem

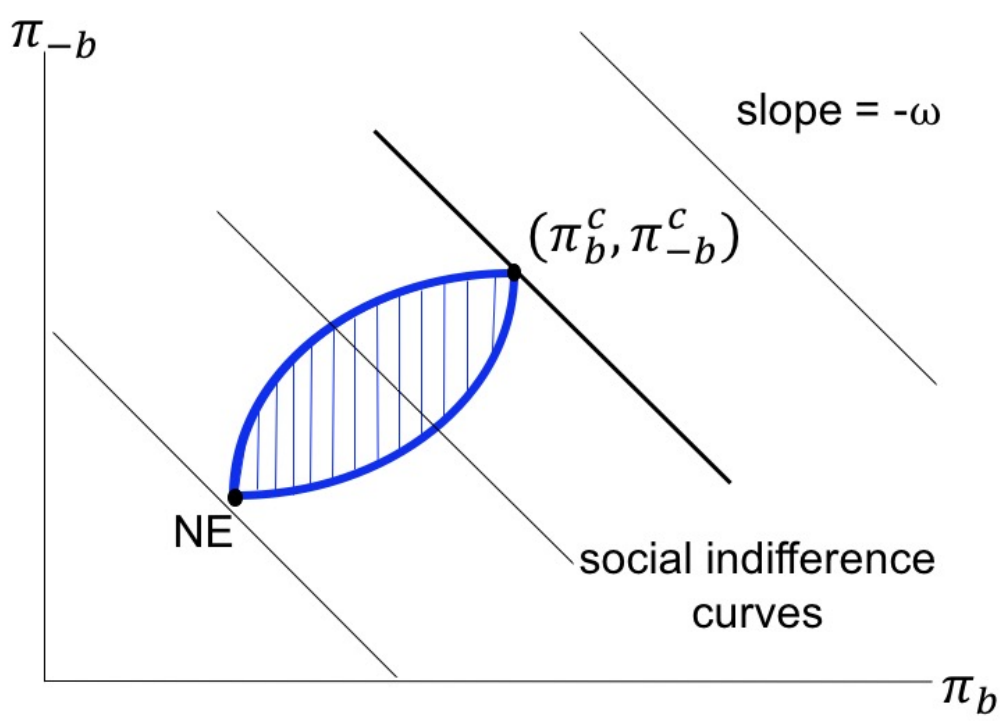

\footnotetext{
${ }^{7}$ Though not apparent in Figure 2.3, the equilibrium can depend on $\tilde{\omega}$, especially as the set of feasible profits reaches the profit possibility frontier
} 


\subsection{Deriving The Equivalence}

I now show that with these refinements, the equilibrium selected by the coordinator is equivalent to the equilibrium in the reduced-form game. The first step is to rewrite the coordinator's problem as the decision problem made by the firms. Specifically, it is possible to derive an equivalent problem to (2.21) and 2.22 in which one firm $b$ chooses actions for itself and its rival in order to maximize its own payoff. In order to maintain the equivalence, an additional constraint needs to be imposed: the maximizing firm has to guarantee that its rival will receive a payoff at least as large as $\pi_{-b}^{C C}$. (Mas-Colell, Whinston and Green (1995); pg. 562-566). Thus, the coordinator's problem can be rewritten in the following manner. In the second stage, firm $b$ solves the following at every possible product choice.

$$
\begin{aligned}
\left(p_{b}^{C}\left(d_{b}, d_{-b}\right), p_{-b}^{C}\left(d_{b}, d_{-b}\right)\right)=\arg \max _{p_{b}, p_{-b}} & \pi_{b}\left(d_{b}, d_{-b}, p_{b}, p_{-b}\right) \\
\text { st } \quad \pi_{-b}\left(d_{b}, d_{-b}, p_{b}, p_{-b}\right) & \geq \pi_{-b}^{C C} \\
\pi_{b}\left(d_{b}, d_{-b}, p_{b}, p_{-b}\right) & \geq \frac{1-\delta}{1-\delta^{T+1}} \pi_{b}^{C D}+\frac{\delta-\delta^{T+1}}{1-\delta^{T+1}} \pi_{b}^{N E} \\
\pi_{-b}\left(d_{b}, d_{-b}, p_{b}, p_{-b}\right) & \geq \frac{1-\delta}{1-\delta^{T+1}} \pi_{-b}^{C D}+\frac{\delta-\delta^{T+1}}{1-\delta^{T+1}} \pi_{-b}^{N E}
\end{aligned}
$$

Then given the optimal collusive prices associated with each choice of products, firm $b$ chooses products in order to solve:

$$
\begin{aligned}
&\left(d_{b}^{C}, d_{-b}^{C}\right)=\arg \max _{d_{b}, d_{-b}} \pi_{b}\left(d_{b}, d_{-b}, p_{b}^{C}, p_{-b}^{C}\right) \\
& \text { st } \quad \pi_{-b}\left(d_{b}, d_{-b}, p_{b}, p_{-b}\right) \geq \pi_{-b}^{C C} \\
& \pi_{b}\left(d_{b}, d_{-b}, p_{b}, p_{-b}\right) \geq \frac{1-\delta}{1-\delta^{T+1}} \pi_{b}^{D C}+\frac{\delta-\delta^{T+1}}{1-\delta^{T+1}} \pi_{b}^{N E} \\
& \pi_{-b}\left(d_{b}, d_{-b}, p_{b}, p_{-b}\right) \geq \frac{1-\delta}{1-\delta^{T+1}} \pi_{-b}^{D C}+\frac{\delta-\delta^{T+1}}{1-\delta^{T+1}} \pi_{-b}^{N E}
\end{aligned}
$$

The identity of the firm making the decision does not matter here. If the decision is made by firm 1, the Lagrange multiplier on the first constraint in 2.23 and 2.24 is defined as $\tilde{\omega}$. Likewise, if firm 2 solves the problem, the Lagrange multiplier on the first constraint in (2.23) and 2.24 is given as $\tilde{\omega}^{-1}$. Let $\omega_{b}=\tilde{\omega}^{(-1)^{b-1}}$ represent the Lagrange multiplier on on the first constraint in 2.23 and 2.24 for each firm $b$. $^{8}$ The equivalence is illustrated in Figure 2.4. In the left panel, firm $b$ chooses the actions to maximize its own payoff, guaranteeing

\footnotetext{
${ }^{8}$ The Lagrange multiplier $\omega_{b}$ is also a function of $\delta$, because when $\delta=0, \omega_{b}=0 \forall b$. In the interest of expositional simplicity, discussion of this is deferred to Section 2.5.
} 
at least the collusive equilibrium payoff to its rival. Thus, it has vertical indifference curves and faces an additional horizontal constraint. In the right panel, firm $-b$ chooses actions to maximize its own payoff, guaranteeing at least the collusive equilibrium to its rival. Thus, it has horizontal indifference curves and faces an additional vertical constraint. The equilibrium in both cases is the same as that depicted in Figure 2.3.

Figure 2.4

Equivalence Of Equilibria Depending On Which Firm Chooses Actions
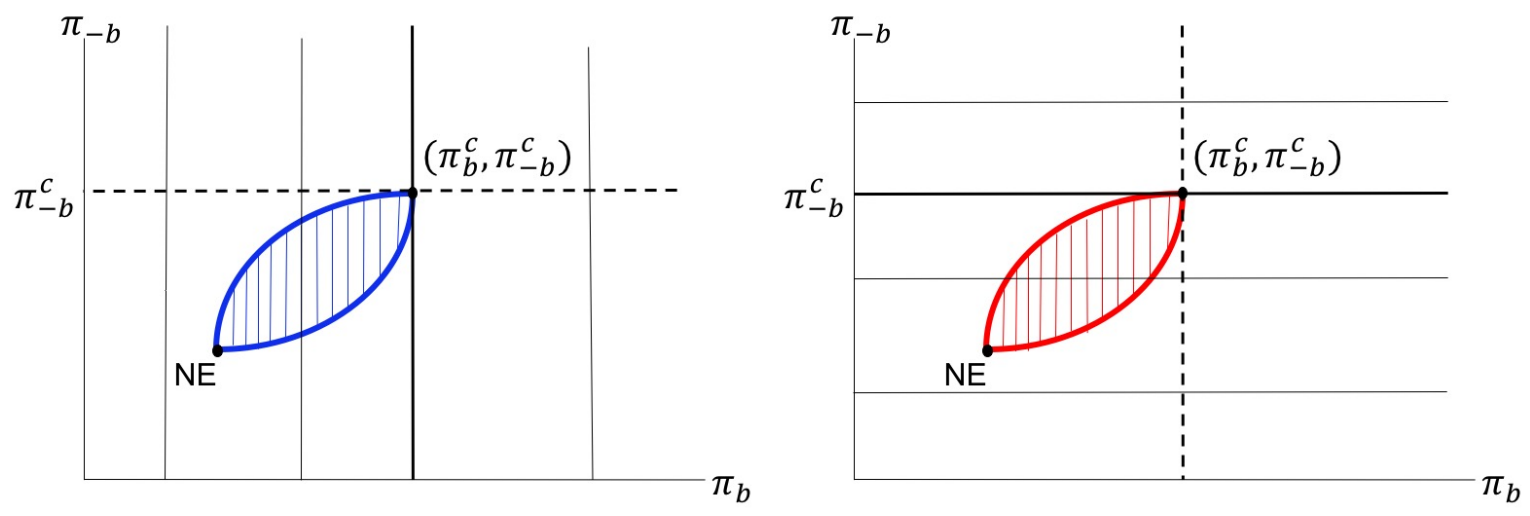

In (2.23) and (2.24) the collusive equilibrium is represented as the solution to constrained maximization problems faced by one firm choosing the actions played by both firms. A key insight of BCLW (2004) is that the collusive equilibrium can also be expressed as the Nash equilibrium in a game where every firm independently and simultaneously chooses its own actions to maximize its profit subject to the same constraints in (2.23) and (2.24). In particular, each firm $b$ chooses its own price according to:

$$
\begin{aligned}
& \max _{p_{b}} \pi_{b}\left(d_{b}, d_{-b}, p_{b}, p_{-b}\right) \\
& \text { st } \quad \pi_{-b}\left(d_{b}, d_{-b}, p_{b}, p_{-b}\right) \geq \pi_{-b}^{C C} \\
& \pi_{b}\left(d_{b}, d_{-b}, p_{b}, p_{-b}\right) \geq \frac{1-\delta}{1-\delta^{T+1}} \pi_{b}^{C D}+\frac{\delta-\delta^{T+1}}{1-\delta^{T+1}} \pi_{b}^{N E} \\
& \pi_{-b}\left(d_{b}, d_{-b}, p_{b}, p_{-b}\right) \geq \frac{1-\delta}{1-\delta^{T+1}} \pi_{-b}^{C D}+\frac{\delta-\delta^{T+1}}{1-\delta^{T+1}} \pi_{-b}^{N E}
\end{aligned}
$$

Then given the optimal collusive prices associated with each choice of products, each firm $b$ 
chooses its own set of products in order to solve:

$$
\begin{array}{ll}
\max _{d_{b}} & \pi_{b}\left(d_{b}, d_{-b}, p_{b}^{C}, p_{-b}^{C}\right) \\
\text { st } \quad \pi_{-b}\left(d_{b}, d_{-b}, p_{b}, p_{-b}\right) \geq \pi_{-b}^{C C} \\
\pi_{b}\left(d_{b}, d_{-b}, p_{b}, p_{-b}\right) \geq \frac{1-\delta}{1-\delta^{T+1}} \pi_{b}^{D C}+\frac{\delta-\delta^{T+1}}{1-\delta^{T+1}} \pi_{b}^{N E} \\
\pi_{-b}\left(d_{b}, d_{-b}, p_{b}, p_{-b}\right) \geq \frac{1-\delta}{1-\delta^{T+1}} \pi_{-b}^{D C}+\frac{\delta-\delta^{T+1}}{1-\delta^{T+1}} \pi_{-b}^{N E}
\end{array}
$$

In Appendix 1, I derive the first order conditions associated with (2.23)-(2.24) and (2.25)(2.26), and show that they are equivalent. Therefore, the Pareto refined subgame perfect Nash equilibrium of the repeated game can be expressed as the subgame perfect Nash equilibrium of a static game played by the firms with constraints.

The final step in proving the equivalence between the refined stationary equilibrium of the repeated game and the SPNE of the reduced-form game is to show that first order conditions in 2.25) and 2.26) are equivalent to the first order conditions of the reduced-form game. In Appendix 1, I show that the first order conditions for firm $b$ in 2.25 can be written as:

$$
\frac{\partial \pi_{b}}{\partial p_{b}}+\left(\frac{\omega_{b}}{1+\lambda_{b, b}(\delta, T)}+\frac{\lambda_{b,-b}(\delta, T)}{1+\lambda_{b, b}(\delta, T)} \frac{\delta-\delta^{T+1}}{1-\delta^{T+1}}\right) \frac{\partial \pi_{-b}}{\partial p_{b}}=0
$$

where $\omega_{b}, \lambda_{b, b}$, and $\lambda_{b,-b}$ are the respective Lagrange multipliers on the first, second, and third constraints in 2.25. Notice that $\lambda_{b, b}$ and $\lambda_{b,-b}$ are functions of $\delta$ and $T$, and implicitly, the profit functions, but not $\tilde{\omega}$. The first order condition for firm $b$ in 2.26 can be written as:

$$
\frac{\mathbf{d} \pi_{b}}{\mathbf{d} d_{b}}+\left(\frac{\omega_{b}}{1+\mu_{b, b}(\delta, T)}+\frac{\mu_{b,-b}(\delta, T)}{1+\mu_{b, b}(\delta, T)} \frac{\delta-\delta^{T+1}}{1-\delta^{T+1}}\right) \frac{\mathbf{d} \pi_{-b}}{\mathbf{d} d_{b}}=0
$$

where $\omega_{b}, \mu_{b, b}$, and $\mu_{b,-b}$ are the respective Lagrange multipliers on the first, second, and third constraints in (2.26), and the total derivatives with respect to product choice are defined as in 2.8 and 2.9). Notice that $\mu_{b, b}$ and $\mu_{b,-b}$ are functions of $\delta$ and $T$, and implicitly, the profit functions, but not $\tilde{\omega}$.

The first order conditions (2.28) and (2.27) have a functional form that is identical to (2.5) and (2.7), the first order conditions to the reduced-form game. Therefore, the collusive outcome is equivalent to the outcome given by the SPNE of a one-shot game with reducedform parameters $\left(\theta_{1}, \theta_{2}\right)$ under the following four assumptions: 1. collusion involves Nash reversion as punishments, 2 . the punishment lengths are given by $T$ and $\infty$ for deviations in one or both stages respectively, 3. the collusive equilibrium is stationary, and 4 . the 
collusive equilibrium is Pareto optimal where $\tilde{\omega}$ indexes the equilibrium choice on the frontier of feasible payoff set. Specifically, given $T$ and $\tilde{\omega}$, a mapping from the structural parameters, $\delta$ and the profit functions, to the reduced form parameters exists for each firm $b$ and is given by: 9

$$
\left(\theta_{1, b}, \theta_{2, b}\right)=\left(\frac{\omega_{b}(\tilde{\omega}, \delta)}{1+\mu_{b, b}(\delta, T)}+\frac{\mu_{b,-b}(\delta, T)}{1+\mu_{b, b}(\delta, T)} \frac{\delta-\delta^{T+1}}{1-\delta^{T+1}}, \frac{\omega_{b}(\tilde{\omega}, \delta)}{1+\lambda_{b, b}(\delta, T)}+\frac{\lambda_{b,-b}(\delta, T)}{1+\lambda_{b, b}(\delta, T)} \frac{\delta-\delta^{T+1}}{1-\delta^{T+1}}\right)
$$

\subsection{Discussion Of The Reduced-Form Parameters}

The mapping in 2.29 provides a theoretical justification for including different reducedform parameters in the product stage and pricing stage. In particular, the price and product collusion parameters differ because $\theta_{1, b}$ is a function of $\mu_{b, b}$ and $\mu_{b,-b}$ while $\theta_{2, b}$ is a function of $\lambda_{b, b}$ and $\lambda_{b,-b} \cdot \mu_{b, b}$ and $\mu_{b,-b}$ measure the marginal benefit of relaxing the constraints on the set of products for which collusion is feasible while $\lambda_{b, b}$ and $\lambda_{b,-b}$ measure the marginal benefit of relaxing the constraints on the sets of feasible prices. These sets depend on the profitability of deviation in the product and pricing stages respectively. Because the profitability of deviation is likely to differ across the stages, so to should the multipliers and therefore the reduced-form parameters measuring collusion.

For expositional simplicity, the maximization problems 2.23$)-(2.26)$ were all written with three constraints. While it is true that all the constraints have to hold at the equilibrium, it is also true that some of the constraints are redundant, depending on the values of the structural parameters and the specific equilibrium being chosen. For example, when $\delta=0$, the firms choose to play the one-shot SPNE of the repeated game and therefore do not collude. At first glance, the mapping in 2.29 seems to imply that $\theta \neq 0$. However, when $\delta=0$, the feasible sets of actions $\mathcal{D}$ and $\mathcal{P}$ collapse to the one shot SPNE. Thus, regardless of $\tilde{\omega}$, the coordinator has to choose $d_{b}^{N E}$ and $p_{b}^{N E}\left(d_{b}^{N E}, d_{-b}^{N E}\right)$ in 2.21 and 2.22 for each firm $b$. This implies that the first constraint in (2.23)-(2.26) is redundant and can be omitted. Therefore, while $\tilde{\omega}$ is a fixed parameter, the Lagrange multiplier $\omega_{b}=0$ when $\delta=0$ and the values of the reduced-form parameters are then 0 . A similar argument can be made when $\delta$ is large and the collusive equilibria lie on the profit possibility frontier. For these values of $\delta$, the incentive constraints in each stage become redundant and can be dropped from the maximization problem. Thus, the $\lambda$ 's and $\mu$ 's $\rightarrow 0$ as $\delta \rightarrow 1$ and collusion parameters in

\footnotetext{
${ }^{9}$ The mapping is not one-to-one with respect to $\delta$. In particular, there exists a lower bound $\underline{\delta}$ such that, for all $\delta>\underline{\delta}$, the equilibrium lies on the profit possibility frontier.
} 
each stage become $\tilde{\omega}$ for firm $b$ and $\tilde{\omega}^{-1}$ for firm $-b$.

Finally, as will become apparent in Section 4.3.2.2, it is important to understand how the reduced-form collusion parameters in the pricing stage would change if either of the firms deviated in the product stage. Recall that following a deviation in the product stage, the firms can still choose to collude in the pricing stage. If each firm plays the collusive price specified for the offered set of products, then the firms are punished for $T$ periods. If either firm plays different prices, the punishment lasts forever. I have assumed that the firms are patient enough such that they will not deviate in both stages. Therefore, the price collusion parameters will not be zero following a deviation in the product stage. However, if the firms are patient enough, any possible menu of off path prices is feasible, suggesting that the reduced-form pricing parameters could take on any value. Notice that, for every choice of products, the firms could choose off path prices such that the value of the reduced-form pricing parameter implied by these prices is the same as it is on path. Since this is one possible equilibrium, I assume it is the one that the firms play. Therefore, the price collusion parameters, $\theta_{2}$, are the same at each possible product deviation as they are on path.

\subsection{Extension To Multiple Markets}

While the previous sections assumed that firms competed in only one market, in my empirical setting, Ben \& Jerry's and Häagen-Dazs compete in many geographic markets each period. Formally, let markets be indexed by $m=1, \ldots, M$. Furthermore, let $\mathbf{d}_{b}=\left\{d_{1 b}, \ldots, d_{m b}\right\}$ and $\mathbf{p}_{b}=\left\{p_{1 b}, \ldots, p_{m b}\right\}$ be vectors of the product choices and prices for each firm in each market. Now, each firm $b$ maximizes the present discount value of its future stream of profits across markets: $\sum_{m=1}^{M} \sum_{t=0}^{\infty} \delta^{t} \pi_{b t m}$.

I assume that the equilibrium refinements applied in the single market repeated game hold here as well. Specifically, the collusive actions on the equilibrium path are still supported via the punishments described in section 2.3.1. Now though, the fact that firms compete in multiple markets each period expands the set of strategies available to the firms in the repeated game, even within this class of punishments. For instance, if a firm were to deviate from the collusive arrangement in only market $m$ during period $t$, does the other firm punish that defection in just market $m$ or in a larger set of markets? Additionally then, I assume that if a firm deviates in any market, it is punished in all markets. Punishing a deviating firm in all markets as opposed to a subset of markets serves as the harshest punishment in this class and supports the highest collusive payoffs, consistent with the assumption of Pareto optimality, a refinement I also extend to the multimarket setting. Thus, conditional on the use of punishments described in section 2.3.1, applying those punishments in all markets is 
the most efficient punishment scheme.

Because punishment occurs in all markets, a firm that deviates will find it optimal to deviate in all markets. Thus, the benefit of deviating in a given period depends on the sum of the deviation profits across markets. The feasible sets of actions (2.19) and 2.20) can now be written as:

$$
\begin{aligned}
\mathcal{P}\left(\delta, \mathbf{d}_{1}, \mathbf{d}_{2}\right)=\left\{\left(\mathbf{p}_{1}^{c}, \mathbf{p}_{2}^{c}\right) \mid \sum_{m=1}^{M} \pi_{m b}\left(d_{m b}, d_{-m b}, p_{m b}^{c}, p_{-m b}^{c}\right) \geq\right. \\
\left.\quad \frac{1-\delta}{1-\delta^{T+1}} \sum_{m=1}^{M} \pi_{m b}^{C D}+\frac{\delta-\delta^{T+1}}{1-\delta^{T+1}} \sum_{m=1}^{M} \pi_{m b}^{N E} \forall b=1,2\right\}
\end{aligned}
$$

and

$$
\begin{array}{r}
\mathcal{D}(\delta)=\left\{\left(\mathbf{d}_{1}^{c}, \mathbf{d}_{2}^{c}\right) \mid \sum_{m=1}^{M} \pi_{m b}\left(d_{m b}^{c}, d_{m-b}^{c}, p_{m b}^{c}\left(\delta, d_{b}^{c}, d_{m-b}^{c}\right), p_{m-b}^{c}\left(\delta, d_{m b}^{c}, d_{m-b}^{c}\right)\right) \geq\right. \\
\left.\frac{1-\delta}{1-\delta^{T+1}} \sum_{m=1}^{M} \pi_{m b}^{D C}+\frac{\delta-\delta^{T+1}}{1-\delta^{T+1}} \sum_{m=1}^{M} \pi_{m b}^{N E} \forall b=1,2\right\}
\end{array}
$$

With the feasibility constraints so defined, the multi-market analog to 2.25 and 2.26 can be written as:

$$
\begin{aligned}
\max _{p_{1 b}, \ldots, p_{M b}} & \sum_{m=1}^{M} \pi_{m b}\left(d_{m b}, d_{m-b}, p_{m b}, p_{m-b}\right) \\
\text { st } \quad & \sum_{m=1}^{M} \pi_{m-b}\left(d_{m b}, d_{m-b}, p_{m b}, p_{m-b}\right) \\
\sum_{m=1}^{M} \pi_{m b}\left(d_{m b}, d_{m-b}, p_{m b}, p_{m-b}\right) & \geq \frac{1-\delta}{1-\delta^{T+1}} \sum_{m=1}^{M} \pi_{m b}^{C C}+\frac{\delta-\delta^{T+1}}{1-\delta^{T+1}} \sum_{m=1}^{M} \pi_{m b}^{N E} \\
\sum_{m=1}^{M} \pi_{m-b}\left(d_{m b}, d_{m-b}, p_{m b}, p_{m-b}\right) & \geq \frac{1-\delta}{1-\delta^{T+1}} \sum_{m=1}^{M} \pi_{m-b}^{C D}+\frac{\delta-\delta^{T+1}}{1-\delta^{T+1}} \sum_{m=1}^{M} \pi_{m-b}^{N E}
\end{aligned}
$$


and

$$
\begin{aligned}
\max _{d_{1 b}, \ldots, d_{M b}} & \sum_{m=1}^{M} \pi_{m b}\left(d_{m b}, d_{m-b}, p_{m b}, p_{m-b}\right) \\
\text { st } \quad & \sum_{m=1}^{M} \pi_{m-b}\left(d_{m b}, d_{m-b}, p_{m b}, p_{m-b}\right) \geq \sum_{m=1}^{M} \pi_{-b}^{C C} \\
& \sum_{m=1}^{M} \pi_{m b}\left(d_{m b}, d_{m-b}, p_{m b}, p_{m-b}\right) \geq \frac{1-\delta}{1-\delta^{T+1}} \sum_{m=1}^{M} \pi_{m b}^{D C}+\frac{\delta-\delta^{T+1}}{1-\delta^{T+1}} \sum_{m=1}^{M} \pi_{m b}^{N E} \\
& \sum_{m=1}^{M} \pi_{m-b}\left(d_{m b}, d_{m-b}, p_{m b}, p_{m-b}\right) \geq \frac{1-\delta}{1-\delta^{T+1}} \sum_{m=1}^{M} \pi_{m-b}^{D C}+\frac{\delta-\delta^{T+1}}{1-\delta^{T+1}} \sum_{m=1}^{M} \pi_{m-b}^{N E}
\end{aligned}
$$

Notice that there is one Lagrange multiplier on each constraint in both problems. Thus, the same Lagrange multiplier applies to the firm's decision in each market. As I show in the next chapter, this feature of the multi-market model ensures that the reduced-form collusion parameters are constant across these markets for a given time period. Thus, the profit weights in the multi-market model are robust to the Corts Critique ${ }^{10}{ }^{11}$ Interestingly, the profit weights in the single market model do run afoul of the Corts Critique. Understanding this distinction is the subject of the next chapter, which I turn to now.

\footnotetext{
${ }^{10}$ While now robust to the Corts critique, these parameter values are still sensitive to the Lucas Critique. Under general counterfactual settings, the value of the collusive parameters is not necessarily fixed. As will be discussed below, the policy relevant counterfactual I consider is one in which the firms cannot collude, and it is known that the reduced-form collusion parameters will be 0 .

${ }^{11}$ In practice, I estimate one set of collusion parameters for 2013 using monthly panel data. In doing so, I implicitly assume that the price and product choices for each month were all made at the beginning of 2013. If deviation occurs during the year, it is not punished until the following year. While it is unlikely that firms punish on a weekly basis, it is also likely that punishment might occur with higher frequency. In the future, I plan on estimating different collusion parameters for each month to test the robustness of my estimates to the Corts Critique.
} 


\section{Chapter 3 Will You Just Hold Still?: Using Cross- Sectional Variation to Circumvent the Corts Critique}

\subsection{INTRODUCTION}

In the previous chapter, I showed how reduced form conduct parameters measuring the degree to which firms collude in products and prices could be derived from a standard structural model of collusion. Before estimating these parameters in the market for super-premium ice cream, it is important to address the well-known critique of conduct parameters presented in Corts (1999), which suggests that estimated conduct parameters often misrepresent the actual state of competition. Corts (1999) shows that the problem is most severe in markets where firms observe exogenous, transitory shocks to demand. What is particularly troubling about this result is that many of the papers that estimate conduct parameters rely on variation in these types of demand shocks, which shift and rotate the demand curve, to identify firm conduct.

The critique presented in Corts (1999) centers on the observation that the underlying conduct parameter and the estimate of that conduct parameter measure different features of the price-cost margin; in particular, the conduct parameter measures its level while the estimated conduct parameters measure how it varies with shocks to demand. For many models of oligopoly, these two measures will be different. In this chapter, I provide an alternative statement of the Corts critique: For many models of oligopoly, the degree to which firms compete will be affected by demand shocks, making the underlying conduct parameter a function of theses shocks. Thus, using demand shocks as instruments to estimate the conduct parameter may lead to inaccurate measures of competition.

Then, I argue that the validity of the Corts critique depends heavily on a feature of the setting he considers: that firms compete in only one market. In order to estimate conduct in one market, a researcher must hold the reduced-form conduct parameters fixed over time and observe behavior in multiple time periods. However, in a structural mode of collusion, the true degree of competition may not be constant over time. Specifically, firms are constrained to actions each period that ensure the present discounted value of colluding is at least as 
large as the profitability of deviating from the collusive arrangement. In the presence of demand shocks, these constraints are changing over time. Thus, the degree to which firms can realize payoffs above the one-shot Nash equilibrium in any period will depend on several factors, crucially the discount factor and the realized demand shocks. When the firms are very patient, or demand shocks are low, it may be feasible for the firms to choose actions that maximize joint outcomes suggesting conduct akin to monopoly, while in other periods, the firms may only be able to sustain payoffs above the one-shot Nash equilibrium but below monopoly levels. I will show that the true values of the conduct parameter each period depend crucially on the shadow values of relaxing the constraints faced by the firms in that period. Thus, when conduct parameters are estimated from only time series data in the presence of demand shocks, the resulting estimates are not necessarily reflective of the degree of competition that was actually present for any given period of the sample.

While Corts focuses on a single market, researchers often observe firms competing in many geographic markets each period. With this additional cross-sectional variation, it is possible to estimate a different collusion parameter each period. At first glance, this seems to replace one problem with another: in order to identify conduct with cross-sectional data, instruments that shift and rotate the demand curve cross-sectionally are needed to identify conduct. But, if the true conduct parameters vary over time with demand shocks, won't they now also vary across markets within a period? I will show that if the researcher is willing to make two assumptions, then the true conduct parameters are constant across markets within a period. First, each firm maximizes the present discounted value of the sum of its profits across all markets. Second, if a firm deviates from the collusive actions in any market, it is punished in all markets. Because punishment occurs in all markets, a firm that deviates will do so in all markets. Thus, the benefit of deviating during each period depends on the sum of the deviation profits across markets. This ensures that the marginal benefit of deviating in any market is the same across all markets. Because the shadow value of relaxing the constraints is constant across markets at a given point in time, the true degree to which firms compete will not vary cross-sectionally and the estimated conduct parameter accurately characterizes the nature of competition in all geographic markets. Therefore, while reliance on time-series variation for one market often results in estimates of conduct that diverge from the truth, cross-sectional variation can be used to accurately measure of conduct for a specific period.

The chapter proceeds as follows: Section 3.2 explains how demand shifters are used in the literature to identify conduct. In Section 3.3, I summarize the Corts Critique and offer my own interpretation of it. Section 3.4 presents the structural model of collusion from Corts (1999). Section 3.5 derives conduct parameters from this model and shows that these 
parameters run afoul of the Corts Critique when only time-series data from one market is available. Section 3.6 then extends the model to multi-market competition, showing how the Corts critique can be avoided with cross-sectional data.

\subsection{Approach to Identifying Market Power in Bresnahan (1982)}

Before discussing the Corts critique, it is first important to understand the assumptions that underly the main technique used in the literature to estimate conduct parameters. Bresnahan (1982) shows that, given sufficient variation in instruments that rotate and shift the demand curve, it is possible to identify market power from equilibrium outcomes (prices and quantities) even if the demand or cost functions that generate those equilibria are unobserved by the econometrician.

Suppose there are $N$ firms selling a homogeneous good in a single market. For simplicity, firms face a linear inverse demand curve, corresponding to equation (3) in Corts (1999):

$$
P\left(Q_{t}, x_{t}\right)=a_{0}+a_{1} x_{t}+a_{2} Q_{t}+e_{t}
$$

where $q_{i t}$ is the quantity produced by firm $i$ in period $t$ and $Q_{t}=\sum_{i} q_{i t}$ is the total quantity produced by all $N$ firms in period $t$. $x_{t}$ is a vector of excluded, exogenous, random demand shifters whose realization is observable to all firms in period $t$ before quantities are chosen. $e_{t}$ is a random iid error term with zero mean that is unobservable to the firms. The firms also have constant marginal costs specified by (4) in Corts (1999).

$$
c^{\prime}\left(q_{i}\right)=c_{0}+c_{1} w_{t}
$$

where $w_{t}$ is a vector of excluded, exogenous, random cost shocks distributed $i i d$ and observed by all firms in period $t$ before choosing quantities.

The first order condition for each firm's maximization problem in period $t$ can be written as:

$$
P=c_{0}+c_{1} w_{t}-\sigma_{i} P^{\prime}\left(Q_{t}\right) q_{i t}
$$

in which $\sigma_{i}$ is a reduced-form conduct parameter that nests distinct levels of competition between the firms. If $\sigma_{i}=0$, the first order condition reduces to $P=c^{\prime}\left(q_{i}\right)$ and firm $i$ behaves in a manner consistent with perfect competition. If $\sigma_{i}=1$, then firm $i$ behaves according to the Cournot equilibrium. Meanwhile, if we assume that firms play a symmetric equilibrium, $\sigma_{i}=N$ is consistent with the firms maximizing joint profits. Beyond these three benchmark equilibria, one can model intermediate forms of competition by allowing $\sigma_{i}$ to vary from 0 to $N$. 
Being able to reliably estimate $\sigma_{i}$ would provide researchers with a measure of the competitiveness a market. However, the data is often limited. Imagine that the econometrician only observes equilibrium outcomes $\left(P_{t}, Q_{t}\right)$, demand shifters $x_{t}$, and cost shifters $w_{t}$ for time periods $t=1, \ldots, T$. It is relatively straightforward to identify the parameters of the demand equation (3.1) using the observed cost shifters, $w_{t}$, as instruments for endogenous market quantity $Q_{t}$. With estimates of the demand parameters in hand, the goal is to identify $\sigma_{i}$ in the first order condition (3.3).

Bresnahan (1982) provides a simple graphical argument for how identification is accomplished when the researcher observes demand shifters $x_{t}$ each period, which is depicted in the following figure 1 Suppose in period $t=1$ the market equilibrium is given by $E_{1}$ and the market demand curve by $D_{1}$. It is unknown whether this equilibrium arose in a perfectly competitive market with marginal costs given by $M C^{P C}$ or a monopoly market with marginal cost given by $M C^{M}$. Suppose however that in period $t=2$ the demand curve shifts

FiguRE 3.1

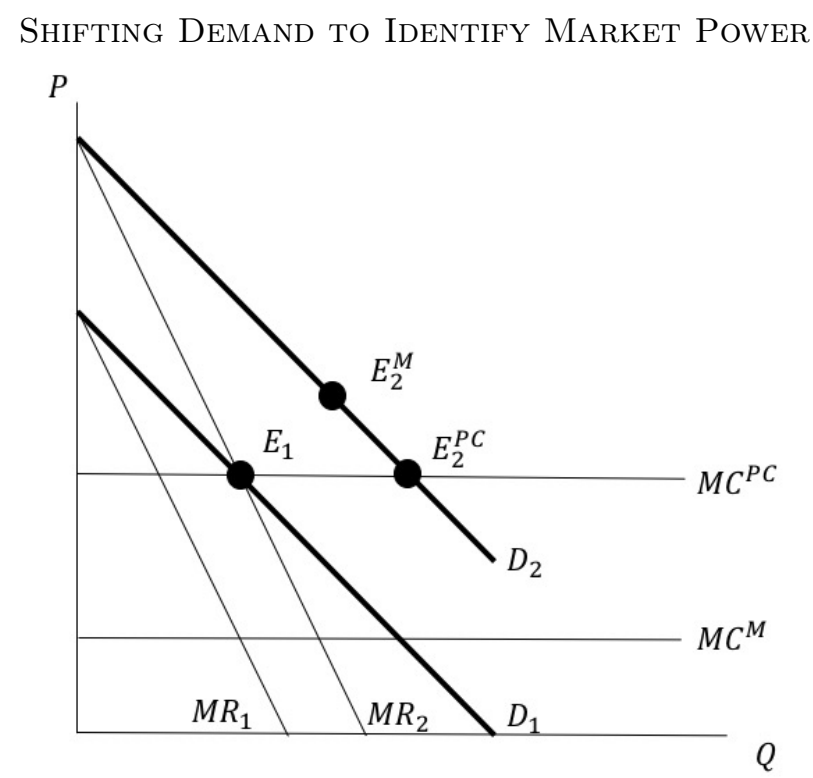

upward to $D_{2} .^{2}$ This shift results in distinct predictions of equilibrium behavior depending on the underlying nature of competition. If in $t=2$ one observes equilibrium $E_{2}^{M}$, it can be inferred that the firms faced marginal cost $M C^{M}$ and behaved in a manner consistent

\footnotetext{
${ }^{1}$ For graphical clarity, I focus here on distinguishing two types of competition, monopoly and perfect competition; however, the technique is general enough to distinguish all intermediate forms of competition between these two extremes.

${ }^{2}$ Bresnahan (1982) argues that demand shifters are insufficient to identify market power. In that paper, marginal cost was permitted to be linear in quantity produced, so instruments that rotate the demand curve were necessary. However, demand shifters are sufficient to identify market power under the the assumption of constant marginal costs.
} 
with monopoly. If equilibrium outcome $E_{2}^{P C}$ is observed instead, it can be inferred that the marginal cost is given by $M C^{C}$ and behavior is consistent with perfect competition. Therefore, conditioning on the sequence of observed cost shifters $\left\{w_{1}, \ldots, w_{T}\right\}$, shifts in the demand curve induced by variation in $x_{t}$ over time will identify the degree of competition between firms so long as that degree in competition is itself not changing with variation in $x_{t}$. If variation in $x_{t}$ induces not only shifts in the demand curve, but affects the level of competition across periods, then the estimates of market conduct may be inaccurate.

\subsection{Reinterpreting the Corts Critique}

Corts (1999) takes issue with measuring conduct via parameters estimated using the method proposed by Bresnahan (1982). To formalize his critique, Corts derives analytic expressions for both the conduct parameter $\sigma$ and the estimated conduct parameter $\hat{\sigma}$. Rearranging (3.3) yields a formula for the conduct parameter, corresponding to equation (2) in Corts (1999).

$$
\sigma=\frac{1}{P^{\prime}} \frac{P-c^{\prime}}{x}\left(\frac{q^{*}}{x}\right)^{-1}
$$

Meanwhile, the presence of excluded demand and cost shifters permit estimating the equations (3.1) and 3.3 using two-stage least squares. Corts shows that under the assumption that a firm's optimal quantity $q^{*}$ is linear in $x_{t} !^{3}$ then the estimated conduct parameter is given as:

$$
\hat{\sigma}=\frac{1}{P^{\prime}} \frac{d\left(P-c^{\prime}\right)}{d x}\left(\frac{d q^{*}}{d x}\right)^{-1}
$$

From (3.4) and (3.5) Corts derives the following proposition:

Proposition 1. For any underlying supply process generating $q^{*}$, the estimated conduct parameter accurately measures market power $(\hat{\sigma}=\sigma)$ if and only if

$$
\frac{P-c^{\prime}}{x}\left(\frac{q^{*}}{x}\right)^{-1}=\frac{d\left(P-c^{\prime}\right)}{d x}\left(\frac{d q^{*}}{d x}\right)^{-1}
$$

Crucially, $\sigma$ measures the average price-cost margin while $\hat{\sigma}$ measures the derivative of the price-cost margin. Corts concern is that in many oligopoly models, these related but distinct measures will be different, preventing one from obtaining accurate measures of market power. Corts summarizes his critique as follows:

"The estimated conduct parameter measures how equilibrium output varies with

\footnotetext{
$\sqrt[3]{\text { Corts }}(1999)$ notes that this assumption is true in the Cournot model.
} 
shifts in the exogenous variables; however, different oligopoly models that produce the same degree of market power on average may generate behavior that, on the margin, varies with the exogenous variables in very different ways. For this reason, it is in general impossible to infer the equilibrium values of the market power measures of interest from the observed equilibrium variation that the estimated conduct parameter captures." (pg. 243)

I will now show that the Corts Critique can be reinterpreted as follows: In oligopoly models where the underlying conduct parameter varies with the observed demand shifters, it is in general impossible to infer the equilibrium values of the market power measures of interest from the observed equilibrium variation that the estimated conduct parameter captures. In other words, it is impossible to estimate firm conduct via demand shifters if that conduct is varying as demand shifts. Notice from equation (3.4) that $P-c^{\prime}=\sigma P^{\prime} q^{*}$. Therefore, I can rewrite 3.5 as follows:

$$
\begin{aligned}
\hat{\sigma} & =\frac{1}{P^{\prime}} \frac{\partial\left(\sigma P^{\prime} q^{*}\right)}{\partial x}\left(\frac{\partial q^{*}}{\partial x}\right)^{-1} \\
& =\frac{1}{P^{\prime}}\left(\frac{\partial \sigma}{\partial x} P^{\prime} q^{*}+\frac{\partial P^{\prime}}{\partial x} \sigma q^{*}+\frac{\partial q^{*}}{\partial x} \sigma P^{\prime}\right)\left(\frac{d q^{*}}{d x}\right)^{-1} \\
& =\sigma+\frac{\partial \sigma}{\partial x}\left(\frac{\partial q^{*}}{\partial x}\right)^{-1} q^{*}
\end{aligned}
$$

Thus it is possible to reexpress Proposition 1 from Corts (1999) as:

Proposition 1. For any underlying supply process generating $q^{*}$, the estimated conduct parameter accurately measures market power $(\hat{\sigma}=\sigma)$ if and only if

$$
\frac{\partial \sigma}{\partial x}\left(\frac{\partial q^{*}}{\partial x}\right)^{-1} q^{*}=0
$$

In many models of oligopoly, $q^{*} \neq 0$. In general then, it will be possible to accurately measure market power only when $\frac{\partial \sigma}{\partial x}=0$. In the next two sections, I show that this condition is violated in a standard, structural model of collusion presented in Corts (1999): a repeated game played in only one market. 


\subsection{The Infinitely Repeated Game in Corts (1999)}

Corts recognizes that on its own, Proposition 1 is not a harsh indictment of estimated conduct parameters; some models of oligopoly will generate data that satisfy (3.6) and (3.10). Thus, he aims to show that the level of competition will be incorrectly estimated in the benchmark structural model of collusive behavior: an infinitely repeated game. As will be seen in the next two sections, Corts is correct: in the specific repeated game he examined, one in which firms compete in only one market, the conduct parameter will be mismeasured. However, that conclusion is crucially dependent on the single market assumption. In Section 3.6, I relax that assumption and show that in environments with multi-market competition, one can accurately estimate the the underlying conduct parameter for a given period.

Here I replicate the structural model of collusion presented in Section 3 of Corts (1999). $N$ firms selling a homogeneous good in a single market play an infinitely repeated game. Each period, the firms simultaneously choose the quantities they will produce that period. For simplicity, firms face the linear inverse demand curve defined in (3.1). The firms also have constant marginal costs specified by (3.2). In addition to perfect information, the firms have a common discount factor, $\delta$. Thus, in each period, firm $i$ chooses $q_{i t}$ to maximize the present discounted value of its future stream of expected profits $\pi\left(q_{i t} ; x_{t}, w_{t}\right)+$ $\sum_{\tau=1}^{\infty} \delta^{\tau} \mathbb{E}_{t}\left[\pi\left(q_{i t+\tau} ; x_{t+\tau}, w_{t+\tau}\right)\right] . \pi$, the per-period profit function, is given as:

$$
\pi\left(q_{i t}, Q_{-i t} ; x_{t}, w_{t}\right)=\left(P\left(Q_{t} ; x_{t}\right)-c_{0}-c_{1} w_{t}\right) q_{i t}
$$

where $Q_{-i t}=\sum_{j \neq i} q_{j t}$ is the total quantity produced by the $N-1$ rivals of firm $i$ in period $t$.

The Folk Theorem makes it clear that this game has a large set of equilibria. Corts (1999) focuses attention on a specific equilibrium. Here, the collusive actions on the equilibrium path are supported via grim trigger punishments: any deviation from the collusive arrangement results in the firms playing the the one-shot Cournot quantities forever. However, these strategies still permit a large set of equilibria. Thus, Corts imposes three additional refinements. First, firms maximize joint profits each period from the set of actions that are sustained by the grim trigger punishments given the realizations of $x_{t}$ and $w_{t}$. This refinement ensures that the supergame equilibrium is efficient for the subclass of equilibria supported by grim trigger punishments. Second, the collusive equilibrium is stationary such that, for each firm $i, q_{i t}^{C}=q_{i}^{C}\left(x_{t}, w_{t}, \delta\right)$. Third, the equilibrium is symmetric such that the collusive quantities in period $t$ are the same for all firms: $q_{i}^{C}\left(x_{t}, w_{t}, \delta\right)=q^{C}\left(x_{t}, w_{t}, \delta\right) \forall i=1, \ldots, N \mathbb{4}^{\mathbb{4}}$

\footnotetext{
${ }^{4}$ The punishment strategies and the symmetric equilibrium refinement used in Corts $(1999)$ are chosen for simplicity. The results would apply to more general punishment strategies, such as stick and carrot
} 
In order for $q_{i t}^{C}$ to be sustained by the grim trigger punishments given the realizations of $x_{t}$ and $w_{t}, q_{i t}^{C}$ must belong to the set of quantities such that the present discounted value of colluding each period is at least as large as the present discounted value of any one-period deviation for all firms. Let $\mathcal{Q}\left(x_{t}, w_{t}, \delta\right)$ be the set of feasible collusive quantities that can be sustained by the grim trigger punishments in period $t$ such that $\left(q_{1 t}^{C}, \ldots, q_{N t}^{C}\right) \in \mathcal{Q}\left(x_{t}, w_{t}, \delta\right)$. We can define $\mathcal{Q}\left(x_{t}, w_{t}, \delta\right)$ as follows:

$$
\begin{aligned}
\mathcal{Q}\left(x_{t}, w_{t}, \delta\right)=\left\{\left(q_{1 t}, \ldots, q_{N t}\right) \mid\right. & \pi\left(q_{i t}, Q_{-i t} ; x_{t}, w_{t}\right) \\
& +\sum_{\tau=1}^{\infty} \delta^{\tau} \mathbb{E}_{t} \pi\left(q_{i}^{C}\left(x_{t+\tau}, w_{t+\tau}, \delta\right), Q_{-i}^{C}\left(x_{t+\tau}, w_{t+\tau}, \delta\right), x_{t+\tau}, w_{t+\tau}\right) \\
& \left.\geq \pi_{i}^{D}\left(Q_{-i t} ; x_{t}, w_{t}\right)+\sum_{\tau=1}^{\infty} \delta^{\tau} \mathbb{E}_{t} \pi_{i}^{N E}\left(x_{t+\tau}, w_{t+\tau}\right) \quad \forall i\right\}
\end{aligned}
$$

where $\pi_{i}^{D}\left(Q_{-i t} ; x_{t}, w_{t}\right)=\max _{q_{i t}} q_{i t}\left(P\left(Q_{-i t}+q_{i t} ; x_{t}\right)-c_{o}-c_{1} w_{t}\right)$ represents the largest per period payoff firm $i$ can earn by deviating from the collusive arrangement given that its $N-1$ rivals jointly offer quantity $Q_{-i t}$. Also, $\pi_{i}^{N E}\left(x_{t}, w_{t}\right)$ represents the one-shot Nash equilibrium (Cournot) profits earned by firm $i$.

In the duopoly setting where $N=2$, the constraint sets can be graphically illustrated. Figure 3.2 does so for the case with linear demand as specified in (3.1) and constant, symmetric marginal costs as given in (3.2). In this figure, the values for $x_{t}$ and $w_{t}$ are fixed and assumed to be constant over time. $5^{5}$ The constraints are drawn for increasing values of $\delta$ from 0 to 1 . When $\delta=0$, the only feasible payoffs are those in which the firms choose the Nash Cournot quantities $q^{N E}\left(x_{t}, w_{t}\right)$. As $\delta$ increases above zero, so too does the set of feasible quantities and payoffs. For high enough values of $\delta$, the firms are able to achieve payoffs on the profit possibility frontier. Because multiple equilibria exist for values of $x_{t}, w_{t}$, and $\delta$, an additional refinement is needed: firms will collude on the symmetric equilibrium that

punishments as well as refinements that did not rely on symmetry.

${ }^{5} \mathrm{I}$ have drawn the graphs assuming complete persistence in $x_{t}$ and $w_{t}$ for simplicity. Because $x_{t}$ and $w_{t}$ are constant, the expected collusive profit earned in each future period by a firm is the same as the profit it earns in the current period from colluding. Thus, to find the constrained sets for given realizations $x_{t}$ and $w_{t}$, one needs to only evaluate the constraints at all possible combinations of quantities for the two firms. However, when $x_{t}$ and $w_{t}$ are stochastic, numerically solving for the constraint sets for a given realization of $x_{t}$ and $w_{t}$ becomes more challenging as the constraints depend not only on the profits earned by the firms given the realization of $x_{t}$ and $w_{t}$, but also on their expected profits over $x$ and $w$. This leads to the curse of dimensionality, as one needs to evaluate the constraints at all possible combinations of quantities for the two firms across all possible values of $x$ and $w$. Preliminary results assuming that $x$ is constant, $w$ is iid, and $q^{C}$ is monotonically decreasing in $w_{t}$ suggest that the constraint sets look similar to the ones presented here. 
maximizes joint profits.

Figure 3.2

Sustainable Payoffs As A Function Of $\delta$

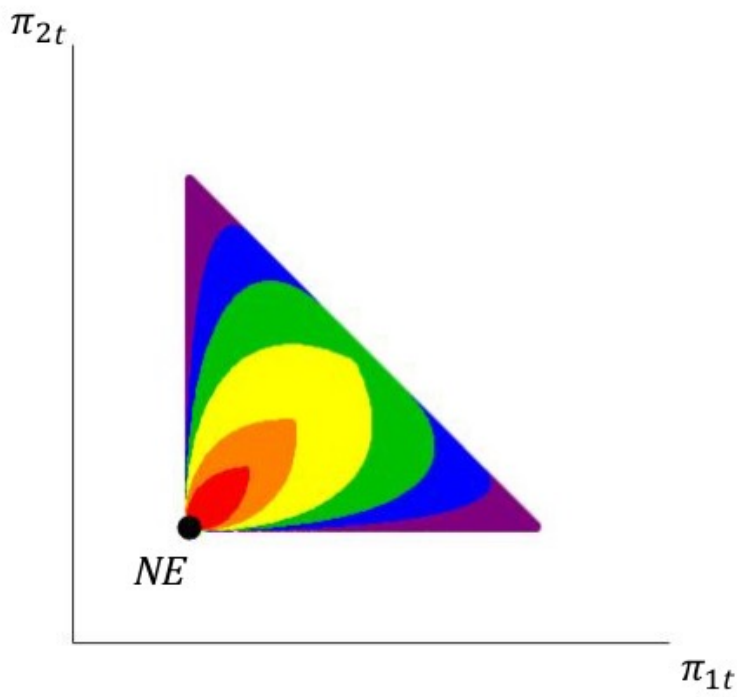

As shown in equations (13)-(16) of Corts (1999) the symmetric, stationary, equilibrium has a closed-form solution. If $\delta$ is large enough for the realized values of $x_{t}$ and $w_{t}$, the firms will be able to reach the profit possibility frontier in period $t$ and jointly produce the monopoly quantity. Thus, each firm $i$ will produce:

$$
q^{M}\left(x_{t}, w_{t}\right)=\frac{a_{0}+a_{1} x_{t}-c_{0}-c_{1} w_{t}}{-2 N a_{2}}
$$

Meanwhile, for lower values of $\delta$, firms will be constrained to choose actions that place them interior to the profit possibility frontier. In this case, the symmetric equilibrium that maximizes the sum of joint profits can be written as:

$$
\tilde{q}\left(x_{t}, w_{t}, \delta\right)=\frac{a_{0}+a_{1} x_{t}-c_{0}-c_{1} w_{t}}{-(N+1) a_{2}}-\frac{2 \sqrt{-a_{2} L\left(x_{t}\right)}}{-(N+1) a_{2}}
$$

where

$L\left(x_{t}\right)=\sum_{\tau=1}^{\infty} \delta^{\tau} \mathbb{E}_{t} \pi\left(q_{i t}^{C}\left(x_{t+\tau}, w_{t+\tau}, \delta\right), Q_{-i t}^{C}\left(x_{t+\tau}, w_{t+\tau}, \delta\right), x_{t+\tau}, w_{t+\tau}\right)-\sum_{\tau=1}^{\infty} \delta^{\tau} \mathbb{E}_{t} \pi_{i}^{N E}\left(x_{t+\tau}, w_{t+\tau}\right)$

and $L\left(x_{t}\right)$ measures the expected profits that would be lost during the punishment phase following a defection in $t$. Thus, it is possible to express the collusive quantity each period 
as follows:

$$
q^{C}\left(x_{t}, w_{t}, \delta\right)= \begin{cases}\tilde{q}\left(x_{t}, w_{t}, \delta\right) & \text { if } \tilde{q}\left(x_{t}, w_{t}, \delta\right) \geq q^{M}\left(x_{t}, w_{t}\right) \\ q^{M}\left(x_{t}, w_{t}\right) & \text { otherwise }\end{cases}
$$

For a given value of $\delta$, variation in $x_{t}$ may induce changes in market conduct whereby firms play $q^{M}$ in some periods and $\tilde{q}$ in others. In the next section, I show that this repeated game has a reduced form representation with a conduct parameter. As will be seen, the conduct parameter is a function of $x_{t}, w_{t}$, and $\delta$ and therefore, may change across periods.

\subsection{Deriving the Reduced Form Conduct Parameter}

As shown in BCLW (2004) and in Chapter 2 of this dissertation, convex profit possibility sets permit representing the collusive equilibrium in each period $t$ as the solution to maximization problem faced by a third party coordinator, akin to a social planner. Figure 3.2 shows that when $x_{t}$ and $w_{t}$ are constant over time, the profit possibility sets in the repeated game are convex at each value of $\delta$. Assuming this to be true when $x_{t}$ and $w_{t}$ are stochastic ${ }^{6}$ permits the following representation of the collusive equilibrium: the coordinator chooses collusive quantities for each of the $N$ firms to maximize its welfare function, a weighted sum of the profits earned by these firms in period $t$. However, the coordinator faces the constraint that the collusive quantities are feasible given realizations of $x_{t}$ and $w_{t}$ and the firms' discount factor $\delta$. Thus, the coordinator solves the following maximization problem:

$$
\begin{array}{r}
\left(q_{1 t}^{C}, \ldots, q_{N t}^{C}\right)=\arg \max _{q_{1 t}, \ldots, q_{N t}} \sum_{i=1}^{N} \omega_{i} \pi\left(q_{i t}, Q_{-i t} ; x_{t}, w_{t}\right) \\
\text { st } \quad\left(q_{1 t}^{C}, \ldots, q_{N t}^{C}\right) \in \mathcal{Q}
\end{array}
$$

where $\omega_{i}$ is the weight that the coordinator places on firm $i$.

With only two firms, we can illustrate the coordinator's problem graphically in Figure 3.3. Given that the coordinator places weights $\omega_{1}$ and $\omega_{2}$ on the profits earned by firm 1 and 2 respectively, the coordinator has linear indifference curves with slope $-\frac{\omega_{1}}{\omega_{2}}$. The coordinator chooses the collusive equilibrium at the point of tangency between its highest indifference curve and the constraints on payoffs induced by $\mathcal{Q}_{t}$.

\footnotetext{
${ }^{6}$ In future work, I hope to verify the conditions for which this assumption is true.
} 
FiguRE 3.3

Representing Collusive Equilibrium As Solution

To Coordinator's Problem

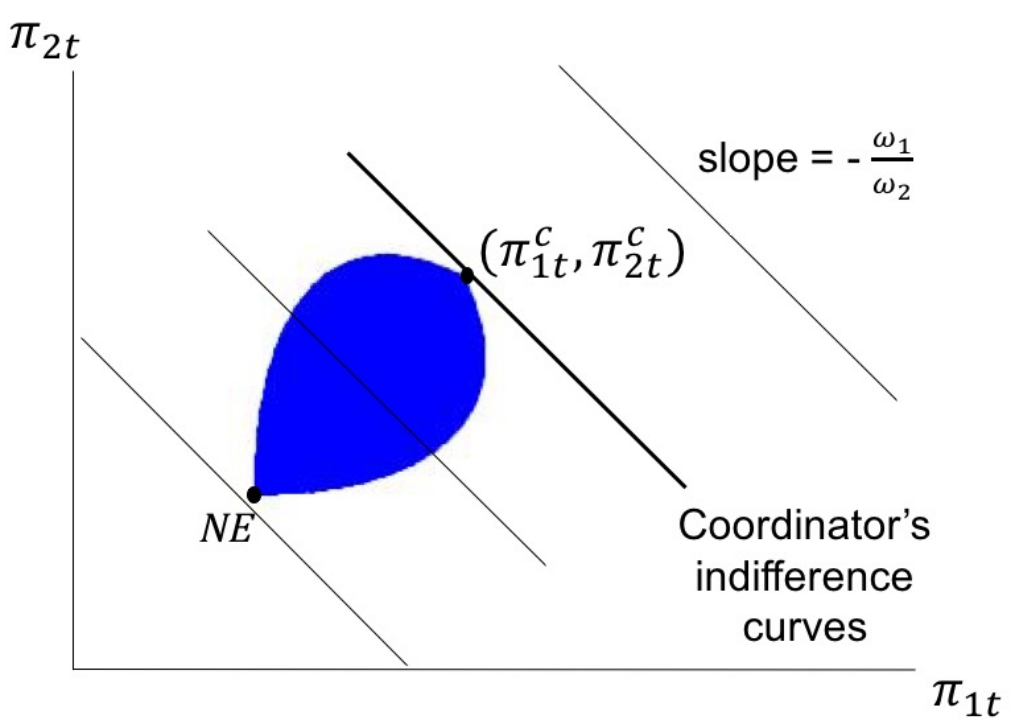

As was also shown in BCLW (2004) and in the previous chapter of this dissertation, the collusive equilibrium arising from the coordinator's problem in each period $t$ can be expressed as the Nash equilibrium in a game where every firm independently and simultaneously chooses its own quantities to maximize its profit subject to a set of constraints. These include the constrains faced by the coordinator and additional constraints ensuring that a firm guarantees to all of its rivals payoffs that are at least as large as those arising from the coordinator's equilibrium. Under the assumption that each of firm $i$ 's rivals (indexed by $j$ ) will choose symmetric quantities and therefore receive the same payoffs, firm $i$ 's constrained maximization problem can be written as:

$$
\begin{gathered}
\max _{q_{i t}} \pi\left(q_{i t}, Q_{-i t} ; x_{t}, w_{t}\right) \\
\text { st } \quad \pi\left(q_{j t}, Q_{-j t} ; x_{t}, w_{t}\right) \geq \pi\left(q_{j}^{C}\left(x_{t}, w_{t}, \delta\right), Q_{-j}^{C}\left(x_{t}, w_{t}, \delta\right) ; x_{t}, w_{t}\right) \quad \forall j \neq i \\
\pi\left(q_{i t}, Q_{-i t}\left(x_{t}, w_{t}, \delta\right) ; x_{t}, w_{t}\right)+\sum_{\tau=1}^{\infty} \delta^{\tau} \mathbb{E}_{t} \pi\left(q_{i}^{C}\left(x_{t+\tau}, w_{t+\tau}, \delta\right), Q_{-i}^{C}\left(x_{t+\tau}, w_{t+\tau}, \delta\right), x_{t+\tau}, w_{t+\tau}\right) \\
\geq \pi_{i}^{D}\left(Q_{-i t} ; x_{t}, w_{t}\right)+\sum_{\tau=1}^{\infty} \delta^{\tau} \mathbb{E}_{t} \pi_{i}^{N E}\left(x_{t+\tau}, w_{t+\tau}\right) \\
\pi\left(q_{j t}, Q_{-j t}\left(x_{t}, w_{t}, \delta\right) ; x_{t}, w_{t}\right)+\sum_{\tau=1}^{\infty} \delta^{\tau} \mathbb{E}_{t} \pi\left(q_{j}^{C}\left(x_{t+\tau}, w_{t+\tau}, \delta\right), Q_{-j}^{C}\left(x_{t+\tau}, w_{t+\tau}, \delta\right), x_{t+\tau}, w_{t+\tau}\right) \\
\geq \pi_{j}^{D}\left(Q_{-j t} ; x_{t}, w_{t}\right)+\sum_{\tau=1}^{\infty} \delta^{\tau} \mathbb{E}_{t} \pi_{j}^{N E}\left(x_{t+\tau}, w_{t+\tau}\right) \quad \forall j \neq i
\end{gathered}
$$


Therefore, it can be shown that each firm $i$ faces the following first order condition: 7

$$
\frac{\partial \pi_{i t}}{\partial q_{i t}}+\frac{\omega}{1+\lambda_{i t}}(N-1) \frac{\partial \pi_{j t}}{\partial q_{i t}}=0
$$

where $\omega=\frac{\omega_{j}}{\omega_{i}}$ is the Lagrange multiplier on the first set of constraints, which guarantee that firm $i$ 's rivals receive at least the collusive level of payoffs. Specifically, $\omega_{i}$ and $\omega_{j}$ are the weights placed on the profits of firm $i$ and each of its rivals $j$ in the coordinator's welfare function. Since the equilibrium refinement restricts firms to play a symmetric equilibrium that maximizes joint profits, $\omega_{i}=\omega_{j}=1$ in all time periods. Also, $\lambda_{i t}$ is the Lagrange multiplier on the second constraint in which the present discounted value of the payoffs from colluding for firm $i$ be at least as large as the profits from a one-shot deviation 8

From the first order condition, we can find the following analytic expression for $\lambda_{i t}$, which I formally derive in Appendix 2 under the symmetry restriction:

$$
\lambda_{i t}=\lambda\left(x_{t}, w_{t}, \delta\right)=\frac{N-1}{N+1} \frac{q^{C}\left(x_{t}, w_{t}, \delta\right)}{q^{N E}\left(x_{t}, w_{t}\right)-q^{C}\left(x_{t}, w_{t}, \delta\right)}-1
$$

Notice that the value of $\lambda_{i t}$ depends on $x_{t}, w_{t}$, and $\delta$. Now, let $\theta_{i t}=\frac{1}{1+\lambda_{i t}}$; then the first order condition faced by firm $i$ could be written as:

$$
\frac{\partial \pi_{i t}}{\partial q_{i t}}+\theta_{i t}(N-1) \frac{\partial \pi_{j t}}{\partial q_{i t}}=0
$$

which is the first order condition to the following optimization problem in which firm $i$ maximizes a weighted sum of its own and its rival's profits in period $t$.

$$
\max _{q_{i}} \pi_{i}\left(q_{i t}, Q_{-i t} ; x_{t}, w_{t}\right)+\theta_{i t}(N-1) \pi_{j}\left(q_{j t}, Q_{-j t} ; x_{t}, w_{t}\right)
$$

Under the symmetry refinement, $\theta_{i t}=\theta_{t}=\theta\left(x_{t}, w_{t}, \delta\right) \forall i$. Chapter two of this dissertation discussed the usefulness of measuring firm conduct using reduced form profit weights like $\theta_{t}$. When $\theta_{t}=0$, the firms play the Nash-Cournot quantities. As $\theta_{t}$ increases above 0 , the firms increasingly internalize the effect of their actions on their rivals' profits. When $\theta_{t}=1$, the firms act to maximize the sum of joint profits. Thus, $\theta_{t}$ can be mapped to conduct parameter

\footnotetext{
${ }^{7}$ Note that by the envelope theorem, $\frac{\partial \pi_{k}^{D}}{\partial q_{i}}=\frac{\partial \pi_{k}}{\partial q_{i}}$ for $k=i, j$

${ }^{8}$ The third constraint is redundant, given the first constraint, and mathematically drops out of the first order condition as $\frac{\partial \pi_{j t}}{\partial q_{i t}}=\frac{\partial \pi_{j t}^{D}}{\partial q_{i t}}$
} 
$\sigma_{t}$ defined in (3.3). The first order condition (3.21) can be written as:

$$
P_{t}=c_{0}-c_{1} x_{t}-\left(1+(N-1) \theta_{t}\right) P^{\prime}\left(Q_{t}\right) q_{t}(N-1)
$$

and

$$
\sigma_{t}=\sigma\left(x_{t}, w_{t}, \delta\right)=1+\frac{N-1}{1+\lambda\left(x_{t}, w_{t}, \delta\right)}
$$

Notice that in this repeated game in which firms compete in one market, $\frac{\partial \sigma_{t}}{\partial x_{t}} \neq 0$. Thus, the condition in Proposition 1 is violated and it is not possible to estimate reliable measures of market power in this standard model of collusion.

Corts (1999) discusses the severity of the mismeasurement of conduct in the repeated game along two dimensions: how often the monopoly outcome is realized, and the persistence of the demand shocks $x_{t}$. Corts argues that if the monopoly outcome is realized in all states, then market power is correctly estimated. For the monopoly outcome to be realized in all periods, $\sigma_{t}=N \forall t$. Thus, the necessary condition in proposition 1 is trivially satisfied. Likewise, Corts finds that as demand becomes more persistent, $\hat{\sigma} \rightarrow \sigma$, and that at full persistence, $\hat{\sigma}=\sigma$. Since mismeasurement results from $\sigma$ varying with $x_{t}$, if $x_{t}$ varies less, this will induce smaller variation in $\sigma$ leading to more accurate estimates of market power.

\subsection{Circumventing the Corts Critique with Cross Sectional Data From Multiple MARKets}

While the previous section assumed that firms competed in one market, in many empirical settings, firms compete in multiple geographic markets. Thus, the researcher often has access to a panel of data on market outcomes (usually there are many more geographic markets in the dataset than there are time periods). Assuming that demand shifts across markets each period, a researcher can use that cross-sectional variation in $x_{t}$ to estimate a different conduct parameter each period instead of having to estimate one fixed collusion parameter over time. However, if the degree to which firms compete in period $t$ varies across markets with this cross-sectional variation in $x_{t}$, the condition in Proposition 1 will still be violated and $\hat{\sigma}$ will mismeasure the level of competition in period $t$. I will show that for the infinitely repeated game in which firms compete in multiple markets, $\sigma$ will not be a function of demand shocks if one is willing to make an additional equilibrium refinement on firm strategies.

Formally, let markets be indexed by $m=1, \ldots, M$. Furthermore, let $\mathbf{q}_{i t}=\left\{q_{i t 1}, \ldots, q_{i t M}\right\}$ be a vector of the quantity choices for each firm in each market. In each market, firms observe realizations of random demand and cost shocks before choosing quantities in that market. Therefore, let $\mathbf{x}_{t}=\left\{x_{t 1}, \ldots, x_{t M}\right\}$ and $\mathbf{w}_{t}=\left\{w_{t 1}, \ldots, w_{t M}\right\}$. Now, in each period, firm $i$ 
chooses $\mathbf{q}_{i t}$ to maximize the sum of present discounted value of its future stream of expected profits across markets: $\sum_{m=1}^{M} \pi\left(q_{i t m} ; x_{t m}, w_{t m}\right)+\sum_{\tau=1}^{\infty} \delta^{\tau} \mathbb{E}_{t}\left[\pi\left(q_{i t+\tau m} ; \mathbf{x}_{t+\tau m}, \mathbf{w}_{t+\tau m}\right)\right] . \pi$, the per-market-period profit function, is now given as:

$$
\pi\left(q_{i t m}, Q_{-i t m} ; x_{t m}, w_{t m}\right)=\left(P\left(Q_{t m} ; x_{t m}\right)-c_{0}-c_{1} w_{t m}\right) q_{i t m}
$$

The equilibrium refinements described in the previous section are applied here as well. The collusive actions on the equilibrium path are supported via grim trigger punishments with Nash-Cournot reversion. Now though, the ability of firms to compete in multiple markets each period expands the set of strategies available to the firms in the repeated game, even within the class of grim trigger punishments. For instance, if a firm were to deviate from the collusive arrangement in only market $m$ during period $t$, do the other firms punish that defection in just market $m$ or in a larger set of markets? Additionally then, I assume that if a firm deviates in any market, it is punished by reversion to the one-shot Cournot equilibrium in all markets for all future periods. In a model with perfect information, punishing a deviating firm in all markets as opposed to a subset of markets serves as the harshest punishment in this class and supports the highest collusive payoffs. Thus, conditional on the use of grim trigger punishments, Nash reversion in all markets is the most efficient punishment scheme. In addition firms continue to maximize joint profits each period from the set of actions that are sustained by the grim trigger punishments given the realizations of $x_{t}$ and $w_{t}$. The collusive equilibrium is also stationary such that, for each firm $i, q_{i t m}^{C}=q_{i}^{C}\left(x_{t m}, w_{t m}, \delta\right) \forall m, t$. Finally, the collusive equilibrium is symmetric.

Because punishment occurs in all markets, a firm that deviates will find it optimal to deviate in all markets. Thus, the benefit of deviating in a given period depends on the sum of the deviation profits across markets. The feasible sets of actions $\mathcal{Q}\left(\mathbf{x}_{t}, \mathbf{w}_{t}, \delta\right)$ defined in (3.12) can now be written as:

$$
\begin{aligned}
\mathcal{Q}\left(\mathbf{x}_{t}, \mathbf{w}_{t}, \delta\right)=\left\{\left(\mathbf{q}_{1 t}, \ldots, \mathbf{q}_{N t}\right) \mid\right. & \sum_{m=1}^{M} \pi\left(q_{i t m}, Q_{-i t m} ; x_{t m}, w_{t m}\right) \\
& +\sum_{\tau=t+1}^{\infty} \delta^{\tau-t} \sum_{m=1}^{M} \mathbb{E}_{t} \pi\left(q_{i}^{C}\left(x_{\tau m}, w_{\tau m}, \delta\right), Q_{-i}^{C}\left(x_{\tau m}, w_{\tau m}, \delta\right), x_{\tau m}, w_{\tau m}\right) \\
& \left.\geq \sum_{m=1}^{M} \pi_{i}^{D}\left(Q_{-i t m} ; x_{t m}, w_{t m}\right)+\sum_{\tau=t+1}^{\infty} \delta^{\tau-t} \sum_{m=1}^{M} \mathbb{E}_{t} \pi_{i}^{N E}\left(x_{\tau m}, w_{\tau m}\right) \quad \forall i\right\}
\end{aligned}
$$

With the feasibility constraints so defined, the multi-market analog to 3.18 can be written 
as:

$$
\begin{aligned}
& \max _{q_{i t 1}, \ldots, q_{i t M}} \sum_{m=1}^{M} \pi\left(q_{i t m}, Q_{-i t m} ; x_{t m}, w_{t m}\right) \\
& \text { st } \quad \sum_{m=1}^{M} \pi\left(q_{j t m}, Q_{-j t m} ; x_{t m}, w_{t m}\right) \geq \sum_{m=1}^{M} \pi\left(q_{j}^{C}\left(x_{t m}, w_{t m}, \delta\right), Q_{-j}^{C}\left(x_{t m}, w_{t m}, \delta\right) ; x_{t}, w_{t}\right) \quad \forall j \neq i \\
& \sum_{m=1}^{M}\left[\pi\left(q_{i t m}, Q_{-i t m} ; x_{t m}, w_{t m}\right)+\sum_{\tau=t+1}^{\infty} \delta^{\tau-t} \mathbb{E}_{t} \pi\left(q_{i}^{C}\left(x_{\tau m}, w_{\tau m}, \delta\right), Q_{-i}^{C}\left(x_{\tau m}, w_{\tau m}, \delta\right), x_{\tau m}, w_{\tau m}\right)\right] \\
& \geq \sum_{m=1}^{M}\left[\pi_{i}^{D}\left(Q_{-i t m} ; x_{t m}, w_{t m}\right)+\sum_{\tau=t+1}^{\infty} \delta^{\tau-t} \mathbb{E}_{t} \pi_{i}^{N E}\left(x_{\tau m}, w_{\tau m}\right)\right] \\
& \sum_{m=1}^{M}\left[\pi\left(q_{j t m}, Q_{-j t m} ; x_{t m}, w_{t m}\right)+\sum_{\tau=t+1}^{\infty} \delta^{\tau-t} \mathbb{E}_{t} \pi\left(q_{j}^{C}\left(x_{\tau m}, w_{\tau m}, \delta\right), Q_{-j}^{C}\left(x_{\tau m}, w_{\tau m}, \delta\right), x_{\tau m}, w_{\tau m}\right)\right] \\
& \geq \sum_{m=1}^{M}\left[\pi_{j}^{D}\left(Q_{-j t} ; x_{t}, w_{t}\right)+\sum_{\tau=1}^{\infty} \delta^{\tau} \mathbb{E}_{t} \pi_{j}^{N E}\left(x_{t+\tau}, w_{t+\tau}\right)\right] \quad \forall j \neq i
\end{aligned}
$$

For each market $m$ in period $t$, firm $i$ faces the following first order condition:

$$
\frac{\partial \pi_{i t m}}{\partial q_{i t m}}+\frac{\omega}{1+\lambda_{i t m}}(N-1) \frac{\partial \pi_{j t m}}{\partial q_{i t m}}=0
$$

In the single market model, the constraints in the optimization problem (3.18) were subject to change over time. This lead to changes over time in the Lagrange multiplier $\lambda_{i t}$ which lead to changes in $\sigma_{t}$. Here, the constraints faced by firm $i$ in choosing the quantity to sell in market $m$ during period $t$ are defined by the sum of payoffs across all the $M$ markets in period $t$. Thus, the firm faces the same set of constraints in every market during period $t$. Because the constraints are not changing, the same Lagrange multiplier applies to the firm's decision in each market $m$ during period $t$. We can define the conduct parameter $\sigma_{t}$ as:

$$
\sigma_{t}=\sigma\left(\mathbf{x}_{t}, \mathbf{w}_{t}, \delta\right)=1+\frac{N-1}{1+\lambda\left(\mathbf{x}_{t}, \mathbf{w}_{t}, \delta\right)}
$$

Because $\lambda\left(\mathbf{x}_{t}, \mathbf{w}_{t}, \delta\right)$ is constant across the $M$ markets in period $t$, cross sectional variation in $\mathbf{x}_{t}$ will not vary $\sigma_{t}$ across markets. Therefore, the condition in Proposition 1 is satisfied in this model and $\sigma_{t}=\hat{\sigma}_{t}$. While reliance on time-series variation for one market often results in estimates of conduct that diverge from the truth, cross-sectional variation can be used to accurately measure of conduct for a specific time period. 


\section{Chapter 4 The Ice Cream Split: Empirically Distinguishing Price and Product Space Collusion}

\subsection{INTRODUCTION}

Chapters 2 and 3 justified the use of profit weights to measure collusion against two main criticisms of conduct parameters: that they lack a theoretical justification and that they run afoul of the Corts Critique. With these criticisms addressed, I can now use the profit weights derived in Chapter 2 to estimate the degree to which Ben \& Jerry's and Häagen-Dazs colluded in their choice of flavors and prices during 2013. The market for super-premium ice cream provides a setting conducive to investigating the role of product space collusion. The market has been dominated by two firms: Ben \& Jerry's and Häagen-Dazs. These brands have long been associated with distinct styles of ice cream: Häagen-Dazs is known to produce "smooth", traditional flavor:11 while Ben \& Jerry's sells so-called "chunky" flavors: ice cream to which extra ingredients like chocolate, caramel, candy, and baked goods have been added 2

There is anecdotal evidence suggesting that Ben \& Jerry's and Häagen-Dazs have coordinated their product choices. First, it seems unlikely that the assortments offered by the brands qualify as best responses. Consider the quintessential flavors: chocolate, coffee, strawberry, and butter pecan. These popular flavors were responsible for 28.2 percent of Häagen-Dazs sales in 2013, so it should come as no surprise that Ben \& Jerry's also makes them. However, Ben \& Jerry's only sells them at its ice cream shops or as the bases for chunky flavors. Secondly, the brands appear to have engaged in periodic product space wars, consistent with collusive behavior supported by trigger strategies as predicted by Green and Porter (1984). The New York Times covered the first product space war between the

\footnotetext{
${ }^{1}$ The top 6 best selling flavors for Häagen-Dazs in 2013 were vanilla, chocolate, coffee, strawberry, butter pecan, and vanilla bean.

${ }^{2}$ Ben \& Jerry's top 6 best selling flavors in 2013 were Cherry Garcia (cherry ice cream with fudge chunks and cherry pieces), Half Baked (blend of chocolate chip cookie dough and chocolate fudge brownie), Chocolate Fudge Brownie, Chocolate Chip Cookie Dough, Coffee Heath Bar Crunch, and Chunky Monkey (banana ice cream with walnuts and dark chocolate chunks).
} 
brands in 1994.

"Yet, by all accounts, the slower growth in the super-premium market has meant tougher competition...[Häagen-Dazs and Ben 85 Jerry's] have invaded each other's turf...The fight began two years ago [1992] when Häagen-Dazs, long known for its 'smooth' ice cream, went after Ben 86 Jerry's market by introducing its own versions [of] 'chunky' ice cream, dubbed 'Exträas'...Last spring Ben E Jerry's... retaliated with its own smooth varieties. To promote its smooth flavors, the company is advertising on television for the first time...Häagen-Dazs isn't amused."

Describing his company's strategy to the media during that period, Ben Cohen asserted "When the smooth get chunky, the chunky get smooth."

In order to credibly claim that the observed pattern of product assortment is indicative of collusive behavior, I have to rule out confounding explanations, chief amongst them that consumer preferences are responsible for firm differentiation $]^{3}$ and that the firms have cost differences that manifest themselves in different product choices. I am able to explicitly control for these stories. Specifically, I estimate demand using the Berry, Levinsohn and Pakes (1995) algorithm while including a fixed effect for each brand-flavor combination as in Nevo (2001). Thus, I control for average quality and perception differences between the versions of flavors produced by each brand. Secondly, I model firms as sequentially choosing products and prices. This permits me to estimate marginal cost using the first order conditions of each firm's second stage pricing decision, allowing me to control for cost differences when estimating the product collusion parameters in the first stage. As such, estimated values of the reduced-form parameters indicative of collusion should be viewed as robust to these two alternative explanations.

This chapter proceeds as follows: Section 4.2 summarizes key features of the market for super-premium ice cream. Section 4.3 presents the empirical models of demand and supply. Section 4.4 describes the data. In Section 4.5, I discuss identification and estimation of the demand, pricing-stage, and product-stage parameters. Parameter estimates are presented in Section 4.6 and counterfactuals are performed in Section 4.7. Finally, Section 4.8 concludes.

\footnotetext{
${ }^{3}$ There could be several reasons for this. First, each brand could specialize in flavors which consumers think are higher quality than the version its rival could produce. Secondly, though no quality difference in each brand's version of a flavor exists, consumers may have come to strongly associate each brand with a style of ice cream.
} 


\subsection{The Market For Super-Premium Ice Cream}

\subsubsection{Market Definitions}

Relevant Product Market: For the purposes of this chapter, the relevant product market consists of super-premium ice cream sold by the pint in supermarkets. The USDA defines four categories of ice cream: super-premium, premium, standard, and economy. Superpremium ice cream is distinguished as "tend(ing) to have very low overrun (air in the ice cream) and high fat content, and the manufacturer uses the best quality ingredients.' "'t There is considerable precedent for defining super-premium ice cream as a distinct product market: the economics literature. ${ }^{5}$ antitrust decisions ${ }^{6}$ and trade publications have all used this assumption.

There are three important exclusions being made here. First, I am assuming that the market for prepackaged ice cream to be consumed at home is distinct from the market for ice cream sold by the scoop in ice cream shops. Second, I am assuming that prepackaged pints sold in supermarkets exist in a separate market from prepackaged or hand packed tubs that a brand might sell at its scoop shops and pints sold in convenience stores and drug stores. These first two assumptions seem largely innocuous. The third assumption, that superpremium ice cream resides in a market distinct from premium, standard, and economy ice cream, is more readily contestable. However, there is a significant degree of horizontal and vertical differentiation between super-premium brands and their closest competitors, the premium brands. In addition to the differences in fat and air content and ingredient quality, super-premium brands are sold in "pints" while premium brands are sold in quarts, half gallons, and gallons. Super-premium and premium brands tend to be sold in different parts of the freezer section, reducing cross-category comparison and substitution.

Relevant Geographic Market: I define the relevant geographic market at the supermarket level. Consumers choose the stores at which they shop for groceries based on the store's location, the set of product bundles offered, and the price of those bundles. Given that the price for a weekly bundle of groceries for a family of four is typically in the hundreds of dollars, a small change in the price of ice cream has a negligible impact on the price of the bundle. Furthermore, consumers tend to shop for their entire bundle of groceries at one supermarket in part because of transportation costs and the costs of learning a store's layout. Thus, they are unlikely to know the prices charged for ice cream in another store. For these reasons, I surmise that the cross price elasticity between stores for ice cream may

\footnotetext{
${ }^{4}$ http://www.ams.usda.gov/sites/default/files/media/CID\%20Ice\%20Cream $\% 2 \mathrm{C} \% 20$ Sherbet $\% 2 \mathrm{C} \% 20 \mathrm{Fruit} \% 20$ and $\% 20$ Juice $\% 20$ Bars $\% 2 \mathrm{C} \% 20$ Ices $\% 2 \mathrm{C} \% 20$ and $\% 20$ Novelties.pdf

${ }^{5} \mathrm{DMS}(2009)$ study the market for premium ice cream as distinct from super-premium.

${ }^{6}$ https://www.ftc.gov/sites/default/files/documents/cases/2003/06/dreyercomplaint.htm
} 
be very low.

\subsubsection{Who Chooses Prices AND Flavors?}

When considering the supply side of the model, there are a variety of actors in the vertical stream of production of ice cream. In particular, there are manufacturers and supermarket retailers. In some instances there are independent distributors. This opens up the possibility for complex vertical arrangements and raises an important question: who chooses the flavors and sets the prices in each market? For the purposes of this chapter, I ignore the possibility of vertical interactions and assume that Ben \& Jerry's and Häagen-Dazs choose the flavors to offer in each market and set the prices for those products. I justify this assumption in two ways. First, it is the operating assumption in the literature. As stated in DMS (2009)

"Since our data is aggregated across stores in a market area, we consider the manufacturers' product-choice decisions of which flavors to offer at the market level abstracting from the manufacturer-retailer interaction. The institutional realities in the ice cream industry suggest that manufacturers have substantial control over the varieties placed in the supermarkets. Ice cream is not handled through supermarket warehouses but through a direct-to-store distribution network. Ice-cream manufacturers 'rent' freezer space in the stores and retain full responsibility for what to stock."

Though I am not aggregating my data, the validity of the above argument should not be affected by aggregation. For the assumption to be true at the city level, it must in some sense hold at every store in the city.

Secondly, the reliance on direct-to-store distribution (DSD) strengthens the credibility of this assumption. Direct-to-store distributors not only deliver the product to the supermarket, but are responsible for stocking the store's shelves with that product. According to a 2008 report from the Grocery Manufacturers Association, "Knowledgeable representatives of suppliers of DSD products are in stores multiple times a week merchandising products ... the supplier assumes the costs for delivery, inventory management and merchandising." Dari Farms, a direct-to-store distributor of ice cream touts amongst its services, "optimiz(ing) product mix and profitability." Given this, I feel comfortable assuming that the supermarkets are not choosing products and prices.

It is possible that distributors are choosing the prices and product offerings. This seems unlikely though. These distributors have been granted exclusive territories by the manufacturers. My conjecture is that the cost to manufacturers from switching distributors is low. Thus, it is likely that distributors have minimal bargaining power with manufacturers and 
would be loathe to contradict their wishes. For these reasons, I assume that the choices of products and prices are made by Ben \& Jerry's and Häagen-Dazs.

\subsection{EMPIRICAL MOdeL}

\subsubsection{Consumer Demand}

Consumers $i=1, \ldots, M_{t}$ shop for groceries in market $t$, where $t=1, \ldots, T$ indexes a unique supermarket-week pair. Each consumer can purchase one pint of ice cream from either Ben \& Jerry's or Häagen-Dazs or consume the outside option. 7 The utility consumer $i$ receives from purchasing flavor $j$ produced by brand $b$ in market $t$ is given by:

$$
U_{i j b t}=\beta_{i} X_{b j}+\alpha p_{b t}+\tilde{\xi}_{b j t}+\epsilon_{i j b t}
$$

where $X_{b j}$ is a vector of observable product characteristics and $p_{b t}$ is the price charged by firm $b$ for all the flavors it sells in market $t]^{8}$ Market specific tastes for each product are captured by $\tilde{\xi}_{b j t}$ while $\epsilon_{i j b t}$ is an consumer-specific idiosyncratic term. Consumer preferences for the characteristics in $X$ are assumed normally distributed across the population such that $\beta_{i} \sim \mathcal{N}\left(\bar{\beta}, \sigma_{\beta}\right)$, while $\alpha$, the coefficient on price, is constant across consumers.

The observable characteristics in $X$ include a constant, a brand dummy, indicators for whether a given flavor has a vanilla, chocolate, coffee, or fruit base, and a categorical variable that measures the number of mix-ins in that flavor. For example, Chunky Monkey is banana ice cream with dark chocolate chunks and walnuts. Thus, it is represented as having a fruit base and two mix-ins. Meanwhile coffee ice cream has a coffee base and no mix-ins.

Admittedly, $X$ excludes many observable flavor characteristics which are important to consumer utility. Diverse flavors like peanut butter cup and mint oreo are observationally equivalent in $X$. Also, consumer utility from a flavor should depend on the interaction between the base and the type of mix-ins used, which are not measured in $X$. For example, most consumers would prefer chocolate ice cream with brownies to chocolate ice cream with grapes. Because of computational and data limitations, I have limited $X$ to the characteristics I think are most important in describing a flavor.9

${ }^{7}$ I do not allow consumers to store ice cream for future consumption. Hendel and Nevo $(2006 a)$ and Hendel and Nevo (2006b) highlight the potential problems in doing so, especially when one considers weekly markets. However, due to the high storage costs both in terms the cost of freezer shelf space faced by retailers and the temptation costs faced by consumers, I do not feel storability is much of an issue in this setting.

8 The assumption is consistent with DMS (2009) and much of the literature on pricing at grocery stores. However, it does preclude sales for a strict subset of flavors offered in a market.

${ }^{9}$ To make the substitution patterns fully flexible, one would need to include dummies for all base flavors, all mix-ins, and their interactions. Unfortunately, this is infeasible. In particular, Ben \& Jerry's alone uses 53 base flavors and 100 mix-ins in my sample. 
To account for these limitations and improve the fit of the model, Nevo (2001) recommends the inclusion of fixed effects. As such, I decompose the market specific product tastes as follows:

$$
\tilde{\xi}_{b j t}=\xi_{b j}+\xi_{s}+\xi_{m}+\xi_{y}+\xi_{b j t}
$$

where $\xi_{b j}, \xi_{s}, \xi_{m}$, and $\xi_{y}$ are respectively product, store, month, and year fixed effects.10 $\xi_{b j t}$ measures the deviation in market specific product tastes from these means. The inclusion of product fixed effects allows the mean utility for products with the same value of $X$ to differ. Each product fixed effect also measures the average utility derived from specific base flavor and mix-in combinations. The month fixed effects are also very important since ice cream is a product that also exhibits a high degree of seasonality 11

I make two assumptions concerning the demand shocks $\xi_{b j t}$. The first is a timing assumption of the sort discussed in Ackerberg and Hahn (2015) and Ackerberg (2016). Let $\xi_{b t}=\left[\xi_{b 1 t}, \ldots, \xi_{b J t}\right]$ be the vector of demand shocks faced by brand $b$ in market $t$. I first assume that each firm chooses both the products it offers and the price it charges in market $t$ before the demand shocks $\xi_{b t}$ and $\xi_{-b t}$ are realized.12 Second, I assume that the $\xi_{b j t}$ are $i i d$ across all products within a market and across markets (cross-sectionally and over time).

In addition to the utility of the inside goods produced by Ben \& Jerry's and HäagenDazs, I have to specify the utility received by consumers who do not purchase a flavor from either brand. I have chosen the traditional normalization: the utility consumer $i$ receives from purchasing the outside option in market $t$ is given by $u_{i 0 t}=\epsilon_{i 0 t}$.

I impose two additional assumptions which are standard in the literature. The first is that the idiosyncratic errors $\epsilon_{i j b t}$ and $\epsilon_{i 0 t}$ are iid draws from a Type I extreme value distribution. The second is that each consumer purchases one unit of the good that gives her the highest utility, including the outside good. Then, if each firm can choose a subset of $J$ products to offer, the market share of product $j$ produced by brand $b$ in market $t$ is represented as:

$$
s_{b j t}=d_{b j t} \int \frac{\exp \left(\beta_{i} X_{b j}+\alpha p_{b t}+\xi_{b j}+\xi_{s}+\xi_{y}+\xi_{m}+\xi_{b j t}\right)}{1+\sum_{h \in\{b,-b\}} \sum_{k=1}^{J} d_{b k t} \exp \left(\beta_{i} X_{h k}+\alpha p_{h t}+\xi_{h k}+\xi_{s}+\xi_{y}+\xi_{m}+\xi_{h k t}\right)} f\left(\beta_{i}\right) \mathrm{d} \beta_{i}
$$

\footnotetext{
${ }^{10}$ I discuss how $\bar{\beta}$ and $\xi_{b j}$ are separately identified in Section 4.5.1.

${ }^{11}$ Though I do not allow for seasonal variation in the utility of individual flavors, seasonal flavors are only sold during certain months of the year. Thus, the product fixed effects are only measured during the months in which each flavor is sold. When constructing moment inequalities, I am careful not to consider deviations in which seasonal flavors are offered out of season.

${ }^{12}$ Admittedly, this assumption is particularly strong. In future work, I plan on relaxing it by allowing $\xi_{b j t}$ to follow and $\operatorname{AR}(1)$ process as in Sweeting (2013). If $\xi_{b j t}=\rho \xi_{b j t-1}+\nu_{b j t}$, the demand parameters are still identified under the assumption that firms choose products and prices in market $t$ before $\nu_{b j t}$ is realized.
} 
where $d_{b j t}$ is an indicator for whether firm $b$ offers product $j$ in market $t$.

\subsubsection{SUPPLY}

Following the theoretical model presented in Chapter 2, I model Ben \& Jerry's and HäagenDazs as competing in static reduced-form game which has two stages: first, firms choose a subset of $J$ products to offer in each market $t$, then they choose prices. It is unlikely that the firms make decisions each week, especially with respect to their product choices. Therefore, I assume that this game is played monthly and, on the supply side, market $t$ corresponds to a supermarket-month.

I now specify the reduced-form game played by Ben \& Jerry's and Häagen-Dazs under the timing and distributional assumptions concerning $\xi_{b j t}$ that were made in the previous section. In the first stage, each firm $b$ solves:

$$
\max _{d_{b 1}, \ldots, d_{b T}} \sum_{t} \mathbb{E}_{\xi}\left[\pi_{b t}\right]+\theta_{1, b} \mathbb{E}_{\xi}\left[\pi_{-b t}\right]
$$

where $d_{b t}=\left[d_{b 1 t}, \ldots, d_{b J t}\right]$. Meanwhile in the second stage, after observing the flavors offered by its rival, firm $b$ chooses the prices to charge in each market in order to solve:

$$
\max _{p_{b 1}, \ldots, p_{b T} \mid d_{b 1}, \ldots, d_{b T}} \sum_{t} \mathbb{E}_{\xi}\left[\pi_{b t}\right]+\theta_{2, b} \mathbb{E}_{\xi}\left[\pi_{-b t}\right]
$$

where the profit function $\pi_{b t}$ is defined as

$$
\pi_{b t}\left(d_{b t}, d_{-b t}, p_{b t}, p_{-b t}\right)=M_{t}\left(p_{b t}-c_{b t}\right) \sum_{j=1}^{J} d_{b j t} s_{b j t}-R_{b t}
$$

and $M_{t}$ is the market size. The profit function includes two cost parameters. The first cost parameter, $c_{b t}$, represents the marginal costs of production, distribution, and retail. As with price, the marginal cost is assumed to be constant across all flavors sold by a brand in a given market 13 I assume that $c_{b t}$ is linear in a set cost shifters

$$
c_{b t}=\mathrm{w}_{b t} \gamma+\omega_{b t}
$$

where $\mathrm{w}_{b t}$ and $\omega_{b t}$ are observed and unobserved cost shifters respectively. The second cost

\footnotetext{
${ }^{13}$ This is also the assumption made in DMS (2009), and is relatively innocuous given that all flavors are largely composed of similar amounts of cream, eggs, and sugar. Thus, the ingredients that distinguish flavors are likely a small part of the production cost. In addition, distribution costs, especially refrigerated transportation, are likely a major component of $c$ and would be constant across flavors.
} 
parameter, $R_{b t}$, represents a fixed cost that brand $b$ has to pay to the retailer in market $t$. I assume this cost is a linear function of $N_{b t}$, the number of flavors that firm $b$ offers in market $t$.

$$
R_{b t}=\eta_{b} N_{b t}
$$

One interpretation of $\eta_{b}$ is as the per-flavor rental cost of freezer shelf space. Freezer space in a supermarket is limited and supermarkets face an opportunity cost to stocking an additional flavor produced by brand $b$. While I do not model the bargaining process between the supermarkets and the brands, this interpretation allows the variable profits to be split between the manufacturers and the retailers. Alternatively, $\eta_{b}$ could capture other costs that scale linearly with the number of varieties produced brand $b$ including the cost of switching a production line from one flavor to another flavor.

With the profit function defined, the SPNE of this reduced-form game can be found by backwards induction. Thus, I now consider the firms' second stage pricing decisions.

\subsubsection{Second Stage Pricing Decision}

In the second stage, firms take the choice of products in the first stage as given. Thus in each market, firm $b$ chooses its price $p_{b t}$ in order to solve the following maximization problem.

$$
\begin{aligned}
\max _{p_{b 1}, \ldots, p_{b T}} \sum_{t=1}^{T} & \left(M_{t}\left(p_{b t}-c_{b t}\right) \sum_{j=1}^{J} d_{b j t} \mathbb{E}_{\xi}\left[s_{b j t}\right]-R_{b t}\right) \\
& +\theta_{2, b} \sum_{t=1}^{T}\left(M_{t}\left(p_{-b t}-c_{-b t}\right) \sum_{j=1}^{J} d_{-b j t} \mathbb{E}_{\xi}\left[s_{-b j t}\right]-R_{-b t}\right)
\end{aligned}
$$

There are $T$ first order conditions associated with this optimization problem. Because the markets are independent, the first order condition associated with $p_{b t}$ depends only on variables specific to market $t$. Thus, each first order condition can be considered separately. Rearranging the first order condition governing firm $b$ 's pricing decision in market $t$ leads to the following expression for the price cost markup:

$$
p_{b t}-c_{b t}=\frac{\sum_{j=1}^{J} d_{b j t} \mathbb{E}_{\xi}\left[s_{b j t}\right]+\theta_{2, b} \Delta_{b,-b, t} \sum_{j=1}^{J} d_{-b j t} \mathbb{E}_{\xi}\left[s_{-b j t}\right]}{\sum_{j=1}^{J} d_{b j t}\left(-\frac{\partial \mathbb{E}_{\xi}\left[s_{b j t}\right]}{\partial p_{b t}}\right)-\theta_{2, b} \theta_{2,-b} \Delta_{b,-b} \sum_{j=1}^{J} d_{-b j t} \frac{\partial \mathbb{E}_{\xi}\left[s_{-b j t}\right]}{\partial p_{b t}}}
$$


where

$$
\Delta_{b,-b}=\frac{\sum_{j=1}^{J} d_{b j t} \frac{\partial \mathbb{E}_{\xi}\left[s_{b j t}\right]}{\partial p_{-b t}}}{\sum_{j=1}^{J} d_{-b j t}\left(-\frac{\partial \mathbb{E}_{\xi}\left[s_{-b j t}\right]}{\partial p_{-b t}}\right)}
$$

The functional form of the markup is fairly intuitive. When the price collusion parameters equal 0, 4.10 reduces to the ratio of firm $b$ 's total market share to its total own price elasticity, which is the standard markup in the literature given Nash-Bertrand competition and logit demand. As the collusion parameters increase above 0 , the firms begin to internalize the impact of their pricing decisions on their rival's profit. Thus, the numerator of the markup is the weighted sum of firm $b$ 's total market share and the total market share of its rival. Likewise, the denominator is the weighted difference of firm b's own price elasticity and the cross price elasticity.

The expression in 4.10 also gives rise to two comparative statics that a reader would expect in a model of collusion. First, increasing the degree to which firms collude leads to higher prices and larger markups. An increase in either $\theta_{b}$ or $\theta_{-b}$ results in an increase in the markup, and because marginal cost is exogenous, an increase in the markup must be the result of an increase in price. Secondly, the effect of collusion on prices and markups depends on the degree to which firms compete in the market. All else equal, there is greater scope for collusion to increase prices in markets where firms offer direct substitutes than in markets where the products offered by firms are not perceived as substitutable. Cross brand substitutability is captured by $\Delta_{b,-b, t}$. Given a marginal increase in $p_{-b t}$, a subset of consumers will stop purchasing products made by firm $-b . \Delta_{b,-b, t}$ measures the fraction of those customers who switch to purchasing products produced by firm $b$ as opposed to those that switch to consuming the outside option. In 4.10 the derivative of the markup with respect to either collusion parameter is increasing in $\Delta_{b,-b, t}$

Combining the first order condition defined in 4.10 with the marginal cost specification (4.7) yields the following equation.

$$
p_{b t}-\frac{\sum_{j=1}^{J} d_{b j t} \mathbb{E}_{\xi}\left[s_{b j t}\right]+\theta_{2, b} \Delta_{b,-b} \sum_{j=1}^{J} d_{-b j t} \mathbb{E}_{\xi}\left[s_{-b j t}\right]}{\sum_{j=1}^{J} d_{b j t}\left(-\frac{\partial \mathbb{E}_{\xi}\left[s_{b j t}\right]}{\partial p_{b t}}\right)-\theta_{2, b} \theta_{2,-b} \Delta_{b,-b} \sum_{j=1}^{J} d_{-b j t} \frac{\partial \mathbb{E}_{\xi}\left[s_{-b j t}\right]}{\partial p_{b t}}}=\mathrm{w}_{b t} \gamma+\omega_{b t}
$$

This is the equation I take to the data to estimate the price collusion parameters. 


\subsubsection{First Stage Product Decision}

In stage 1 , firm $b$ chooses subset of $J$ products to offer in market $t$, taking into account the effect that the choice of products has on the second stage pricing decision. Firm $b$ chooses flavors to solve:

$$
\max _{d_{b 1}, \ldots, d_{b T}} \sum_{t=1}^{T} \mathbb{E}_{\xi}\left[\pi_{b t}\left(d_{b t}, d_{-b t}, p_{t}\left(d_{b t}, d_{-b t} ; \theta_{2}\right)\right)\right]+\theta_{1, b} \sum_{t=1}^{T} \mathbb{E}_{\xi}\left[\pi_{-b t}\left(d_{b t}, d_{-b t}, p_{t}\left(d_{b t}, d_{-b t} ; \theta_{2}\right)\right)\right]
$$

Unlike in the theoretical model, the characteristics defining the flavors are not continuous, so the equilibrium choices of flavors $\left(d_{b t}^{*}, d_{-b}^{*}\right)$ are not defined by a set of first order conditions. However, a necessary condition for a SPNE is that each firm $b$ could not be made better off by unilaterally deviating to an alternative flavor choice $d_{b t}^{\prime}$. Thus, the following set of inequalities have to hold at an equilibrium.

$$
\begin{aligned}
& \sum_{t=1}^{T} \mathbb{E}_{\xi}\left[\pi_{b t}\left(d_{b t}^{*}, d_{-b t}^{*}, p_{t}\left(d_{b t}^{*}, d_{-b t}^{*} ; \theta_{2}\right)\right)\right]+\theta_{1, b} \sum_{t=1}^{T} \mathbb{E}_{\xi}\left[\pi_{-b t}\left(d_{b t}^{*}, d_{-b t}^{*}, p_{t}\left(d_{b t}^{*}, d_{-b t}^{*} ; \theta_{2}\right)\right)\right] \geq \\
& \sum_{t=1}^{T} \mathbb{E}_{\xi}\left[\pi_{b t}\left(d_{b t}^{\prime}, d_{-b t}^{*}, p_{t}\left(d_{b t}^{\prime}, d_{-b t}^{*} ; \theta_{2}\right)\right)\right]+\theta_{1, b} \sum_{t=1}^{T} \mathbb{E}_{\xi}\left[\pi_{-b t}\left(d_{b t}^{\prime}, d_{-b t}^{*}, p_{t}\left(d_{b t}^{\prime}, d_{-b t}^{*} ; \theta_{2}\right)\right)\right] \forall d_{b t}^{\prime} \neq d_{b t}^{*}, b, t
\end{aligned}
$$

where $p_{t}\left(d_{b t}^{*}, d_{-b t}^{*} ; \theta_{2}\right)$ are the observed prices and $p_{t}\left(d_{b t}^{\prime}, d_{-b t}^{*} ; \theta_{2}\right)$ are the prices chosen in the second stage given the alternative set of flavors but holding the pricing collusion parameters fixed ${ }^{14}$ I take these inequalities to the data in order to estimate the product collusion parameters $\theta_{1}=\left(\theta_{11}, \theta_{12}\right)$ and the retail costs $R_{b t}$.

\subsection{DATA}

My data come from the Nielsen Supermarket Scanner Dataset. This dataset contains weekly price and quantity data for every barcode sold in a subset of supermarkets, massmerchandizers, and convenience stores in the United States from 2006-2013. As will be discussed below, I use weekly-level data to estimate demand. However, like DMS (2009), I use monthly data to estimate the supply model. Thus, I generate a monthly dataset for 5,377 stores. To be included in this sample, the store must be classified as a supermarket by Nielsen. It must also report positive sales of both Ben \& Jerry's and Häagen-Dazs in each week of the sample. I also exclude any products sold by either Ben \& Jerry's or Häagen-Dazs

\footnotetext{
${ }^{14}$ The rationale for why the collusion parameters can be held fixed is discussed in Section 2.5.
} 
that are not full-fat ice cream. I further restrict attention to pints, excluding quarts from the analysis 15

Monthly quantities are formed by adding the quantity purchased for each flavor offered in the store across weeks. As was mentioned in Section 4.3.1, I am assuming that the brands charge one price for all flavors in each market. However, in the data I observe different prices for flavors offered by a brand in a given supermarket-week. Nielsen reports the average price for the product sold in a given week. Thus, the reason the average prices differ within a brand appears to be that prices change midweek, causing the average prices for the most purchased products to differ from the average prices of those less purchased. Therefore, I reset the prices to equal the median price reported for a brand in a given supermarket week. ${ }^{16}$ I then take a weighted average of the weekly prices to generate the monthly price.

Because aggregating to the month level eliminates much of the variation in the data that will identify the substitution patterns, I create a weekly-level dataset to estimate demand. It is not computationally feasible to include all 5,377 stores in the estimation, so I restrict attention to the 39 stores that sold the most pints of Ben \& Jerry's and Häagen-Dazs during my sample. I choose the largest stores for two reasons. First, the largest stores carry the most flavors, allowing me to estimate brand-flavor fixed effects for all the flavors present in the larger sample. Second, a feature of scanner data is that products that do not sell any units during a week are not included in the dataset. Because ice cream sales are likely to be correlated with market size, this problem will be mitigated for the largest stores. I correct for the missing data problem by assuming that a flavor must appear for four consecutive weeks after any appearance in a store. After filling in the missing flavors, I have to adjust their quantities as the logit model does not allow a product to have a market share of zero. To do so, I increase the quantity of all products, including the outside option, by one before computing the market share ${ }^{17}$ Like in the monthly sample, I reset the prices in the data to the median price charged by the brand in the store-week.

I also need to compute the market size, which I estimate from data on weekly milk purchases for the stores in my dataset. I define the market size based on milk sales for a few reasons. Most importantly, because it is both a staple good and perishable, consumers who drink milk are likely to purchase it each week. Also, it is a dairy product, so its demand should be correlated with demand for ice cream. Using the annual per capita consumption of fluid milk reported by the US Department of Agriculture, I am able to estimate the number

\footnotetext{
${ }^{15}$ Very few supermarkets sell quarts of Ben \& Jerry's and Häagen-Dazs and the brands only produce them for a small subset of flavors.

${ }^{16}$ This rules out the possibility that the brands can offer sales for specific flavors.

${ }^{17}$ Gandhi, Lu, and Shi (2013) propose more sophisticated techniques for dealing with this problem.
} 
of customers shopping in a store in a given week from its milk sales ${ }^{18}$ I then average the weekly sales across all weeks in my data and use the average number of consumers as the weekly market size in a store, fixing the market size of a supermarket for the entire sample. ${ }^{19}$

I obtain cost data from a variety of sources. In particular, I collect data on shifters of the marginal cost of production, distribution, and retail. Determinants of production costs include average annual wages paid to grocery workers by state, which I obtain from the Bureau of Labor Statistics Quarterly Census of Employment and Wages ${ }^{20}$ and the average monthly price of electricity for industrial users for each state. ${ }^{21}$ From 2006-2013, Ben \& Jerry's manufactured ice cream in three locations: St. Albans VT; Waterbury, VT; and Henderson, NV; while Häagen-Dazs had two manufacturing plants: Laurel, MD and Tulare, CA. I assume that the ice cream sold in each supermarket was produced in the nearest manufacturing plant. Nielsen reports the FIPS state and county code for each store in the dataset. I compute the distances from a store to each plant using the latitude and longitudes for each FIPS county obtained from the 2010 US Census Gazetter I then assign the production costs for the nearest plant to each store. To proxy for the cost of distribution, I obtain the average regional on-highway diesel prices in dollars per gallon by month from the US Energy Information Administration. ${ }^{23}$ For each store, I choose the diesel prices in the region in which the store is located and then interact this with the distance to the nearest manufacturing plant to measure total fuel costs. At the retail level, I get average weekly wages over a given quarter for food manufacturing workers by state from the BLS Quarterly Census of Employment and Wages. I also get the average monthly price paid for electricity by commercial users in each state from the EIA.

$18 \frac{\text { number of customers }}{\text { week }}=\frac{\text { oz. milk sold }}{\text { week }} * \frac{52 \text { weeks }}{1 \text { year }} * \frac{1 \mathrm{lb} .}{128 \mathrm{oz} .} *\left(\frac{\text { lbs. milk consumed }}{\text { per person year }}\right)^{-1}$

${ }^{19}$ DMS (2009) define the market size using the total sale of ice cream sold in the same size containers as their inside good. In my context, this would correspond to a market size based on the total sale of pints. I do not use this definition for two reasons. First, it does not capture the consumers who choose to purchase other sizes of ice cream or who choose not to buy ice cream at all. Second, the estimation routine is considerably slower if the market is defined with the sales of pints than if it is defined with milk sales. On average, Ben \& Jerry's and Häagen-Dazs account for a large fraction of the pints sold in supermarkets but are purchased by only a small fraction of the total number of customers shopping in a supermarket. Dube, Fox and $\mathrm{Su}$ (2012) show that the speed of the convergence of the BLP contraction increases as the share of the outside option increases. I plan on checking the robustness of the results to alternative definitions of the market size in future work.

${ }^{20}$ http://data.bls.gov/cgi-bin/dsrv?en

${ }^{21}$ http://www.eia.gov/electricity/data/browser/

${ }^{22}$ https://www.census.gov/geo/maps-data/data/gazetter2010.html

${ }^{23} \mathrm{https}$ ///www.eia.gov/dnav/pet/pet_pri_gnd_dcus_nus_w.htm 


\subsection{IDENTIFicAtion AND Estimation}

\subsubsection{Demand Parameters}

The main threat to identification of the demand parameters in my model, as is the case generally with demand estimation, is that firms might choose their products and set their prices based on realizations of unobservable determinants of utility. To ameliorate this issue, I follow Nevo (2001) and include product, store, month, and year fixed effects $\left(\xi_{b j}, \xi_{s}, \xi_{m}\right.$, and $\xi_{y}$ ). These fixed effects control for all unobservables that are constant either within a product, a store, a month, or a year. Thus, the source of any endogeneity is limited to the set of unobservables that vary across these dimensions, denoted as $\xi_{b j t}$.

Endogeneity resulting from selection on $\xi_{b j t}$ is ruled out with the timing assumption made in Section 4.3.1. In each market $t$, firms choose their products and prices before any demand shocks specific to market $t$ are realized. The inclusion of fixed effects requires the distributional assumption in Section 4.3.1: the $\xi_{b j t}$ are iid across all products within a market and across markets. These assumptions taken together yield the following identification assumption:

$$
\mathbb{E}\left[\xi_{b j t} \mid d_{b t^{\prime}}, d_{-b t^{\prime}}, p_{b t^{\prime}}, p_{-b t^{\prime}}\right]=0 \quad \forall b, j, t, t^{\prime}
$$

I estimate the parameters in the market share equation using continuously updated GMM following the BLP algorithm. To simulate the integral in the market share equation, I use 1000 Halton draws. In order to identify the standard deviations of the random coefficients, I need a set of instruments. Because these standard deviations serve to distinguish the estimated substitution patterns from those implied by the logit model, the variation in the instruments should induce consumer substitution. Two ways to induce consumer substitution are to change the characteristics of the set of competing products and to change the relative prices charged for those products. I exploit both sources of variation to identify the standard deviation of the random coefficients.

For product $j$ produced by brand $b$ in market $t$, the instruments I use to identify the standard deviation on the constant and the brand indicator for Ben \& Jerry's include the total number of flavors offered in the market, the number of flavors offered by brand $b$, and the price ratio $\frac{p_{-b t}}{p_{b t}}{ }^{24}$ As the number of products offered in the market increases, consumers are induced to substitute from the outside option to the inside goods. Likewise, when one brand offers an additional product or lowers its price relative to its rival, consumers are induced to substitute to that brand. To identify the standard deviation of the coefficient on

\footnotetext{
${ }^{24}$ I can form the price ratio because there is only one price for each brand in each market.
} 
base flavors and mix-ins, I follow Gandhi and Houde (2015) and proxy for the amount of competition faced by each flavor with respect to that characteristic using two instruments. First, I measure the number of other flavors sold by brand $b$ in the market that share the same value for the characteristic as product $j$. Then, I measure the number of flavors produced by $-b$ that have the same value of the characteristic as product $j$. Because the products and prices in market $t$ are chosen before $\xi_{t}$ is realized, all these variables are valid instruments.

Implementing the BLP algorithm provides estimates for all parameters except $\bar{\beta}$, the means of the random coefficients. Given that the store fixed effects are estimated via the within estimator, it is not possible to identify the mean of the random coefficient on the constant. However, Nevo (2001) shows that the mean values of the random coefficients on the observed product characteristics can be recovered by regressing the estimated product fixed effects on the characteristics defining those products. Specifically let

$$
\xi_{b j}=\bar{\beta} \tilde{X}_{b j}+\mu_{b j}
$$

where $\tilde{X}_{b j}$ includes the brand dummy for Ben \& Jerry's, the indicators for the four base flavors, and the number of mix-ins. I assume $\mathbb{E}\left[\mu_{b j} \mid X_{b j}\right]=0$ and estimate $\bar{\beta}$ as:

$$
\hat{\bar{\beta}}=\left(\tilde{X}^{\prime} V_{d}^{-1} \tilde{X}\right)^{-1} \tilde{X}^{\prime} V_{d}^{-1} \hat{\xi}_{b j}
$$

where $V_{d}$ is the covariance matrix of the estimated product fixed effects.

As mentioned in the data section, I estimate the demand parameters using weekly data for the 39 largest supermarkets by sale of Ben \& Jerry's and Häagen-Dazs. I estimate the supply side using monthly data for 5,377 stores. I impose that the demand parameters estimated from the subset of stores hold across all stores. This is reasonable because the subset is geographically diverse. Furthermore, I have no reason to think consumer tastes for ice cream vary much across the population. Then, holding these parameters fixed, I can recover the store fixed effects and the demand shocks $\xi_{b j t}$ for the larger sample. This allows me to non-parametrically estimate the empirical distribution of $\xi_{b j t}$ which I use to simulate firm expectations.25

\footnotetext{
${ }^{25}$ In my estimates, I ignore issues of heteroskedasticity in $\xi_{b j t}$. However, it is likely that the variance depends on, amongst other variables, the size of the supermarket. I plan on addressing this in future work by allowing the variance of $\xi_{b j t}$ to depend on the market size.
} 


\subsubsection{Pricing Stage Parameters}

I can either directly observe or simulate all variables in the pricing equation, 4.12 except the unobserved cost shifter $\omega_{b t}$. I assume $\omega_{b t}$ is iid both across brands within a market and across markets. Thus to estimate the price collusion parameters, one could imagine rearranging (4.12) by moving the markups to the right hand side of the equation. At first glance, it might appear that the price collusion parameters could then be directly estimated by nonlinear least squares. However, the brand-level market shares and price derivatives in the markups are explicit functions of prices, and are therefore correlated with the unobservable cost shifters $\omega_{b t}$. As such, a set of instruments $Z_{b t}$ for the brand-level market shares and price derivatives is required. Bresnahan (1982) and Berry and Haile (2014) show that firm conduct can be separately identified from marginal cost via the use of instruments that rotate and shift the demand curve. In particular, Berry and Haile (2014) highlight "variation in the number of competing firms, the set of competing goods, characteristics of competing products, or costs of competing firms" (pg. 1779). While the number of competing firms does not change in my model, I exploit the other three sources of variation.

Because I am instrumenting for brand-level market shares and price derivatives, $Z_{b t}$ should contain variables defined over the set of products offered by each brand in market $t$ as opposed to the individual products that comprise those sets. Thus, I include eight market specific brand-level instruments in $Z_{b t}$ : the number of products offered by each brand, the average popularity of the flavors in each brand's product set, three variables that measure the distance in characteristic space between those product sets, and the observed cost shifters of the rival brand. I proxy for the popularity of a flavor in a given market with its brandflavor fixed effect, $\xi_{b j}$. I use one variable to measure the distance in characteristic space between the product sets with respect to the base flavors (vanilla, chocolate, coffee, fruit). Specifically, for each base, I compute the absolute difference in the number of flavors offered by each brand containing that base flavor. I then add these distances across bases. Then, to capture the distance with respect to the number of mix-ins I include two instruments, one for each brand, which measure the average number of mix-ins per flavor offered by that brand in each market.

In theory, these instruments should be relevant because variation in each should induce consumer substitution across brands, affecting both the brand-level market shares and price derivatives. By offering an additional product or increasing the popularity of the set of products it currently offers, a brand can induce substitution from the rival brand and the outside option to its own flavors. Likewise, an increase in the distance between the brand's offerings or a rival's marginal cost should affect the prices charged by the brands, impacting both the brand shares and price derivatives. The instruments are also exogenous, which 
is guaranteed by the timing and distributional assumptions in the model. In particular, I assume that the set of products to be offered in market $t$ is fixed at the time firm $b$ makes its pricing decision. Furthermore, the brand-flavor fixed effects are assumed known to each firm, which chooses its price conditional on their value. Likewise, the observed cost shifters for firm $b$ in market $t$ are assumed uncorrelated with the unobserved determinants of $c_{-b t}$.

I make one additional identifying assumption, that the observed cost shifters for firm $b$ in market $t$ are uncorrelated with the unobserved determinants of $c_{b t}$. Thus, for each brand in each market the following moment condition holds:

$$
\mathbb{E}\left[\omega_{b t}\left(\theta_{2}, \gamma\right) \mid Z_{b t}, \mathrm{w}_{b t}\right]=0 \quad \forall b, t
$$

where $\theta_{2}=\left(\theta_{21}, \theta_{22}\right)$. With this moment, both the price collusion parameters and the parameters on the cost shifters could be directly estimated via GMM. Instead, I replace $Z_{b t}$ with the optimal instruments $Z_{b t}^{*}$ to improve efficiency, where $Z_{b t}^{*}$ defined as:

$$
Z^{*}\left(Z_{b t}, \mathrm{w}_{b t}\right)=\mathbb{E}\left[\frac{\partial \omega_{b t}}{\partial \rho} \mid Z_{b t}, \mathrm{w}_{b t}\right]
$$

where $\rho=\left(\theta_{2}, \gamma\right)$. Thus, I consider the following sample moment:

$$
G\left(\theta_{2}, \gamma\right)=\frac{1}{2 T} \sum_{t} \sum_{b} \omega_{b t}\left(\theta_{2}, \gamma\right) \hat{Z}_{b t}^{*}\left(\theta_{2}, \gamma, Z_{b t}, \mathrm{w}_{b t}\right)
$$

where $\hat{Z}^{*}$ is a continuously updated estimate of $Z^{*}$. With this sample moment, I estimate the parameters in 4.12 via GMM such that:

$$
\left(\hat{\theta}_{2}, \hat{\gamma}\right)=\arg \min _{\theta_{2}, \gamma} G^{\prime} W G
$$

where $W$ is the inverse of the finite sample variance of $G\left(\theta_{2}, \gamma\right)$.

To simplify estimation, I solve the maximization problem sequentially. For a given guess of $\theta_{2}$, I compute the left hand side of 4.12 . Note that this requires me to first simulate the expectations in the markup using random draws from the empirical distribution of $\xi_{b j t}{ }^{26}$

\footnotetext{
${ }^{26}$ In my estimates, I currently set the $\xi_{b j t}$ to their mean value, 0 , when simulating the expectation as opposed to taking $S$ draws from the distribution. This is done for computational reasons. I have compared these results to estimates obtained from a small number of draws and find no meaningful difference. However, I plan on relaxing this in future work.
} 
Then I regress the left hand side on the cost shifters $\mathrm{w}_{b t}$ which yields:

$$
\hat{\gamma}\left(\theta_{2}\right)=\left(\mathrm{w}^{\prime} \mathrm{w}\right)^{-1}\left(\mathrm{w}^{\prime} \omega\left(\theta_{2}\right)\right)
$$

My estimator for $\theta_{2}$ is

$$
\hat{\theta}_{2}=\arg \max _{\theta_{2}} G\left(\theta_{2}, \hat{\gamma}\left(\theta_{2}\right)\right)^{\prime} W G\left(\theta_{2}, \hat{\gamma}\left(\theta_{2}\right)\right)
$$

Given estimates of the price collusion parameters, I can now estimate the product collusion parameters and the market level fixed costs.

\subsubsection{Product Stage Parameters}

Let the equilibrium product choice be represented as $d_{t}^{*}=\left(d_{b t}^{*}, d_{-b t}^{*}\right)$. Also, let $d_{t}^{\prime}=\left(d_{b t}^{\prime}, d_{-b t}^{*}\right)$ indicate an alternative product choice for firm $b$ in market $t$ while keeping its rival's product choice fixed at $d_{-b t}^{*}$. For any function of the product choices, $f\left(d_{b t}, d_{-b t}\right)$, define:

$$
\Delta f\left(d^{*}, d^{\prime}\right)=f\left(d^{*}, p\left(d^{*} ; \theta_{2}\right)\right)-f\left(d^{\prime}, p\left(d^{\prime} ; \theta_{2}\right)\right)
$$

With this notation, the SPNE conditions defined by (4.14) can be rewritten as

$$
\sum_{t=1}^{T} \mathbb{E}_{\xi}\left[\Delta \pi_{b t}\left(d_{t}^{*}, d_{t}^{\prime}, \cdot\right)\right]+\theta_{1, b} \sum_{t=1}^{T} \mathbb{E}_{\xi}\left[\Delta \pi_{-b t}\left(d_{t}^{*}, d_{t}^{\prime}, \cdot\right)\right] \geq 0 \quad \forall d_{b t}^{\prime} \neq d_{b t}^{*}, b, t
$$

I do not observe the firms' expectations, so it is not possible to evaluate the above inequality directly. However, because I have estimates of the demand parameters, marginal costs, and price collusion parameters, I can simulate the expected profits for both firms up to the fixed cost parameter $R_{b t}$ for any possible choice of products $d_{t}$.

$$
r_{b t}\left(d_{t}\right)=\frac{1}{S} \sum_{s} M_{t}\left(p_{t}\left(d_{t}, \theta_{2}\right)-c_{b t}\right) \sum_{j=1}^{J} d_{b j t} s_{b j t}\left(d_{t}, p_{t}\left(d_{t}, \theta_{2}\right), \xi_{s t}\right)
$$

To compute $r_{b t}\left(d_{t}\right)$, I draw $S$ vectors from the empirical distribution of $\xi_{b j t}$, where the length of each draw $\xi_{s t}$ corresponds to the number of products in market $t$. Then, for each draw $\xi_{s t}$, I find the optimal set of prices for both firms to charge $\left(p_{t}\left(d_{t}, \theta_{2}\right)\right)$ by solving for a fixed point to the pricing first order conditions for both firms in market $t{ }^{27}$ With these prices, I

\footnotetext{
${ }^{27}$ As was mentioned above, the price collusion parameter can be held fixed given an alternative choice of products. See Section 2.5 for further discussion
} 
can then evaluate the market shares and the profits given $\xi_{s t}$. Averaging the profits across the draws gives an approximation to firm $b$ 's expected variable profits. ${ }^{28}$

The expected profits earned by firm $b$ in market $t$ are given as:

$$
\mathbb{E}\left[\pi_{b t}\right]=M_{t}\left(p_{b t}-c_{b t}\right) \sum_{j=1}^{J} d_{b j t} \mathbb{E}_{\xi}\left[s_{b j t}\right]-R_{b t}
$$

Following Pakes (2010), 4.27) can be rewritten as

$$
\mathbb{E}\left[\pi_{b t}\right]=r_{b t}+v_{1 b t}-v_{2 b t}
$$

where $v_{1 b t}$ is mean 0 error term which includes both simulation and measurement error

$$
v_{1 b t}\left(d_{t}\right)=M_{t}\left(p_{b t}-c_{b t}\right) \sum_{j=1}^{J} d_{b j t} \mathbb{E}_{\xi}\left[s_{b j t}\right]-r_{b t}
$$

and $v_{2 b t}$ is structural error

$$
v_{2 b t}\left(d_{t}\right)=R_{b t}
$$

With this notation, the SPNE necessary condition can be rewritten as a function of $r_{b t}$

$$
\begin{array}{cc}
\sum_{t=1}^{T} \Delta r_{b t}\left(d_{t}^{*}, d_{t}^{\prime}\right)+\theta_{1, b} \sum_{t=1}^{T} \Delta r_{-b t}\left(d_{t}^{*}, d_{t}^{\prime}\right)+\sum_{t=1}^{T} \Delta v_{1 b t}\left(d_{t}^{*}, d_{t}^{\prime}\right)+\theta_{1, b} \sum_{t=1}^{T} \Delta v_{1-b t}\left(d_{t}^{*}, d_{t}^{\prime}\right) \\
-\sum_{t=1}^{T} \Delta v_{2 b t}\left(d_{t}^{*}, d_{t}^{\prime}\right)-\theta_{1, b} \sum_{t=1}^{T} \Delta v_{2-b t}\left(d_{t}^{*}, d_{t}^{\prime}\right) \geq 0 & \forall d^{\prime} \neq d^{*}
\end{array}
$$

The two parameters to be estimated are the product collusion parameters $\theta_{1}$ and the market fixed cost $R_{b t}$. In order to separately identify the two parameters, I rely on an assumption made in Section 4.3.2: $R_{b t}$ depends only on the number of flavors sold in market $t$, not the identity of those flavors or the quantities sold. With this assumption, I consider alternative product sets for firm $b$ which differ from the observed choices by one product. There are three ways to construct these alternative product choices: firm $b$ could add a product to $d_{t}^{*}$, remove a product from $d_{t}^{*}$, or replace one product in $d_{t}^{*}$ with a product not in $d_{t}^{*}$. I will show that $\theta_{1}$ is set identified and can be estimated by constructing inequalities

\footnotetext{
${ }^{28}$ In the estimates I present, I simplify computation in two ways. First, instead of drawing from the distribution of $\xi_{b j t}$ to simulate the firm's expectations, I set all $\xi_{b j t}$ to their mean value 0. Secondly, when computing the expected profits for an alternative set of products, I use the observed price instead of solving for the firm's optimal price. I plan on removing these restrictions in future work.
} 
with "replacement" moments. Once I estimate $\theta_{1}$, the "add" and "remove" moments can be used to identify and estimate $R$.

I first consider identification and estimation of $\theta_{1}$. In every possible "replacement" moment, the number of products offered in the market is unchanged. Because $R$ only depends on the number of products offered, it is the same for the observed product choice $d^{*}$ and the alternative product choice $d^{\prime}$. Because of this, $\Delta v_{2 b t}\left(d_{t}^{*}, d_{t}^{\prime}\right)=0$ for each firm $b$ in each market $t$ and the structural error differences out of the inequality. If I divide both sides of the inequality by the number of markets $T$, the inequality becomes:

$$
\overline{\Delta r}_{b}\left(d^{*}, d^{\prime}\right)+\theta_{1, b} \overline{\Delta r}_{-b}\left(d^{*}, d^{\prime}\right)+\underbrace{\bar{v}_{1 b}}_{\rightarrow_{p} 0}+\theta_{1, b} \underbrace{\bar{v}_{1-b}}_{\rightarrow_{p} 0} \geq 0
$$

where the bar above a variable represents the average across markets. Notice that since $v_{1 b t}$ is iid mean 0 , as $T \rightarrow \infty, \bar{v}_{1 b}$ and $\bar{v}_{1-b} \rightarrow_{p} 0$. Asymptotically, the inequality can be written as:

$$
\overline{\Delta r}_{b}\left(d^{*}, d^{\prime}\right)+\theta_{1, b} \overline{\Delta r}_{-b}\left(d^{*}, d^{\prime}\right) \geq 0
$$

Rearranging this inequality permits me to construct bounds on $\theta_{1 b}$.

$$
\theta_{1, b} \lessgtr-\frac{\overline{\Delta r}_{b}}{\overline{\Delta r}_{-b}}
$$

There are four cases summarized in the following table.

TABLE 4.1

Possible Bounds on Product Parameters

\begin{tabular}{c|c|c|c|c} 
Case & $\operatorname{sgn}\left(\overline{\Delta r}_{b}\right)$ & $\operatorname{sgn}\left(\overline{\Delta r}_{-b}\right)$ & Bound & $\operatorname{sgn}($ Bound $)$ \\
\hline 1 & $<0$ & $>0$ & Lower & $>0$ \\
2 & $>0$ & $<0$ & Upper & $>0$ \\
3 & $>0$ & $>0$ & Lower & $<0$ \\
4 & $<0$ & $<0$ & Upper & $<0$
\end{tabular}

In the first case, the switch results in higher expected profits for brand $b\left(\overline{\Delta r}_{b}>0\right)$ and lower expected profits for its rival $\left(\overline{\Delta r}_{-b}>0\right)$. In the absence of collusion, firm $b$ would offer $d_{b}^{\prime}$ instead of $d_{b}^{*}$. Thus, firm $b$ must be internalizing the impact of its product choice on its rival by at least the amount needed to prevent it from offering $d_{b}^{\prime}$. Thus, this case provides a positive lower bound on the value of $\theta_{1, b}$. In the second case, the switch results in lower expected profits for brand $b\left(\overline{\Delta r}_{b}<0\right)$ and higher expected profits for its rival $\left(\overline{\Delta r}_{-b}<0\right)$. This case shows the limit on the degree to which firm $b$ internalizes the impact it has on its 
rival, providing an upper bound on the collusion parameter. In the third case, both firms are hurt by the switch $\left(\overline{\Delta r}_{b}, \overline{\Delta r}_{-b}<0\right)$. This switch is uninformative about the value of the collusion parameter, providing a negative lower bound. Finally, in the fourth case, both firms would be made better off as a result of the switch, providing a negative upper bound. This case would make sense during a punishment period in which firms forego mutually beneficial behavior. I assume the firms are choosing actions on the equilibrium path, so the first two cases provide the bounds on the collusion parameters.

Because I include brand-flavor fixed effects in the demand system, I can only consider alternative product choices which switch a flavor produced by brand $b$ in 2013 with one it produced earlier in my sample. Though this limits the inequalities I can construct, this restriction allows me to control for a competing rationale for the observed product choices, namely, that consumers prefer the chunky flavors produced by Ben \& Jerry's and the smooth flavors produced by Häagen-Dazs. During 2013, Ben \& Jerry's offered 39 of its non-seasonal flavors for the entire year. Häagen-Dazs offered 32 such flavors. Meanwhile, from 2006-2012, Ben \& Jerry's produced 19 non-seasonal flavors that were not sold in 2013 while Häagen Dazs produced 26 such flavors.29 Therefore, I am able to construct 741 alternative product choices for Ben \& Jerry's and 832 alternative product choices for Häagen-Dazs.

\section{FiguRE 4.1}

Average Change In Profits For Each Brand By Replacing Ten Worst Selling Ben \& Jerry's Flavors With Chocolate

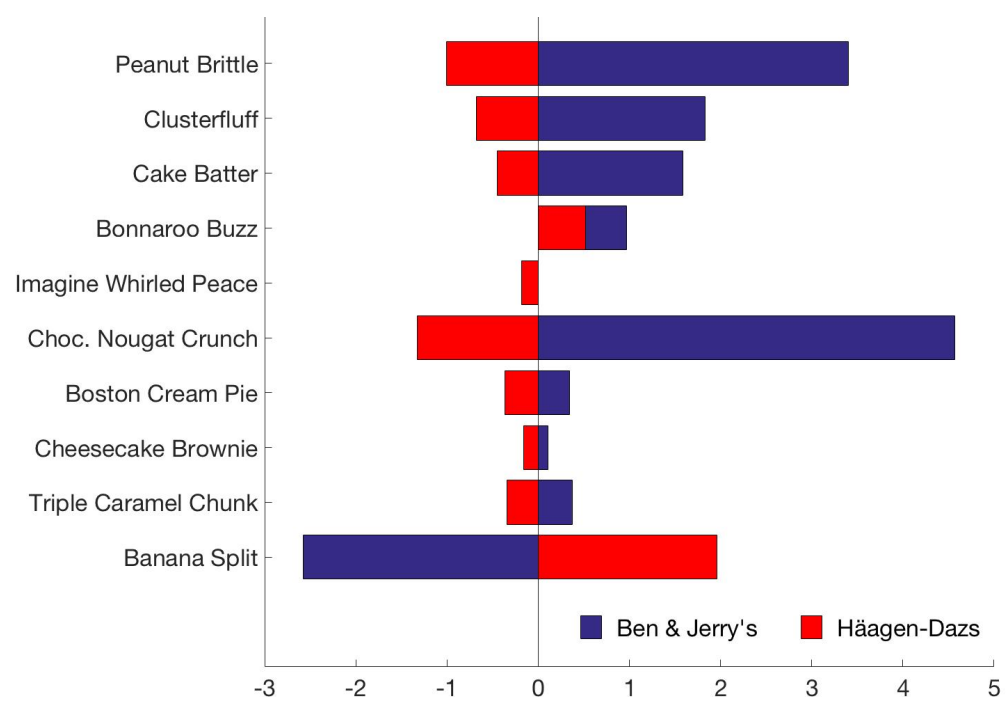

\footnotetext{
${ }^{29}$ I avoid moments constructed from seasonal flavors for three reasons. First, I do not estimate brand-flavor fixed effects separately for each season. Thus, the brand-flavor fixed effect I estimate is only appropriate in the season the flavor is offered. Furthermore, because Ben \& Jerry's and Häagen-Dazs know these flavors have a limited releases, they may offer these flavors with dynamic considerations, such as experimentation. Also, in my dataset, seasonal flavors are sold with the same barcode. Therefore, I have to arbitrarily declare the date on which the identity of the seasonal flavors changes.
} 
From the entire set of alternative product choices for each brand $b$, a subset will be informative about the lower bound of $\theta_{1, b}$. This subset contains all switches that increase the profits earned by brand $b$ while lowering the profits earned by its rival. One such switch could be generated by replacing an unpopular flavor produced by brand $b$ with its own version of a popular flavor produced by $-b$. I illustrate this idea by performing switches in which each of the ten worst selling Ben \& Jerry's flavors during 2013 are replaced with chocolate. Figure 4.1 shows the average change in expected profits for both Ben \& Jerry's and Häagen-Dazs resulting from each pairwise switch. These switches result in an increase in expected profits for Ben \& Jerry's and a decrease in expected profits for Häagen Dazs in seven of the ten cases, and thus would be informative about the lower bound of $\theta_{1, b}$.

Meanwhile, the subset of alternative product choices that hurt brand $b$ but help its rival will be informative about the upper bound of $\theta_{1, b}$. This can be achieved by replacing a popular flavor produced by brand $b$ with one of its previously sold unpopular flavors. In Figure 4.2, I consider the average effect on expected profits by replacing Ben \& Jerry's ten worst selling flavors with Black and Tan 30 The effect of each pairwise switch is to lower Ben \& Jerry's profits and increases the profits of Häagen Dazs in all but one case, making them informative about the upper bound of $\theta_{1, b}$.

Figure 4.2

Average Change In Profits For Each Brand By Replacing Ten Worst Selling Ben \& Jerry's Flavors With Black \& Tan

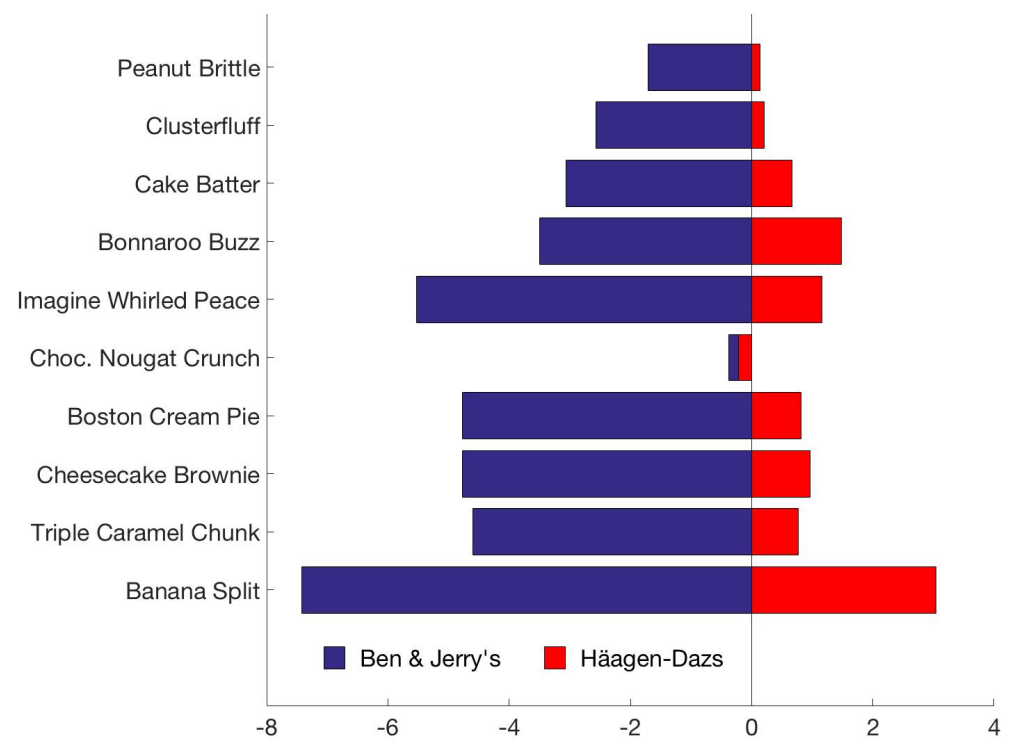

To estimate the bounds on $\theta_{1, b}$, I generate the following sample moment for each possible

\footnotetext{
${ }^{30}$ This flavor was created by Ben \& Jerry's to taste like the Black and Tan drink, which is an ale mixed with a stout. It was offered in 2006 and 2007 and was unpopular. It can now be found in the Flavor Graveyard.
} 
alternative product choice $k=1, \ldots, K_{b}$ :

$$
\bar{m}_{b k}\left(\theta_{1, b}\right)=\overline{\Delta r}_{b}\left(d^{*}, d_{k}^{\prime}\right)+\theta_{1, b} \overline{\Delta r}_{-b}\left(d^{*}, d_{k}^{\prime}\right)
$$

I then aggregate across the moments. Following Pakes et al. (2011), the estimator for set of collusion parameters $\Theta_{1, b}$ is given as:

$$
\Theta_{1, b}=\arg \min _{\theta \in \Theta} \sum_{k=1}^{K_{b}}\left[\frac{\bar{m}_{b k}\left(\theta_{1, b}\right)}{\sigma_{b k}\left(\theta_{1, b}\right)}\right]_{-}^{2}
$$

where $[x]_{-}=\min \{0, x\}$. Following Andrews and Soares (2010), each moment is weighted by $\sigma_{b k}^{2}$, an estimate of the asymptotic variance of $n^{1 / 2} \bar{m}_{b k}(\theta)$ where:

$$
\sigma_{b k}^{2}(\theta)=T^{-1} \sum_{i=1}^{T}\left(m_{b k t}(\theta)-\bar{m}_{b k}(\theta)\right)^{2}
$$

With this estimator, I estimate the bounds on the parameter set as:

$$
\underline{\hat{\theta}}_{1, b}=\min \left(\Theta_{1, b}\right) \quad \hat{\bar{\theta}}_{1, b}=\max \left(\Theta_{1, b}\right)
$$

In practice, I find $\underline{\hat{\theta}}_{1, b}=\hat{\bar{\theta}}_{1, b}$ for both brands.

Given estimates of the collusion parameters, it is possible to find the market-level fixed cost. Under the assumption that $R_{b t}=\eta_{b} N_{b t}$, I can generate two types of alternative product sets, those in which firm $b$ adds a product to $d_{b t}^{*}$ and those in which firm $b$ removes a product from $d_{b t}^{*}$. Alternative sets created by adding an additional product result in the following inequalities:

$$
\bar{r}_{b}\left(d^{*}, d_{k}^{\prime}\right)+\hat{\theta}_{1, b} \bar{r}_{-b}\left(d^{*}, d_{k}^{\prime}\right)+\eta_{b} \geq 0
$$

Adding a flavor provides a lower bound on the per flavor fixed cost $\eta_{b}$. Since firm $b$ chose not to include this flavor in equilibrium, the fixed costs have to be large enough to justify this decision. Meanwhile, the following inequalities are derived by removing a product from $d_{b t}^{*}$ :

$$
\bar{r}_{b}\left(d^{*}, d_{k}^{\prime}\right)+\hat{\theta}_{1, b} \bar{r}_{-b}\left(d^{*}, d_{k}^{\prime}\right)-\eta_{b} \geq 0
$$

These moments provide an upper bound on $\eta_{b}$. Because firm $b$ chose to offer the removed flavor in equilibrium, the fixed cost cannot exceed the benefit firm $b$ received by offering it.

Given the sets of flavors produced in my dataset, I am able to construct 39 alternative 
product sets for Ben \& Jerry's by removing one flavor and 19 alternative product sets by adding an additional flavor. For Häagen-Dazs, I construct 32 alternative product sets by removing a flavor and 26 alternative product sets by adding a flavor. With the moments that are generated from these alternative product sets, I estimate bounds on $\eta_{b}$ and $\eta_{-b}$ following the procedure described for $\theta_{1}$.

\subsection{Results}

\subsubsection{Demand Parameter Estimates}

Table 4.2 presents the estimates of the demand parameters. Reassuringly, I find the price coefficient $\alpha$ is negative. I also find vanilla has the highest mean utility, followed by chocolate. Furthermore, I find that the standard deviations for the random coefficients on fruit and coffee are considerably higher than those for chocolate and vanilla. This matches my expectation that vanilla

TABLE 4.2

Estimates Of Demand Parameters

\begin{tabular}{lcc}
\hline \hline Parameter & Mean & Standard Deviation \\
\hline$\beta_{\text {constant }}$ & $-11.8350^{a}$ & $2.7354^{* * *}$ \\
& & $(0.0058)$ \\
$\beta_{\text {Ben \& Jerry's }}$ & $-4.9678^{* * *}$ & $0^{b}$ \\
$\beta_{\text {vanilla }}$ & $(0.0204)$ & $(0.0193)$ \\
& $1.2686^{* * *}$ & $1.8406^{* * *}$ \\
$\beta_{\text {chocolate }}$ & $(0.0111)$ & $(0.0015)$ \\
& $0.4240^{* * *}$ & $1.1590^{* * *}$ \\
$\beta_{\text {coffee }}$ & $(0.0167)$ & $(0.0021)$ \\
& $-6.9614^{* * *}$ & $2.7405^{* * *}$ \\
$\beta_{\text {fruit }}$ & $(0.0233)$ & $(0.0016)$ \\
& $-4.0359^{* * *}$ & $3.3601^{* * *}$ \\
$\beta_{\text {mix-ins }}$ & $(0.0197)$ & $(0.0012)$ \\
$\alpha$ & $-0.3254^{* * *}$ & $0.3246^{* * *}$ \\
$\alpha$ & $(0.0055)$ & $(0.0004)$ \\
\hline
\end{tabular}

a. mean value of the random coefficient on the constant is not separately identifiable from the store fixed effects. I have reported the mean of the store fixed effects weighted by the number of observations in each store.

b. $\sigma_{\text {brand }}$ is estimated at boundary. Therefore, standard error not credible.

and chocolate to have broad appeal throughout the population while coffee and fruit tend 
to be more polarizing. The constant is negative, which results mechanically from the fact that the share of the outside option is large in most markets $(\sim 90 \%)$.

I also check that the estimated month fixed effects match the seasonal pattern ice cream demand is known to follow. Figure 4.3 plots the $95 \%$ confidence interval for the estimated month fixed effects $\left(\xi_{m}\right)$ where the fixed effect for January has been normalized to zero. The pattern is exactly as expected, consumer preferences for super-premium ice cream increase from February through July and then decrease from July through December.

FigURE 4.3

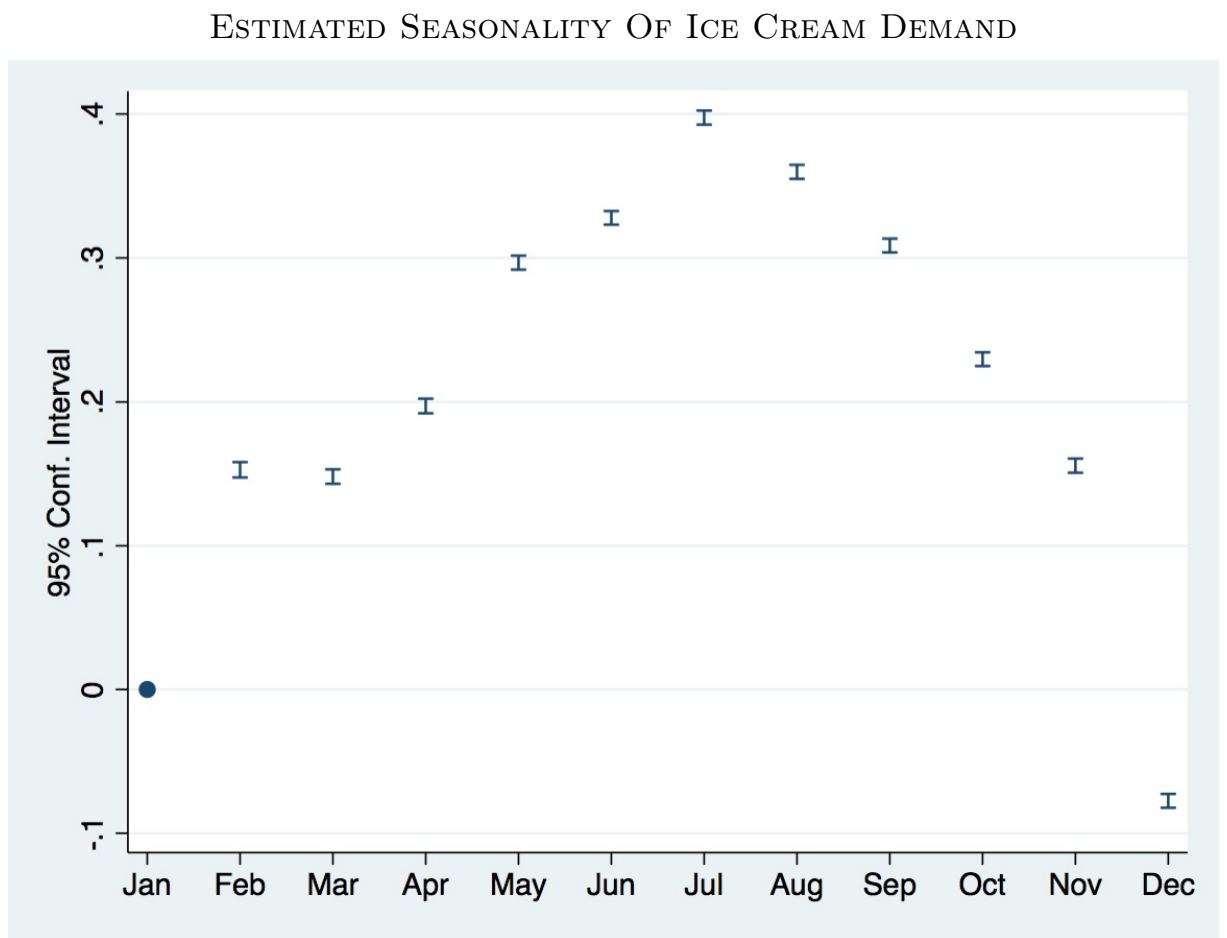

Plot displays the estimated 95\% confidence intervals for month fixed effects $\left(\xi_{m}\right)$. Standard errors for each $\xi_{m}$ are computed using the standard formula for GMM standard errors with optimal weight matrix. The fixed effect for January has been normalized to 0 .

Finally, the standard deviation of the constant plays a particularly important role in determining the substitution patterns. In a standard logit specification, an increase in price causes consumers to substitute to goods proportionally based on their relative market shares. Because the share of the outside option is so large, the logit model would predict that an increase in Ben \& Jerry's price would result mostly in substitution to the outside option as opposed to Häagen-Dazs. The fact that the constant has a large standard deviation helps generate more realistic substitution patterns in this model. In Figure 4.4, I plot a histogram of $\Delta_{b,-b, t}$ for each brand. In an average market, around $25 \%$ of the customers who switch 
as a result of a price increase switch to the rival brand as opposed to the outside option. Though this might seem small, the outside option includes all other brands of ice cream as well as not purchasing any ice cream.

Figure 4.4

Estimated Cross Brand Substitution

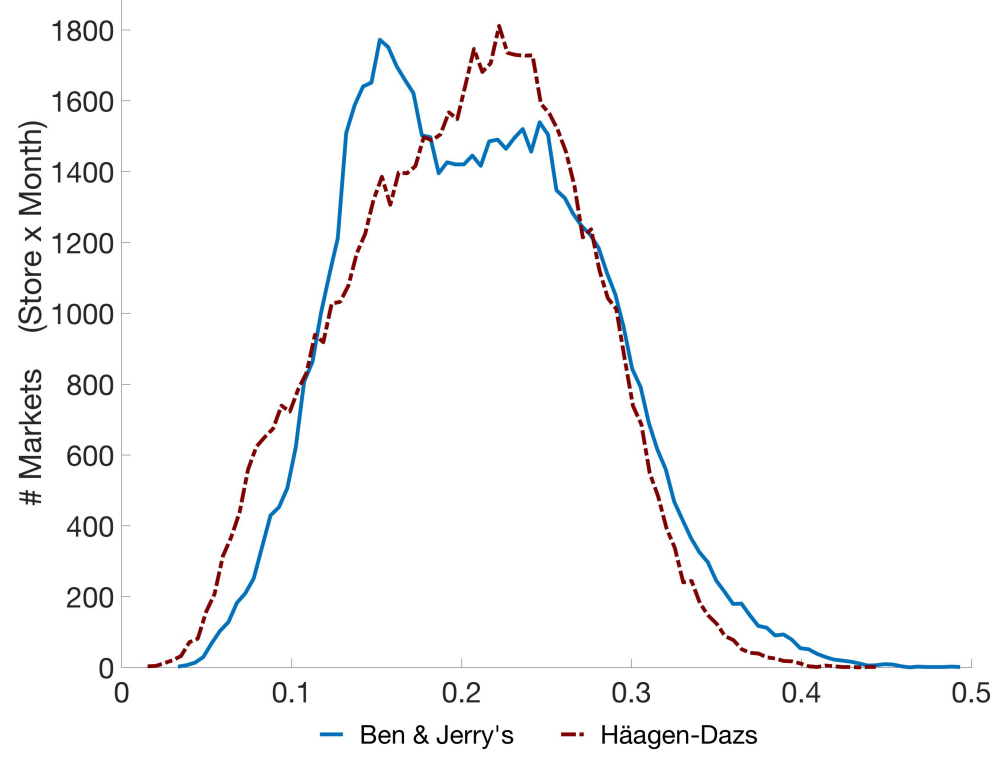

\subsubsection{Pricing Stage Parameters}

Parameter estimates from the pricing stage are included in Table 4.3. I estimate three different specifications. In the first two specifications, I constrain Ben \& Jerry's and HäagenDazs to have the same price collusion parameter. In the third specification, I allow the price collusion parameters for the two brands to differ. This is my preferred specification and I use these estimates in all subsequent analysis. In all three specifications, I control for ingredient prices using month fixed effects. This assumes that both brands face the same cost of ingredients. In addition, I include cost shifters for the manufacturing, distribution, and retail components of marginal cost. The last two specifications have store fixed effects to control for additional store specific components of marginal cost.

I find strong evidence that Ben \& Jerry's and Häagen-Dazs were colluding on price during 2013. Estimates from the first specification suggest that the brands internalize $37 \%$ of the externality each imposes on its rival. When I include store fixed effects, this rises to $66 \%$. Allowing the collusion parameters to differ across brands does not substantially alter the estimates, which I would expect given that these are similarly sized firms. Importantly, all 
three specifications reject zero as the value of the collusion parameters. Though the collusion parameters are informative as to the presence of price collusion, they cannot tell us how far firms are pricing above the Nash prices and, therefore, do not speak directly to the impact on social surplus. Therefore, I perform counterfactual analysis in the next section in which I set the price collusion parameters to 0 .

TABLE 4.3

Estimates Of Pricing Stage Parameters

\begin{tabular}{|c|c|c|c|}
\hline & $(1)$ & $(2)$ & (3) \\
\hline$\theta_{2, B e n} \&$ Jerry's & $\begin{array}{c}0.3743^{* * *} \\
(0.0075)\end{array}$ & $\begin{array}{c}0.6590^{* * *} \\
(0.0034)\end{array}$ & $\begin{array}{r}0.5366^{* * *} \\
(0.0032)\end{array}$ \\
\hline$\theta_{2, \text { Häagen-Dazs }}$ & $\begin{array}{l}0.3743^{* * *} \\
(0.0075)\end{array}$ & $\begin{array}{l}0.6590^{* * *} \\
(0.0034)\end{array}$ & $\begin{array}{r}0.8135^{* * *} \\
(0.0034)\end{array}$ \\
\hline \multicolumn{4}{|l|}{ Cost Shifters: } \\
\hline Constant & $\begin{array}{c}6.2426 \\
(0.0012)\end{array}$ & $3.8228^{a}$ & $3.6772^{a}$ \\
\hline Ben \& Jerry's & $\begin{array}{c}0.0696 \\
(0.0018)\end{array}$ & $\begin{array}{c}0.0836 \\
(0.0001)\end{array}$ & $\begin{array}{c}0.2111 \\
(0.0018)\end{array}$ \\
\hline $\begin{array}{l}\text { Food Manu. Wage } \\
\text { (\$'00s/week, quarter x state) }\end{array}$ & $\begin{array}{c}0.1231 \\
(0.0002)\end{array}$ & $\begin{array}{c}0.1060 \\
(0.0002)\end{array}$ & $\begin{array}{l}0.10014 \\
(0.0016)\end{array}$ \\
\hline $\begin{array}{l}\text { Indus. Elec. Price } \\
\text { (cent/kWh, month x state) }\end{array}$ & $\begin{array}{l}-0.0130 \\
(0.0001)\end{array}$ & $\begin{array}{c}5.82 \times 10^{-5} \\
\left(4.03 \times 10^{-5}\right)\end{array}$ & $\begin{array}{l}-0.0035 \\
(0.0004)\end{array}$ \\
\hline $\begin{array}{l}\text { Diesel } \\
(\$ / \text { gal, month x state })\end{array}$ & $\begin{array}{l}-1.3316 \\
(0.0003)\end{array}$ & $\begin{array}{l}-0.8372 \\
(0.0035)\end{array}$ & $\begin{array}{l}-0.7926 \\
(0.0108)\end{array}$ \\
\hline Diesel x Distance (000's) & $\begin{array}{c}0.0326 \\
(0.0005)\end{array}$ & $\begin{array}{c}-0.0411 \\
\left(4.78 \times 10^{-5}\right)\end{array}$ & $\begin{array}{l}-0.0416 \\
(0.0018)\end{array}$ \\
\hline $\begin{array}{l}\text { Commer. Elec. Price } \\
\text { (cent/kWh, month x state) }\end{array}$ & $\begin{array}{c}0.0274 \\
(0.0001)\end{array}$ & $\begin{array}{c}0.0506 \\
(0.0024)\end{array}$ & $\begin{array}{c}0.0495 \\
(0.0011)\end{array}$ \\
\hline $\begin{array}{l}\text { Grocery Wage } \\
(\$ \text { '000s/year, year x county })\end{array}$ & $\begin{array}{c}-0.0158 \\
\left(5.24 \times 10^{-5}\right)\end{array}$ & - & - \\
\hline Customers ('000s) & $\begin{array}{c}0.0229 \\
(0.0002)\end{array}$ & - & - \\
\hline Month FEs & Yes & Yes & Yes \\
\hline Store FEs & No & Yes & Yes \\
\hline
\end{tabular}

The marginal cost estimates are both functions of the demand parameters and price collusion parameters. Figure 4.5 presents the distribution of estimated marginal costs across markets for each brand. 
Figure 4.5

Estimated Distribution Of Marginal Costs (in \$)

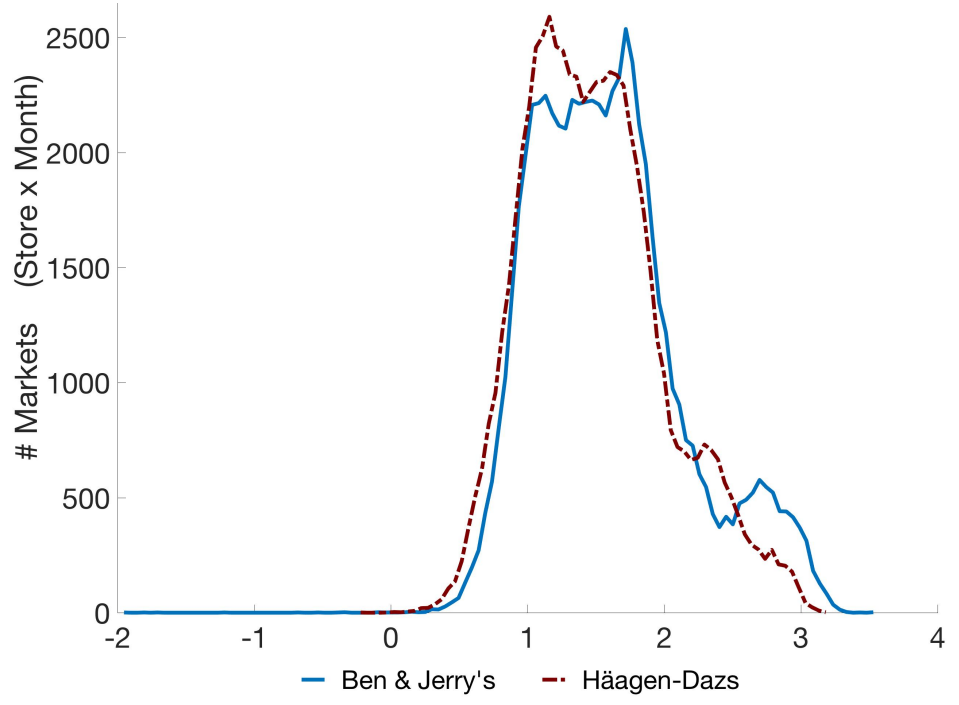

An important feature of these distributions is that there is almost no mass below zero. Furthermore, the implied price cost markups seem reasonable. For the vast majority of markets, the markup on a pint of Ben \& Jerry's and Häagen-Dazs ranges from $\$ 2$ - $\$ 3$. Taken together, this evidence helps validate the demand and price parameter estimates.

Figure 4.6

Estimated Distribution Of Price Cost Markup $\left(p_{b t}-c_{b t}\right)$

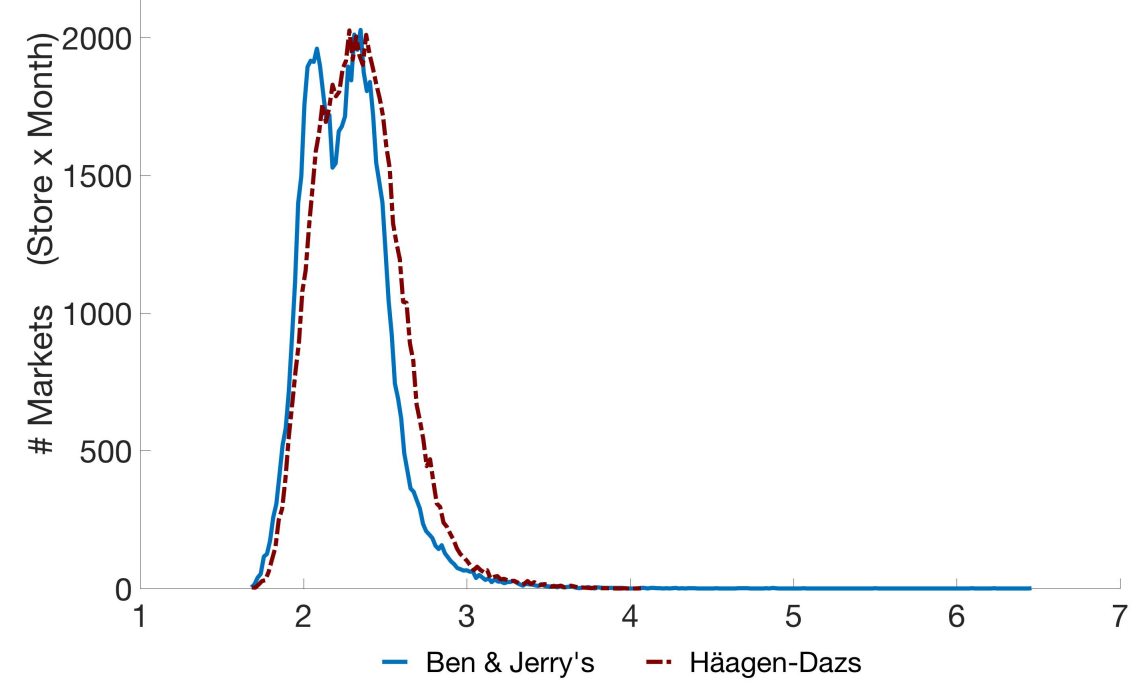




\subsubsection{Product Stage Parameters}

Table 4.4 presents estimates of the product space collusion parameters $\theta_{1}$ and the per flavor retail fixed costs $\eta$. I find substantial evidence of product space collusion for both brands. Whereas Häagen-Dazs was more accommodating in the pricing stage, I find that Ben \& Jerry's internalizes more of its affect on Häagen-Dazs in the product stage than vice versa.

TABLE 4.4

Estimates Of Product Stage Parameters

\begin{tabular}{lc}
\hline \hline Product Collusion Parameters: & \\
$\theta_{1, \text { Ben } \text { \& Jerry's }}$ & 1.7900 \\
$\theta_{1, \text { Häagen-Dazs }}$ & 1.5428 \\
\hline Per-Flavor Retail Fixed Cost: & \\
$\eta_{\text {Ben \& Jerry's }}$ & $\$ 8.39$ \\
$\eta_{\text {Häagen-Dazs }}$ & $\$ 10.34$ \\
\hline
\end{tabular}

Having obtained estimates of the fixed costs, it is possible to compute the profits the firms expected to earn in each market. Table 4.5 reports the total expected profits across all markets in my sample as well as the components of those profits. For publicly traded companies, it is easy to validate the estimates in Table 4.5 as the companies have to list their annual revenue, cost and profit in their 10-K filing to the SEC. Unfortunately, Häagen-Dazs has been a subsidiary of various corporations since 1983 while Ben \& Jerry's was acquired by Unilever in 2000 , thus there is no recent data to compare ${ }^{31}$

TABLE 4.5

Total Firm Profits And Costs In Sample (in millions)

\begin{tabular}{lcc}
\hline \hline & Ben \& Jerry's & Häagen-Dazs \\
\hline Total Expected Revenue & $\$ 76.844$ & $\$ 78.470$ \\
Total Expected Variable Costs & $\$ 28.279$ & $\$ 27.301$ \\
Total Fixed Costs & $\$ 13.767$ & $\$ 13.277$ \\
\hline Total Expected Profit & $\$ 34.798$ & $\$ 37.892$ \\
\hline
\end{tabular}

\footnotetext{
${ }^{31}$ Ben \& Jerry's was publicly traded before 2000 , and it filed a 10-K in 1999 . In that file, Ben \& Jerry's reported $\$ 213.8$ million in profits (measured in 2013 dollars) for 1998. The expected profits in Table 4.5 are computed from the sale of pints in the 5,377 stores in my sample. According to Bureau of Labor Statistics there were 89,435 supermarkets in US in 2013. Furthermore, in its 10-K, Ben \& Jerry's reported that pints accounted for $81 \%$ of sales. Extrapolating the expected profits in Table 4.5 suggests that Ben \& Jerry's expected to earn $\$ 714,550,376.82$ in profits during 2013. Also in its 10-K, Ben \& Jerry's reported that costs accounted for $65.1 \%$ of its revenue while profit accounted for the other $34.9 \%$ in 1998 . I find that costs are $54.72 \%$ of its revenue and profits are $45.3 \%$ of its revenue in 2013. It is comforting that the estimates are somewhat similar, and that the estimated profits in 2013 are higher than in 1998. In particular, the merger with Unilever likely would have resulted in cost reductions as Ben \& Jerry's could utilize Unilever's distribution network.
} 
Table 4.5 provides a compelling interpretation of the estimated fixed costs. The expected variable profits (revenue - variable costs) measure the producer surplus to be split between each brand and the supermarkets. I find that fixed cost payments account for $28.35 \%$ of the expected variable profits earned by Ben \& Jerry's and $25.95 \%$ of the expected variable profits earned by Häagen-Dazs. While I have not modeled the bargaining process between the supermarkets and the brands, it seems reasonable that the supermarkets receive between $1 / 4$ and $1 / 3$ of producer surplus.

When considering the product collusion parameters, the reader might be concerned that the estimates lie above one. In the context of my model, these results suggest that the brands place more weight on their rival's profits than their own. To understand why this mechanically occurs, consider the expression in 4.34. For a given replacement, an implied lower bound of $\theta_{1, b}$ will exceed one if the benefit of the replacement for firm $b$ exceeds the loss to its rival.

Below, I plot the histogram of the bounds implied by the 741 replacement moments generated for Ben \& Jerry's and the 832 replacement moments generated for Häagen-Dazs.

Figure 4.7

Distribution Of Implied Bounds For $\theta_{1}$
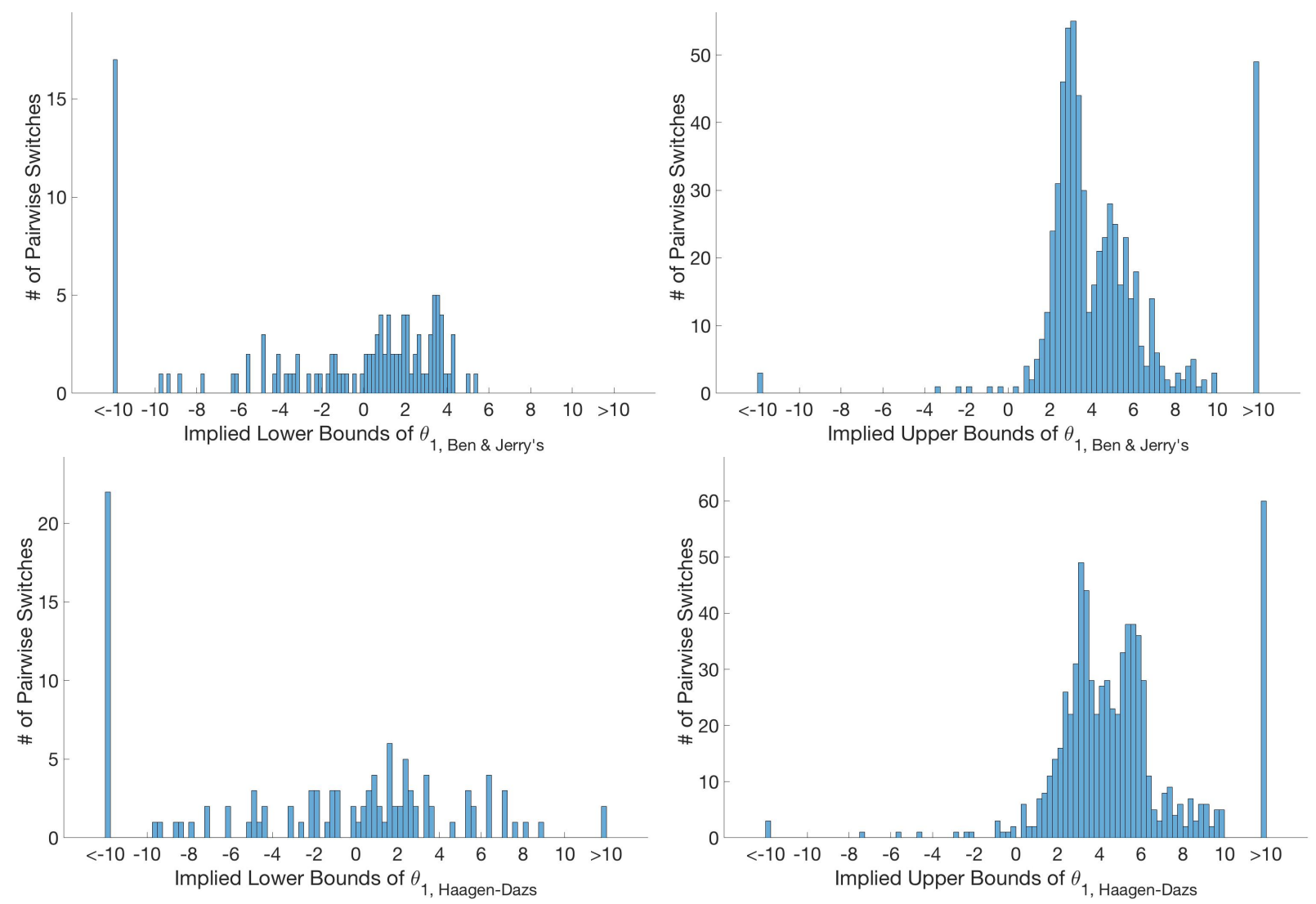
I have separated the histograms into those that imply upper bounds and those that imply lower bounds. It is reassuring that there are not many negative upper bounds. I only estimate negative upper bounds for $1.08 \%$ of the 741 Ben \& Jerry's deviation moments and $1.94 \%$ of the 832 Häagen-Dazs moments. However, it is also apparent that there is still a lot of variability in the moments implied by the bounds. This could partly be the result of misspecification of the profit function or remaining structural error that has not been accounted for. There is another possibility: firms might be highly accommodating in the first stage to signal their commitment to the collusive agreement. Given that the firms appear to be concluding a product space war from 2006-2012, this might not be unrealistic.

The most likely explanation though is that the demand system is misspecified. In particular, when Ben \& Jerry's replaces a flavor with butter pecan, the substitution patterns are not rich enough to fully capture the impact that the replacement would have on Häagen-Dazs sales of butter pecan. Crucially, this misspecification should bias the estimated product collusion parameters upward. Also, the model is missing brand-region fixed effects, which are important given that Ben \& Jerry's publicly advocates for liberal political causes. I plan on trying to improve the flexibility of the demand system in future work. Importantly though, the large estimates of $\theta_{1}$ are suggestive of substantial product collusion between the firms.

\subsection{COUNTERFACTUALS}

\subsubsection{Effect Of Eliminating Price Collusion}

I first want to measure the effect of price collusion on outcomes and welfare ignoring collusion on the product space. These measures will serve as baseline estimates reflecting the current state of the literature. To do so, I estimate the prices firms would have charged in the absence of price collusion, holding the observed set of products fixed. I obtain these price estimates by setting $\theta_{2}$ to 0 , and finding the fixed point of the pricing first order conditions in each market. I simulate the expectations in the first order condition by taking draws from the empirical distribution of $\xi_{b j t} \cdot 32$

In Figure 4.8, I present a histogram of the price increases that result in each market when only price collusion is considered. I find that by colluding on price, Ben \& Jerry's was able to charge on average $\$ 0.32$ or $9 \%$ more for each pint in 2013. The effect on Häagen-Dazs prices was almost identical; on average it charged $\$ 0.38$ or $11 \%$ more for each pint.

\footnotetext{
${ }^{32}$ I set all $\xi$ 's to 0 , their mean value, in order to simplify computation.
} 
Figure 4.8

Price Increase Above Nash Pricing At Observed Product Choice

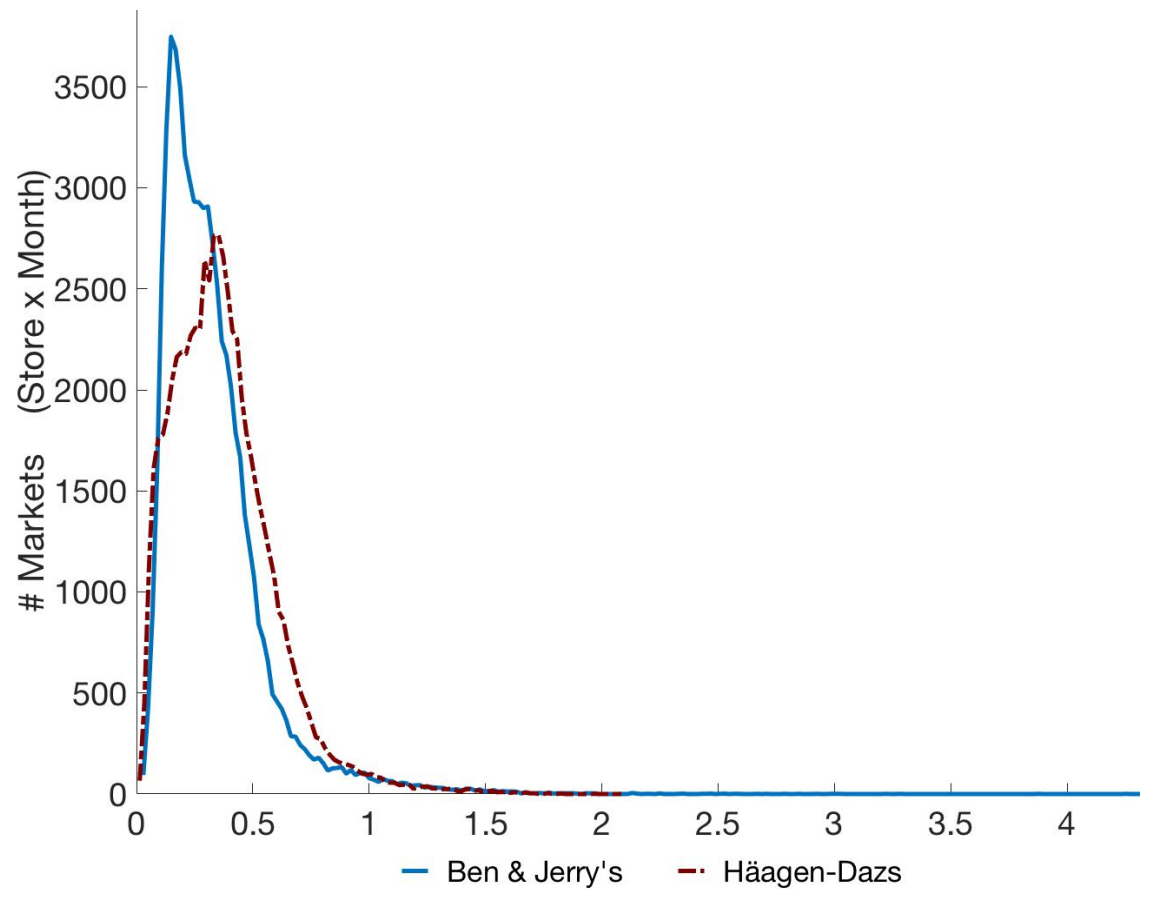

The measured effect of price collusion on producer surplus across the markets in my sample is recorded in Table 4.6. Since the set of products offered is not allowed to adjust, the fixed cost payments to supermarkets do not change, and the effect on producer surplus is fully captured by the change in Ben \& Jerry's and Häagen-Dazs profits. Overall producer surplus increases by $4.11 \%$ in my sample. Of that increase, $66.32 \%$ goes to Ben \& Jerry's, $33.68 \%$ to Häagen-Dazs. There are 5,377 stores in my sample. According to the Bureau of Labor Statistics there were 89,435 supermarkets in the US in 2013. Extrapolating across all the supermarkets in the US suggests that price collusion yielded a $\$ 47,775,994.04$ increase in producer surplus in 2013.

TABLE 4.6

Total Changes In Producer Surplus From Collusion (in millions)

\begin{tabular}{lccc}
\hline \hline & Total & Ben \& Jerry's & Häagen-Dazs \\
\hline Total Profits: Price Collusion & $\$ 72.689$ & $\$ 34.798$ & $\$ 37.892$ \\
Total Profits: No Price Collusion & $\$ 69.817$ & $\$ 32.893$ & $\$ 36.924$ \\
Benefit of Price Collusion & $\$ 2.872$ & $\$ 1.905$ & $\$ 0.967$
\end{tabular}

Following Small and Rosen (1981) and Fan (2013), I estimate effect of price collusion on consumer welfare via compensating variation. In particular, the expected effect of collusion on consumer surplus can be expressed as follows: 


$$
\Delta C S=\iint \frac{V_{i t}^{N}-V_{i t}^{C}}{\alpha} f(\beta) f(\xi) \mathrm{d} \beta \mathrm{d} \xi
$$

where

$$
V_{i t}^{N}=\ln \left(\sum_{b} \sum_{j=1}^{J} d_{b j t} e^{u_{i b j t}^{N}}+1\right)
$$

and $u_{i b j t}^{C}=U_{i b j t}^{C}-\epsilon_{i j b t}$ is the utility given in 4.1 minus the idiosyncratic shock evaluated at the observed set of products and prices and where $u_{i b j t}^{N}$ is the same utility measure evaluated at the observed set of products and the prices that would be charged in the absence of price collusion. Table 4.7 lists the expected impact of price collusion on welfare, ignoring product collusion.

TABLE 4.7

Welfare Effects Of Price Collusion

\begin{tabular}{lc}
\hline \hline & Welfare Effect (in millions) \\
\hline$\Delta$ Consumer Surplus & $-\$ 17.143$ \\
$\Delta$ Producer Surplus & $\$ 2.872$ \\
$\Delta$ Social Surplus & $-\$ 14.271$
\end{tabular}

The antitrust authorities would likely infer large effects on consumer and social welfare from these estimates. Extrapolating across all supermarkets suggests that $\$ 237.368$ million was lost in social surplus in 2013. However, this estimate is misleading for two reasons. First, it does not account for how firms colluding on products might reposition their flavor offerings if prevented from colluding on price. Therefore, this estimate would not necessarily reflect the welfare gains from preventing price collusion. Second, it does not account for the direct effect of product collusion on welfare which is ambiguous. To address these issues, I now consider the effect of product space collusion on welfare.

\subsubsection{Effect Of Eliminating Product \& Price Collusion}

To account for the effect of product collusion on welfare, I compute two additional counterfactuals in which I allow firms to reoptimize both their product and pricing decisions. In the first, I set both the product and price collusion parameters to zero and find the equilibrium set of products and prices when the firms are not allowed to collude in either stage. This allows me to measure the direct effect of product and product collusion on welfare. In the second, I hold the product collusion parameters fixed at the levels in Table 4.4 and set the 
price collusion parameters to 0. It is unknown if the firms would collude to the same degree on the product space if they could not collude in price, making this second counterfactual highly speculative. I therefore present this counterfactual merely to highlight a potential problem associated with implementing antitrust policies without considering the full scope of collusion: namely the welfare effects of preventing price collusion are ambiguous when firms also collude on the product space.

To find the equilibrium set of products in both counterfactuals, I employ an algorithm developed in Fan and Yang (2016), which the authors describe in depth. I will provide a brief summary here. I define the product space as consisting of all non-seasonal flavors offered in my sample. The algorithm begins with both firms offering the subset of products observed in the data. I then allow Ben \& Jerry's to consider all one product deviations. These include all one-product additions, one-product removals, and one-product switches. At every deviation, I update the firm's prices to satisfy the pricing first order conditions. If Ben \& Jerry's does not find it profitable to deviate 33 then the observed set of products is Ben \& Jerry's best response and I consider all one-product deviations for Häagen-Dazs. If Ben \& Jerry's finds it profitable to deviate, I consider all one-product deviations from the set of products that yeilded the highest payoff, continuing in this way until Ben \& Jerry's does not find it profitable to deviate. The algorithm continues until neither firm can benefit from any one-product deviation given the actions of its rival.

Because both the set of products is large and the firms update their prices at each deviation, it is not feasible to perform the counterfactual in all markets. Thus, I focus attention on the median market based on the average profitability of the firms. In this supermarketmonth, the total expected profits, excluding fixed costs, were $\$ 399.25$ and $\$ 412.34$ for Ben \& Jerry's and Häagen-Dazs respectively. The firms jointly offered 66 products in this supermarket-month, 37 Ben \& Jerry's flavors and 29 Häagen-Dazs flavors. A summary of the characteristics in these flavor sets is reported in the first column of Table 4.8 .

\footnotetext{
${ }^{33}$ Profitability has different meanings in the two counterfactuals. In the first counterfactual, the payoff to firm $b$ is just its own profits, $\pi_{b}$. In the second, where the firms are allowed to collude on the product space, the payoff to each firm $b$ is measured as $\pi_{b}+\theta_{1, b} \pi_{-b}$.
} 
TABLE 4.8

Characteristics Of Flavor Sets

\begin{tabular}{lcccccc}
\hline \hline & \multicolumn{2}{c}{ Observed Product Set } & \multicolumn{2}{c}{ No Price or Prod. Collusion } & \multicolumn{2}{c}{ No Price Collusion Only } \\
& Ben \& Jerry's & Häagen-Dazs & Ben \& Jerry's & Häagen-Dazs & Ben \& Jerry's & Häagen-Dazs \\
\hline Number Flavors & 37 & 29 & 42 & 28 & 15 & 23 \\
Vanilla & 0.270 & 0.241 & 0.238 & 0.250 & 0 & 0.348 \\
Chocolate & 0.243 & 0.172 & 0.262 & 0.214 & 0.400 & 0.182 \\
Coffee & 0.054 & 0.069 & 0.071 & 0.036 & 0 & 0.046 \\
Fruit & 0.162 & 0.138 & 0.190 & 0.179 & 0.333 & 0.091 \\
Mixins & 2.432 & 1.345 & 2.357 & 1.143 & 2.133 & 1.091 \\
\hline
\end{tabular}

I measure the overall welfare effects from both product and price collusion in this selected market. The first column of Table 4.9 replicates the analysis in Section 4.7.1, comparing the observed collusive outcome to the counterfactual in which the products are held fixed and the price parameters are set to 0 . The second column takes into account both product and price collusion, comparing observed outcomes to the counterfactual in which all collusion parameters are set to 0 . I find that failure to account for product space collusion considerably underestimates the negative effect of collusion on consumer and social surplus.

TABLE 4.9

Effect Of Collusion In Median Market

\begin{tabular}{lcc}
\hline \hline & \multicolumn{2}{c}{ When Accounting for the Presence of ... } \\
& Price Collusion Only & Prod. \& Price Collusion \\
\hline$\Delta$ Consumer Surplus & $-\$ 236.27$ & $-\$ 281.24$ \\
$\Delta$ Total $\pi$ & $\$ 40.75$ & $\$ 34.77$ \\
$\Delta$ Fixed Cost & $\$ 0$ & $-\$ 31.53$ \\
\hline$\Delta$ Social Surplus & $-\$ 195.52$ & $-\$ 278.00$ \\
\hline
\end{tabular}

I do find that failure to account for product space collusion overstates the positive effect on producer surplus. This is because the counterfactual in which the product set is held fixed and the price collusion parameters set to 0 does not reflect the optimal product and pricing choice that the firms would make at those parameter values. In this market, I find that the producer surplus would be higher if the firms did not collude in either stage than if they were forced to offer the produced products when they could no longer collude on price.

Given that firms would have chosen different product offerings in this market if the antitrust authorities had prevented price collusion, it is important to perform the second counterfactual as an illustration even if it is subject to the Lucas Critique. In doing so, I find that the firms would have dramatically curtailed the set of flavors offered if they could not collude in price but continued to collude to the same degree on the product space. 
In particular, I find two equilibria, one in which Ben \& Jerry's and Häagen Dazs offer 15 and 23 products respectively, the other in which they offer 24 and 20 flavors. The third column of Table 4.8 summarizes the product sets for the first equilibrium. Strikingly, not only does the number of products shrink, but the differentiation in the offerings between the brands increases a great deal. As a result, I find that consumers are better off when firms are colluding both in prices and products than when firms can only collude on the product space. In particular, consumer surplus falls by $\$ 195.52$ in the first equilibrium when price collusion is prevented and $\$ 45.00$ in the second equilibrium. This suggests a potential caveat if regulators focus only on price collusion.

Taken together, these findings are fairly intuitive. When the firms can only collude in product choice, they withdraw considerably from their rival's designated part of the product space. This allows them to avoid significant price competition. If the firms have the ability to also collude in prices, they are able to move their product sets closer to each other without triggering price competition. Finally, when the firms cannot collude in either stage, the firms directly enter each other's space. In my example, as long as the firms are colluding on the choice of products, Ben \& Jerry's does not offer chocolate ice cream. However, if the firms were prevented from colluding at all, chocolate would be sold by both firms.

It is important to bear in mind that these results are derived from only one supermarket month, albeit one that has been chosen to be representative. Because the theoretical predictions are ambiguous, it is possible that product space collusion could have the opposite effect on welfare in other settings. I plan on checking the robustness of these results in future work. However, they do suggest the importance of accounting for product collusion.

\subsection{Conclusion}

In this paper, I presented a methodology by which researchers can measure product space collusion. I then applied that method to the market for super-premium ice cream during 2013. I found substantial evidence that Ben \& Jerry's and Häagen-Dazs colluded on both the set of products offered and the prices charged for these products. I also constructed counterfactuals to quantify the effects of product and price collusion on firm actions and welfare.

There are four main implications of my paper for antitrust policy. First, ignoring product collusion can result in either anticompetitive behavior going undetected or the welfare effects being miscalculated. Second, there exists the possibility that policy interventions to prevent price collusion may have negative impacts on welfare when product collusion is not considered. Third, collusion does not necessarily reduce welfare when both price and products are 
considered, so it should be evaluated on a case-by-case basis rather than being per se illegal. Finally, in merger analysis, the antitrust authorities often allow firms to merge if they do not compete in the same markets. For example, airlines are often permitted to merge so long as they do not offer service on the same point-to-point routes. It is possible though that airlines service different routes because of product collusion and that competition would have caused them to compete directly. Thus, it seems that current antitrust policy may be rewarding firms for behaving anticompetitively with respect to their product choices. 
Appendices 


\section{Appendix 1}

Here I show the equivalence between the first order conditions associated with 2.23 and (2.25). The equivalence between (2.24) and (2.26) follows in the same manner. In (2.23), one firm $b$ chooses the prices for each firm under the guarantee that its rival receives at least

its collusive payoff $\pi_{-b}^{C, C}$. The identity of the firm has no bearing on the equilibrium. The Lagrangian for firm b's optimization problem can be expressed as:

$$
\begin{aligned}
\mathcal{L}=\pi_{b} & +\tilde{\omega}\left(\pi_{-b}-\pi_{-b}^{C C}\right)+\lambda_{b, b}\left(\pi_{b}-\frac{1-\delta}{1-\delta^{T+1}} \pi_{b}^{C D}-\frac{\delta-\delta^{T+1}}{1-\delta^{T+1}} \pi_{b}^{N E}\right) \\
& +\lambda_{b,-b}\left(\pi_{-b}-\frac{1-\delta}{1-\delta^{T+1}} \pi_{-b}^{C D}-\frac{\delta-\delta^{T+1}}{1-\delta^{T+1}} \pi_{-b}^{N E}\right)
\end{aligned}
$$

Note that $\pi_{-b}^{C C}, \pi_{b}^{N E}$, and $\pi_{-b}^{N E}$ are fixed. Furthermore,

$$
\pi_{b}^{C D}=\arg \max _{p_{b}} \pi_{b}\left(d_{b}, d_{-b}, p_{b}, p_{-b}\right)
$$

Therefore, $\pi_{b}^{C D}$ is a function only of the product choices and $p_{-b}$. So, from the perspective of firm $b, \pi_{b}^{C D}$ is fixed in the pricing stage. Then, if firm 1 makes the pricing decisions, the first order conditions to 2.23 can be written as follows:

$$
\begin{aligned}
& \frac{\partial \pi_{1}}{\partial p_{1}}+\tilde{\omega} \frac{\partial \pi_{2}}{\partial p_{1}}+\lambda_{1,1} \frac{\partial \pi_{1}}{\partial p_{1}}+\lambda_{1,2}\left(\frac{\partial \pi_{2}}{\partial p_{1}}-\frac{1-\delta}{1-\delta^{T+1}} \frac{\partial \pi_{2}^{C D}}{\partial p_{1}}\right)=0 \\
& \frac{\partial \pi_{1}}{\partial p_{2}}+\tilde{\omega} \frac{\partial \pi_{2}}{\partial p_{2}}+\lambda_{1,1}\left(\frac{\partial \pi_{1}}{\partial p_{2}}-\frac{1-\delta}{1-\delta^{T+1}} \frac{\partial \pi_{1}^{C D}}{\partial p_{2}}\right)+\lambda_{1,2} \frac{\partial \pi_{2}}{\partial p_{2}}=0
\end{aligned}
$$


If firm 2 had been allowed to choose prices for both firms, the associated first order conditions are given by:

$$
\begin{aligned}
& \tilde{\omega}^{-1} \frac{\partial \pi_{1}}{\partial p_{1}}+\frac{\partial \pi_{2}}{\partial p_{1}}+\lambda_{2,1} \frac{\partial \pi_{1}}{\partial p_{1}}+\lambda_{2,2}\left(\frac{\partial \pi_{2}}{\partial p_{1}}-\frac{1-\delta}{1-\delta^{T+1}} \frac{\partial \pi_{2}^{C D}}{\partial p_{1}}\right)=0 \\
& \tilde{\omega}^{-1} \frac{\partial \pi_{1}}{\partial p_{2}}+\frac{\partial \pi_{2}}{\partial p_{2}}+\lambda_{2,1}\left(\frac{\partial \pi_{1}}{\partial p_{2}}-\frac{1-\delta}{1-\delta^{T+1}} \frac{\partial \pi_{1}^{C D}}{\partial p_{2}}\right)+\lambda_{2,2} \frac{\partial \pi_{2}}{\partial p_{2}}=0
\end{aligned}
$$

I now multiply both sides of (A5) and (A6) by $\tilde{\omega} .^{34}$

$$
\begin{aligned}
& \frac{\partial \pi_{1}}{\partial p_{1}}+\tilde{\omega} \frac{\partial \pi_{2}}{\partial p_{1}}+\tilde{\omega} \lambda_{2,1} \frac{\partial \pi_{1}}{\partial p_{1}}+\tilde{\omega} \lambda_{2,2}\left(\frac{\partial \pi_{2}}{\partial p_{1}}-\frac{1-\delta}{1-\delta^{T+1}} \frac{\partial \pi_{2}^{C D}}{\partial p_{1}}\right)=0 \\
& \frac{\partial \pi_{1}}{\partial p_{2}}+\tilde{\omega} \frac{\partial \pi_{2}}{\partial p_{2}}+\tilde{\omega} \lambda_{2,1}\left(\frac{\partial \pi_{1}}{\partial p_{2}}-\frac{1-\delta}{1-\delta^{T+1}} \frac{\partial \pi_{1}^{C D}}{\partial p_{2}}\right)+\tilde{\omega} \lambda_{2,2} \frac{\partial \pi_{2}}{\partial p_{2}}=0
\end{aligned}
$$

Since the first order conditions (A3) and (A4) and the first order conditions (A7) and (A8) define the same equilibrium, it must be the case that $\lambda_{1,1}=\tilde{\omega} \lambda_{2,1}$ and $\lambda_{1,2}=\tilde{\omega} \lambda_{2,2}$. Therefore, the pair of first order conditions (A3) and (A6) provide necessary conditions for the equilibrium.

Now, consider the game defined by 2.25 in which each firm $b$ chooses its own prices to maximize the same objective function in 2.23 while facing the same constraints imposed in 2.23). Thus, the first order condition for firm b's pricing decision is given as:

$$
\begin{array}{ll}
\text { if } b=1: & \frac{\partial \pi_{1}}{\partial p_{1}}+\tilde{\omega} \frac{\partial \pi_{2}}{\partial p_{1}}+\lambda_{1,1} \frac{\partial \pi_{1}}{\partial p_{1}}+\lambda_{1,2}\left(\frac{\partial \pi_{2}}{\partial p_{1}}-\frac{1-\delta}{1-\delta^{T+1}} \frac{\partial \pi_{2}^{C D}}{\partial p_{1}}\right)=0 \\
\text { if } b=2: & \tilde{\omega}^{-1} \frac{\partial \pi_{1}}{\partial p_{1}}+\frac{\partial \pi_{2}}{\partial p_{2}}+\lambda_{2,1}\left(\frac{\partial \pi_{1}}{\partial p_{2}}-\frac{1-\delta}{1-\delta^{T+1}} \frac{\partial \pi_{1}^{C D}}{\partial p_{2}}\right)+\lambda_{2,2} \frac{\partial \pi_{2}}{\partial p_{2}}=0
\end{array}
$$

The equilibrium to the game in 2.25 must satisfy the first order condition for each firm. Notice that (A9) and (A10) are the same expressions as (A3) and (A6). Therefore, the equilibria in (2.23) and 2.25) are equivalent.

It is possible to invoke the envelope theorem to simplify the first order conditions (A9) and (A10). In doing so,

$$
\frac{\partial \pi_{b}^{C D}}{\partial p_{-b}}=\frac{\partial \pi_{b}}{\partial p_{-b}}
$$

\footnotetext{
${ }^{34}$ Since $\tilde{\omega}$ is a relative weight, it cannot be 0 .
} 
Therefore, (A9) and (A10) can be rewritten as

$$
\begin{aligned}
& \frac{\partial \pi_{1}}{\partial p_{1}}+\left(\frac{\tilde{\omega}}{1+\lambda_{1,1}}+\frac{\lambda_{1,2}}{1+\lambda_{1,1}} \frac{\delta-\delta^{T+1}}{1-\delta^{T+1}}\right) \frac{\partial \pi_{2}}{\partial p_{1}}=0 \\
& \frac{\partial \pi_{2}}{\partial p_{2}}+\left(\frac{\tilde{\omega}^{-1}}{1+\lambda_{2,2}}+\frac{\lambda_{2,1}}{1+\lambda_{2,2}} \frac{\delta-\delta^{T+1}}{1-\delta^{T+1}}\right) \frac{\partial \pi_{1}}{\partial p_{2}}=0
\end{aligned}
$$

Similarly, it can be shown that the product stage equilibrium in 2.24) and 2.26) has the following necessary conditions:

$$
\begin{aligned}
& \frac{\mathbf{d} \pi_{1}}{\mathbf{d} d_{1}}+\left(\frac{\tilde{\omega}}{1+\mu_{1,1}}+\frac{\mu_{1,2}}{1+\mu_{1,1}} \frac{\delta-\delta^{T+1}}{1-\delta^{T+1}}\right) \frac{\mathbf{d} \pi_{2}}{\mathbf{d} d_{1}}=0 \\
& \frac{\mathbf{d} \pi_{2}}{\mathbf{d} d_{2}}+\left(\frac{\tilde{\omega}^{-1}}{1+\mu_{2,2}}+\frac{\mu_{2,1}}{1+\mu_{2,2}} \frac{\delta-\delta^{T+1}}{1-\delta^{T+1}}\right) \frac{\mathbf{d} \pi_{1}}{\mathbf{d} d_{2}}=0
\end{aligned}
$$




\section{Appendix 2}

Given the linear demand in (3.1) and the constant marginal cost (3.2), the derivative of firm $i$ 's profit function with respect to its own quantity in period $t$ is given as follows:

$$
\frac{\partial \pi_{i t}}{\partial q_{i t}}=a_{0}+a_{1} x_{t}+2 a_{2} q_{i t}+(N-1) a_{2} q_{j t}-c_{0}-c_{1} w_{t}
$$

Meanwhile, the derivative of the profits earned by firm $j$, one of the symmetric rivals of firm $i$, with respect to $q_{i t}$ can be expressed as:

$$
\frac{\partial \pi_{j t}}{\partial q_{i t}}=a_{2} q_{j t}
$$

One can rearrange the first order condition (3.19) to obtain the following equality:

$$
\begin{aligned}
\frac{(N-1)}{1+\lambda_{i t}} & =-\frac{\partial \pi_{i t} / \partial q_{i t}}{\partial \pi_{j t} / \partial q_{i t}} \\
& =\frac{a_{0}+a_{1} x_{t}+2 a_{2} q_{t}+(N-1) a_{2} q_{t}-c_{0}-c_{1} w_{t}}{-a_{2} q_{t}} \\
& =\frac{a_{0}+a_{1} x_{t}-c_{0}-c_{1} w_{t}}{-a_{2} q_{t}}+\frac{2 a_{2} q_{t}+(N-1) a_{2} q_{t}}{-a_{2} q_{t}}
\end{aligned}
$$

In this model, the Nash-Cournot quantities in period $t$ are defined as:

$$
q_{t}^{N E}=\frac{a_{0}+a_{1} x_{t}-c_{0}-c_{1} w_{t}}{-(N+1) a_{2}}
$$

Thus, dividing the numerator and denominator of the first term on the RHS of (A19) by $-(N+1) a_{2}$ yields:

$$
\begin{aligned}
\frac{(N-1)}{1+\lambda_{i t}} & =\frac{\frac{a_{0}+a_{1} x_{t}-c_{0}-c_{1} w_{t}}{-(N+1) a_{2}}}{\frac{-a_{2} q_{t}}{-(N+1) a_{2}}}-(N+1) \\
& =(N+1) \frac{q_{t}^{N E}-q_{t}}{q_{t}}
\end{aligned}
$$


Therefore, the expression for $\lambda_{i t}$ can be written as:

$$
\lambda_{i t}=\frac{N-1}{N+1} \frac{q_{t}}{q_{t}^{N E}-q_{t}}-1
$$


BIBLIOGRAPHY 
Ackerberg, Daniel. 2016. "Timing Assumptions and Effciency: Empirical Evidence in a Production Function Context." working paper.

Ackerberg, Daniel, and Jinyonh Hahn. 2015. "Some Non-Parametric Identification Results using Timing and Information Set Assumptions." working paper.

Andrews, Donald, and Gustavo Soares. 2010. "Inference for Parameters Defined by Moment Inequalities Using Generalized Moment Selection." Econometrica, 78(1): 119-157.

Berry, Steven, and Philip Haile. 2014. "Identification in Differentiated Products Markets Using Market Level Data." Econometrica, 82(5): 1749-1797.

Berry, Steven, James Levinsohn, and Ariel Pakes. 1995. "Automobile Prices in Market Equilibrium." Econometrica, 63(4): 841-890.

Black, Michael, Gregory Crawford, Shihua Lu, and Halbert White. 2004. "A Virtual Stakes Approach to Measuring Competition in Product Markets." working paper.

Bresnahan, Timothy. 1982. "The Oligopoly Solution Concept is Identified." Economics Letters, 10: 87-92.

Bresnahan, Timothy. 1987. "Competition and Collusion in the American Automobile Industry: The 1955 Price War." The Journal of Industrial Economics, 35(4): 457-482.

Corts, Kenneth. 1999. "Conduct Parameters and the Measurement of Market Power." Journal of Econometrics, 88(8): 227-250.

Crawford, Gregory, and Ali Yurukoglu. 2012. "The Welfare Effects of Bundling in Multichannel Television Markets." American Economic Review, 102(2): 643-685.

Crawford, Gregory, and Matthew Shum. 2007. "Monopoly Quality Degradation and Regulation in Cable Television." Journal of Law and Economics, 50(1): 181-209.

Draganska, Michaela, Michael Mazzeo, and Katja Seim. 2009. "Beyond Plain Vanilla: Modeling Joint Product Assortment and Pricing Decisions." Quantative Marketing and Economics, 7(2): 105-146.

Dube, Jean-Pierre, Jeremy Fox, and Che-Lin Su. 2012. "Improving the Numerical Performance of Static and Dynamic Aggregate Discrete Choice Random Coefficients Demand Estimation." Econometrica, 80(5): 2231-2267. 
Fan, Ying. 2013. "Ownership Consolidation and Product Characteristics: A Study of the US Daily Newspaper Market." American Economic Review, 103(5): 1598-1628.

Fan, Ying, and Chenyue Yang. 2016. "Competition, Product Proliferation and Welfare: A Study of the U.S. Smartphone Market." working paper.

Fershtman, Chaim, and Ariel Pakes. 2000. "A Dynamic Oligopoly with Collusion and Price Wars.” RAND Journal of Economics, 31(2): 207-236.

Gandhi, Amit, and Jean-Francois Houde. 2015. "Measuring Substitution Patterns in Differentiated Products Industries." working paper.

Gandhi, Amit, Zhentong Lu, and Xiaoxia Shi. 2013. "Estimating Demand for Differentiated Products with Error in Market Shares." working paper.

Green, Edward, and Robert Porter. 1984. "Noncooperative Collusion under Imperfect Information." Econometrica, 52(1): 87-100.

Hackner, Jonas. 1995. "Endogenous Product Design in an Infinitely Repeated Game." International Journal of Industrial Organization, 13(2): 277-299.

Hendel, Igal, and Aviv Nevo. 2006a. "Measuring the Implications of Sales and Consumer Inventory Behavior." Econometrica, 74(6): 1637-1673.

Hendel, Igal, and Aviv Nevo. 2006b. "Sales and Consumer Inventory." RAND Journal of Economics, 37(3): 543-561.

Mailath, George, Volker Nocke, and Lucy White. forthcoming. "When and How the Punishment Must Fit the Crime." International Economic Review.

Mas-Colell, Andreu, Michael Whinston, and Jerry Green. 1995. Microeconomic Theory. New York, NY:Oxford University Press.

Mazzeo, Michael. 2002. "Product Choice and Oligopoly Market Structure." RAND Journal of Economics, 33(2): 221-242.

Miller, Nathan, and Matthew Weinberg. 2015. "Mergers Facilitate Tacit Collusion: An Empirical Investigation of the Miller/Coors Joint Venture." working paper.

Nevo, Aviv. 1998. "Identity of the Oligopoly Solution Concept in a Differentiated Products Industry." Economics Letters, 59(3): 391-395. 
Nevo, Aviv. 2001. "Measuring Market Power in the Ready-to-Eat Cereal Industry." Econometrica, 69(2): 307-342.

Orhun, A. Yesim. 2013. "Spatial Differentiation in the Supermarket Industry: The Role of Common Information." Quantitive Marketing and Economics, 11(1): 3-37.

Orhun, A. Yesim, Sriram Venkataraman, and Orafeeo Chintagunta. 2015. "Impact of Competition on Product Decisions: Movie Choices of Exhibitors." Journal of Marketing Science, 35(1): 73-92.

Pakes, Ariel. 2010. "Alternative Models for Moment Inequalities." Econometrica, 78(6): 1783-1822.

Pakes, Ariel, Jack Porter, Kate Ho, and Joy Ishii. 2011. "Moment Inequalities and Their Application." working paper.

Schmalensee, Richard. 1978. "Entry Deterrence in the Ready-to-Eat Breakfast Cereal Industry." Bell Journal of Economics, 9(2): 305-327.

Small, Kenneth, and Harvey Rosen. 1981. "Applied Welfare Economics with Discrete Choice Models." Econometrica, 49(1): 105-130.

Sweeting, Andrew. 2013. "Dynamic Product Repositioning in Differentiated Product Markets: The Effect of Fees for Musical Performance Rights on the Commercial Radio Industry." Econometrica, 81(5): 1763-1803.

Wollmann, Thomas. 2016. "Trucks without Bailouts: Equilibrium Product Characteristics for Commercial Vehicles." working paper.

Xu, Xu, and Kalyn Coatney. 2015. "Product Market Segmentation and Output Collusion Within Substitute Products." Journal of Economics and Business, 77: 1-15. 